\title{
Dahinter - Traumbilder und Traumtexte
}

\section{Authors: Dörte Oppermann}

Submitted:

3. October 2015

Published:

Volume:

Issue:

3. October 2015

2

Keywords:

6

Dream book, Dreams of the author, Condensed texts, Dream prose, Graphic paintings, Artistic dream research

DOl: $\quad$ 10.17160/josha.2.6.69 
DAHINTER DÖRTE OPPERMANN TRAUMBILDER UND TRAUMTEXTE

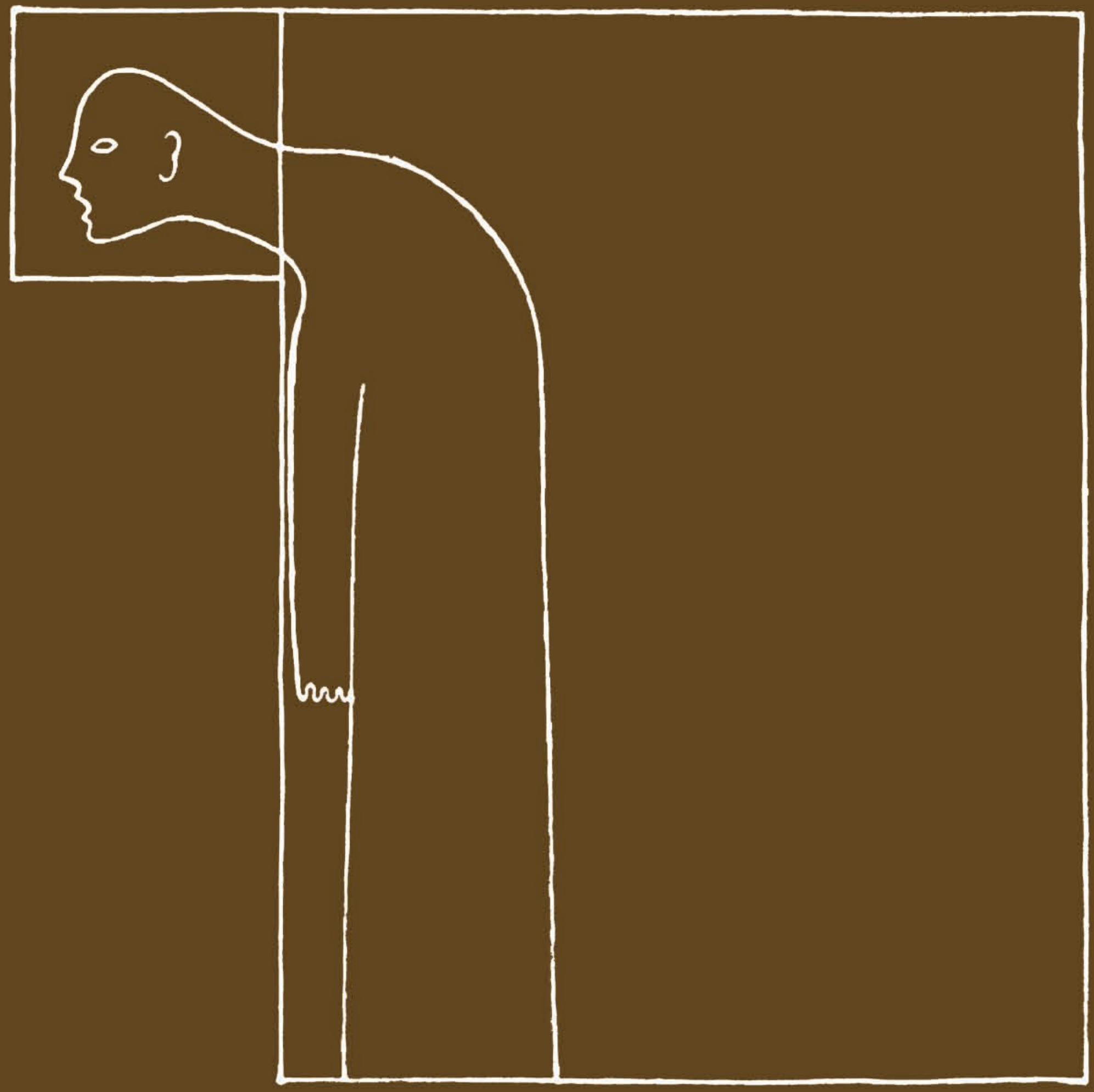



W
00
(O)
(i)

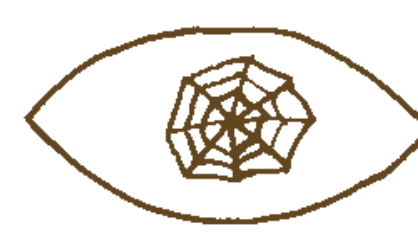

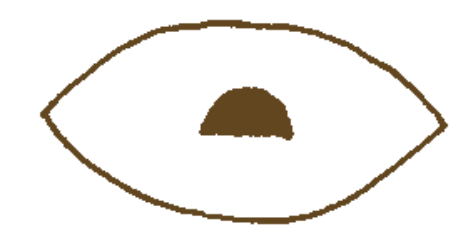

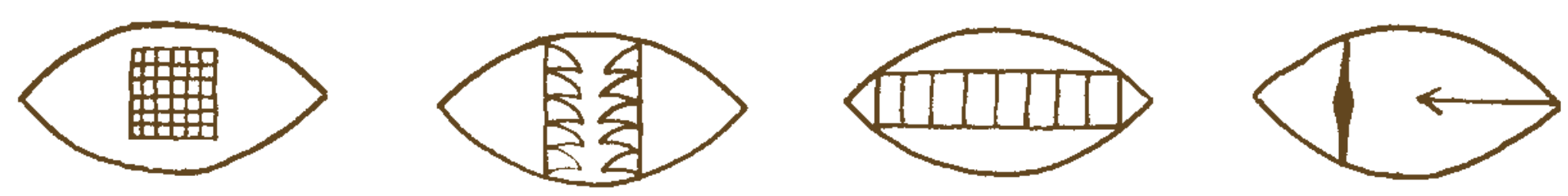

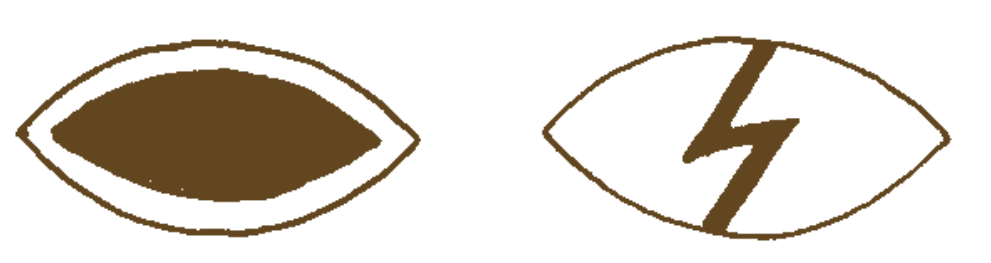
:

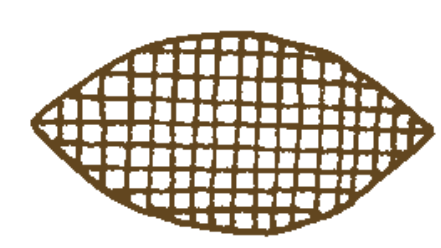
瓜众会

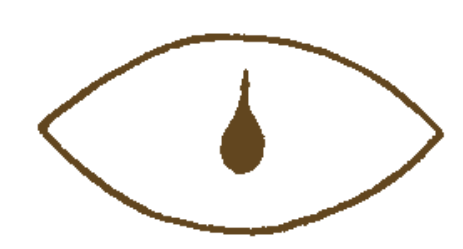
$\rightarrow$ (2)
运
\&
世us
$\square$
(0) (P)
D
$\Leftrightarrow$
(2)
(IIII)
Anususs

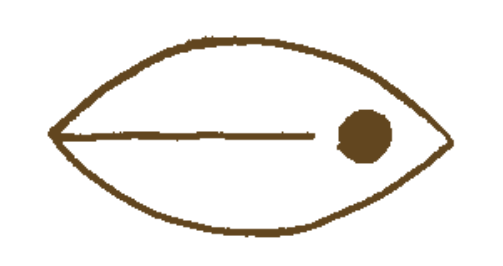
(IIIIII)
(now
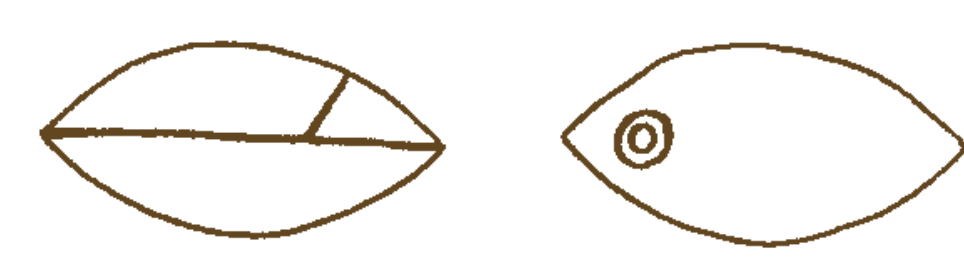
$x$
$x+x+x+x$
$x+x+x$
$x+x$
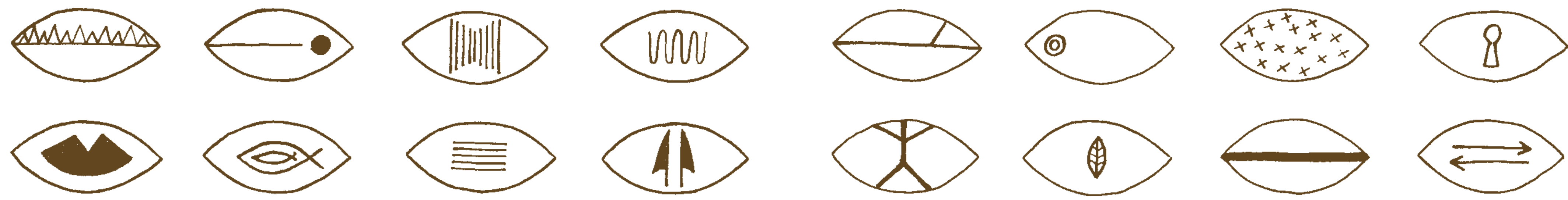
$\infty$
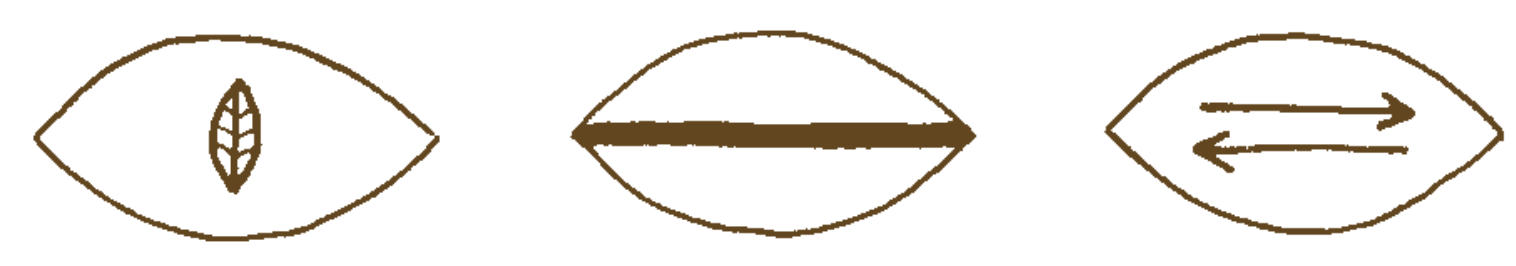

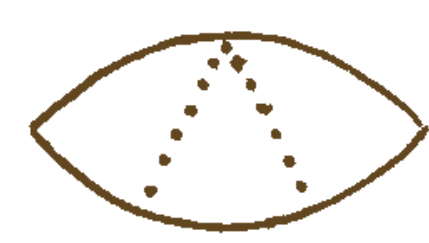
\& 进
(i):
(2)
(m)
$E=$

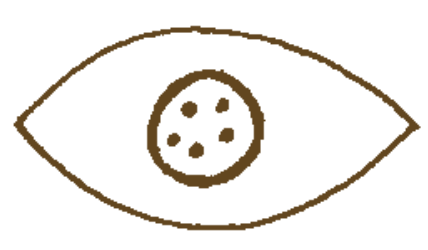
俩
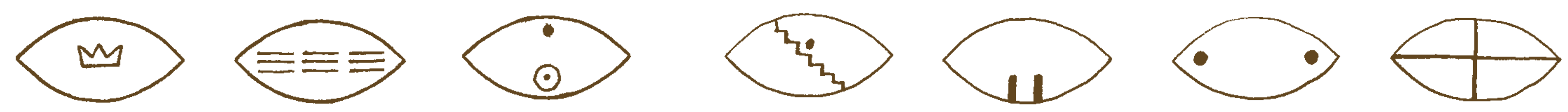
span
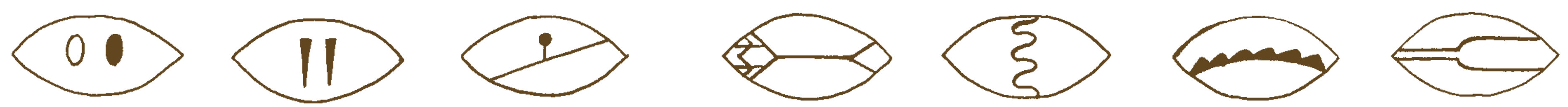
III

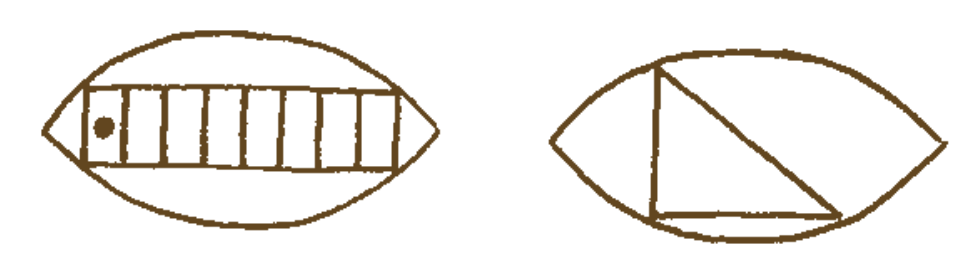
1060000
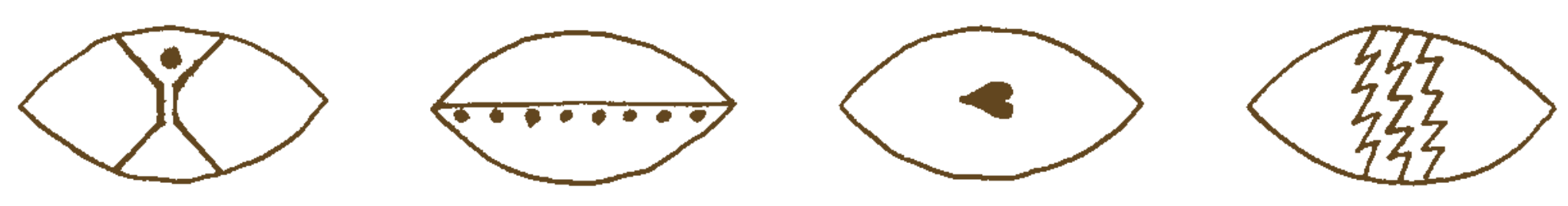
DAHINTER 


\section{DAHINTER - TRAUMBILDER UND TRAUMTEXTE}

Traumtexte, Traumbilder, Traumsprache, Traumleben, Traumgestalt/en

Traumbewegung/en, Traumtheater.

Das Leben ein Traum, derTraum ein Leben?

Unwillkürlich stellt sich diese Frage beim Einlassen auf das vorliegende Buch, das in einer beeindruckenden Fülle und Vielfalt Innerseelisches Gestalt werden läßt. Ein roter Faden, der sich dabei erkennbar durchzieht, ist die Beziehung zum Körper(lichen) und seiner Bewegung in Raum und Zeit, ebenso wie im Raum- und Zeitlosen. Dynamische Elemente und Erstarrung zeigen das "Dahinter" auf.

Die Nähe dieser Träume (und allerTräume) zu Theater und Film wird dabei immer wieder deutlich; das Verwandte. Schon die Antike kennt und nutzt die enge Verbindung zwischen Theater und Traum. In den Tempel-,,Kranken"-Häusern des griechischen Heil-Gottes Asklepios, Sohn des Apoll und Schüler des Kentauren und verwundeten Heilers" Chiron, in Epidaurus, Kos und Pergamon haben gleichermaßen Tanz, Maskenspiele, Drama und die ,leibbezogene“ Arbeit an und mit Träumen für die Heilung von Menschen größte Bedeutung gehabt.

Die Intensität des Traumerlebens und der unverbrüchliche Gestaltungswille von Dörte Oppermann tragen durchaus Züge der antiken Praxis der .Traum-Inkubation“ als eines Rückzugs aus der äußeren Welt in den „geheiligten" Innen-Raum des Schlaftempels, um im Traum und durch die Träume Heilung zu finden. ,Wir sind aus jenem Stoff, aus dem die Träume sind und unser kleines Leben umfaßt ein Schlaf." läßt Shakespeare seinen Prospero in „Der Sturm" sagen. 
Um aus unserem ,kleinen Leben“ einen vielleicht nur ahnungsvollen Schimmer, vielleicht aber auch die erkennende Vision des „großen“ Lebens zu erfahren, sollten wir unseren Träumen mit offenen Sinnen und aktiv gestaltend begegnen, wie es die Autorin beeindruckend getan hat.

Carl Gustav Jung, neben Freud der ganz Große der Traum-,,Arbeiter" schreibt: „,Der Traum ist jenes Theater, wo der Träumer Szene, Spieler, Souffleur, Regisseur, Autor, Publikum und Kritiker ist." (GW Bd. 8 / Randnummer 509)

Die Träumerin, deren Buch uns einlädt, mit ihr zwischen den Welten zu wandern, uns mitnehmen zu lassen in einen erstaunlichen Prozess des schöpferischen Entdeckens verborgener Wirklichkeiten, ist einerseits die Bildnerin und Bewegerin ihrer Träume, so wie sie andererseits von ihren Träumen gebildet und bewegt worden ist. In dieser dialogischen Dynamik zwischen Traumleben und Wachleben wird Bewußtheit möglich. Filmisches scheint auf in der Art, wie Dörte Oppermann Geträumtes umsetz in Bewegung, Bewegung erstarren läßt, und wie diese Bewegung in ihrer zweifachen Form sich wiederum manifestiert im Bild. Es ist wie einen zweiten ,anderen“ Blick zu werfen auf das, was sich in der Nacht gezeigt hat und es dadurch transparent zu machen. Ein Vorgang, den der Dichter William Blake, den „doppelten Blick" nennt

(In: ,Poetry and Prose of William Blake").

Die Traum-Gestalten werden von innen nach außen gesetzt und durchformt in einem intuitiven, dem schöpferischen Unbewußten entstammenden Entwurf und enthüllen so zumindest eine ihrer möglichen Wahrheiten. Der gestalterische Prozess der Vereinigung des innerlich gesehenen (nachts oft erlittenen) Bildes mit dem äußeren aktiv erschaffenen ist Ausdruck dieses ",doppelten Blicks“ und zeigt die Bildung von Symbolen auf. Diese Art der Symbolbildung, die hier ein einzelner schöpferischer Mensch vollzieht, ist, so der Mythenforscher Mircea Eliade, nicht Vorrecht des Kindes, des Dichters oder des „,gestörten Geistes" - wie zu sehen etwa in der hochinteressanten Prinzhorn-Sammlung mit Bildern der sogenannten Verrückten, sondern es ist: ,gleichen Wesens mit menschlichem Sein, es kommt vor der Sprache und diskursivem Verstand. Das Symbol enthüllt bestimmte Aspekte der menschlichen Realität - die tiefsten Aspekte - die sich jedem anderen Mittel des Wissens entziehen. Bilder, Symbole und Mythen sind keine unverantwortlichen Kreationen der Psyche. Sie erfüllen den Bedarf und die Funktion, die unentdeckten Modalitäten des Seins ans Licht zu bringen".

(aus: „Ewige Bilder und Sinnbilder")

..Die unentdeckten Modalitäten des Seins ans Licht zu bringen..." wieder stellt sich der Bezug her zur Arbeit des Schauspielers in ihrem tiefsten Sinn. Hier ist nicht bloß die nachahmende Erschaffung einer Figur gemeint, sondern die gestaltende Schöpfung aus innersten Seelenbildern und den die Person weit übersteigenden archetypischen Wirklichkeiten.

Jerzy Grotowski, einer der großen Theaterreformer des vergangenen Jahrhunderts, schrieb 1965 in seinem Aufruf „,Für ein armes Theater" über die Arbeit des Schauspielers: „Das Theater bietet die Möglichkeit für etwas, das man Integration nennen könnte, für das Abreißen der Masken, für die Offenbarung der wahren Substanz... Alles ist auf das „Reifen“ des Schauspielers konzentriert, das aus der Spannung zu seinen extremsten Möglichkeiten hervorgeht, durch vollkommene Selbstenthüllung, durch Bloßlegung seines Innersten - all dies ohne die geringste Spur von Egoismus und Selbstgefälligkeit. Der Schauspieler verwirklicht sich in einer totalen Hingabe. Es handelt sich... um die Integration aller psychischen und physischen Kräfte des Schauspielers, die sich aus den tiefsten Schichten seines Seins und seiner Triebe herleiten und in einer Art "Durchleuchtung" aufscheinen."

Gestatten wir uns für einen Moment, das Wort Theater durch das Wort Traum und das Wort

Schauspieler durch das Wort Träumerin oder träumende Bildnerin zu ersetzen, und wir haben eine exakte Beschreibung des Vorgangs, der im vorliegenden Buch dokumentiert ist. Dass dieser Vorgang nicht leicht ist, sondern immer wieder aufs Neue den ganzen Menschen fordert, versteht sich von selbst. So auch bei Dörte Oppermann: Die Traumbilder, das Traumgeschehen, setzen sich teilweise in den Tag hinein fort, drohen das Wachleben zu dominieren, evozieren hypnagoge Bilder und Visionen.

Über einen Zeitraum von 43 Jahren hat Dörte Oppermann ihre Träume gesammelt und führt dieses Vorhaben auch weiter. 1961 - im Alter von 19 Jahren - hat sie die ersten erinnerten Träume aufgeschrieben; verstärkt dann ab 1970 und wieder ab 1980. Um 1990 kommt es zu einer Steigerung und Ende 1994, aufgrund einer tiefen persönlichen Krise, zu einer extrem hohen Dichte intensiver Träume, die auch körperliche Empfindungen und Symptome hervorrufen und umgekehrt.

Sie muß erleben, dass die Sprache, das Schreiben, der Kraft der (inneren) Bilder nicht mehr gewachsen ist und beginnt, diesen Bildern zeichnerisch Ausdruck zu verleihen. Zuerst als eine Art Notwehr, Abwehr daraus folgend dann als die befreiende Entdeckung, dass sich die Träume auch bildnerisch gestalten lassen. Von diesem Zeitpunkt an widmet sie ihre Arbeit ganz der Gestaltung derTraumbilder.

Aus der Ganzheit, auch teils der Verworrenheit eines Traumes erscheint eine Szene besonders deutlich, komprimiert zu einem Bild, zu einer „Hauptszene“, manchmal verknüpft mit einem schreckhaften

Enwachen. Häufiger klingt derTraum im halbwachen Zustand so nach, dass die Träumerin Schwierigkeiten hat, in die Wach-Realität zu finden. Manchmal stehen die Traum-Bilder schon am Ende des Traumes fast fertig vor dem inneren Auge, mitunter sogar derTitel. Sie entwickelt ein bestimmtes Vorgehen, um mit dieser Traum-Wirklichkeit kreativ umgehen zu können. (Dabei treten zwei unterschiedliche Motivationen zutage: Manchmal ist die Thematik des Traumes seelisch so bedrängend, dass sie gestaltet werden muss, manchmal ist das Bildmaterial so stark, dass es auf Gestaltung drängt.)

Das Gestalten ermöglicht Abstand, Distanz. Der Traum wird spontan festgehalten, ,,wenn die Worte nicht reichen", schon mit einer Skizze. Er wird dann übertragen in das Traumtagebuch, ebenfalls oft mit ersten Skizzen und mit Anmerkungen zum Kontext sowie Notizen über Assoziationen, Traumziel und Traumsymbole.

Der weitere Gestaltungsprozess konzentriert sich auf das Finden adäquater Formen und Farben. Und hier wird es wieder ,,schauspielerisch“: Dörte Oppermann erforscht tätig, d.h. im Tun, im körperlichbewegten Nachvollzug des Traumgeschehens Bewegung/en, Emotionen, Aktionen, Handlungen und Handlungsabläufe, Gesten und Gebärden... und bringt sie dann in eine Art Erstarrung. Es findet eine Umsetzung ins fast Plakative statt - ein surrealer Eindruck entsteht. Surrealismus sucht die eigentliche Wirklichkeit des Menschen im Unbewußten. Die Träumerin sucht und findet die eigentliche Wirklichkeit im Traum - der dem Unbewußten entspringt. Die Surrealität entspricht der Traum-Logik. 
In diesem Buch finden sich 116 Träume als Texte und 63 als Bilder.

Davon beziehen sich nur 20 Bilder und Texte jeweils auf denselben Traum.

\section{Ein Buch also, das Raum läßt für Assoziationen.}

André Breton berichtet in seinem „,ersten Manifest über den Surrealismus", dass der Dichter Saint-

Pol-Roux jeweils vor dem Schlafengehen ein Schild an seiner Schlafzimmertür angebracht habe:

Nicht stören. Der Autor arbeitet."

Dörte Oppermann hat gearbeitet. Tag und Nacht.

\section{SCHWARZER FRIEDEN, DAS BISSCHEN REALITÄT UND DIE BOTSCHAFT DES ZUNGENKOPFES}

„,Aus dem Menschen entweicht die Luft zuerst. Und er kratzt sich am Kopf, wo es von animalischer Nervosität nur so wimmelt." (Tristan Tzara)

„Nach innen geht der geheimnisvolle Weg." (Novalis)

,..... dürfen wir das gesamte wache Leben des einzelnen Menschen als eine Vorbereitung für seinen Traum ansehen ..." (Friedrich Nietzsche)

Zwei Arten von Träumen gibt es. Die bewussten, die von dem handeln, was man wünscht. Und die unbewussten Träume des Schlafes, von deren undurchsichtigem Geschehen wir Nacht für Nacht belebt sind, selbst wenn wir uns nicht einmal eine Spur daran erinnern. Zwei Dinge sind beiden Traumarten gemeinsam: sie zeigen ein ,anderes" Leben, und sie sind, wie der Psychoanalytiker und Vater der psychologischen Traumdeutung Sigmund Freud feststellte, Wunscherfüllungen. Wir träumen immer, das steht allemal fest. Um all das, was in unserem Seelischen drängt und wirkt, in einem bewegten Gleichgewicht zu halten, grundsätzlich der Erfahrung Rechnung tragend, dass darin immer vieles gleichzeitig geschieht und im Seelischen nichts verloren geht. Und als ein Gegenbild zur zweckbestimmten Alltagserfahrung in der so vieles zurückgehalten, unterdrückt und verleugnet wird, was trotzdem so beharrlich und unauslöschbar auf Entfaltung drängt.

Seit der religiösen Malerei des späten Mittelalters ist das Traumgeschehen ein fester Bestandteil in der Kunst des Abendlandes, schließlich handelte auch der christliche Glauben immer auch von phantastischen Erscheinungen und vernunftüberschreitenden Phänomenen. Spätestens seit Hieronymus Bosch 
und Francisco Goya haben die Darstellungen von Träumen dann ihren festen Platz in der Malerei. Und zu Beginn des 20. Jahrhunderts machten die Künstler der sogenannten surrealistischen Bewegung aus dem Traumgeschehen und seiner die Vernunft sprengenden Kraft sogar ein eigenständiges Kunstprinzip, das die bürgerlich geprägte Kunstauffassung radikal überschreiten und grundlegend aus den Angeln heben wollte. Träume besitzen einige Sprengkraft, weil sie die gewohnte Sichtweise und die von Zweckvernunft bestimmte Ordnung des Lebens auf den Kopf stellen. „Der Traum der Vernunft gebiert Ungeheuer," stellte Goya fest. Und Sigmund Freud formulierte in seinem legendären, im Jahre 1900 erschienenen Buch „Die Traumdeutung“: ,Ein Mensch, dem man die Fähigkeit nehmen würde, zu träumen, müsste in gegebener Zeit geistesgestört werden, weil sich in seinem Hirn eine Unmasse unfertiger, unausgedachter Gedanken und seichter Eindrücke ansammeln würde, unter deren Wucht dasjenige ersticken müsste, was dem Gedächtnisse als fertiges Ganzes einzuverleiben wäre. Der Traum leistet dem überbürdeten Gehirn die Dienste eines Sicherheitsventils. Träume haben eine heilende, entlastende Kraft."

All das ist auch in den Bildern von Dörte Oppermann enthalten. Rund I30 hat sie in den letzten Jahren nach ihren Träumen gemalt. Außerst eigenwillige Bilder, in einer ganz persönlichen Färbung, wie sie auch jedem Traum innewohnt. Zugleich sind diese Bilder aber so allgemein, dass jeder andere Mensch sich darin wiedererkennt. Weil er gleichfalls einen Körper und ein Seelisches hat, die ständig allen möglichen Verwicklungen und Belagerungen ausgesetzt sind und die trotz aller Individualität doch an bestimmte Gesetze gebunden bleiben. Weil er sich auch bisweilen klein und ratlos dem großen geheimnisvollen Universum gegenüber vorkommt. Und nicht zuletzt, weil er auch träumt und diese Verrücktheiten und Parodoxien kennt, die bei aller vordergründigen Sinnlosigkeit gerade deswegen ihren Sinn besitzen. Der Sinn des scheinbar Sinnlosen ist eine weithin unterschätzte Kategorie.

Seit über vierzig Jahren schreibt Dörte Oppermann ihre Träume auf. Im Jahre 196| hat sie damit angefangen, und inzwischen ist das Jahr 2006. Ihre Träume sind in vielen Notizbüchern aufgehoben Din A4 groß, mit festem Einband. Über 1000 Träume hat sie darin aufgeschrieben. Grundsätzlich hat sie immer ein Blatt Papier und einen Stift neben ihrem Bett liegen, damit sie sofort reagieren kann, wenn ein Traum die Grenze zum Bewusstsein berührt, am Morgen nach dem Aufwachen oder mitten in der Nacht, bei einem plötzlichen Erwachen durch einen Traum. Nur so sind die Traumfragmente zu retten. Sekunden nach dem Erwachen verfüchtigen sie sich bereits. Später überträgt sie die rasch gekritzelten Aufzeichnungen in ordentlicher Schrift in ihre Notizbücher. Manchmal setzt sie kleine Zeichnungen zu dem Geschriebenen. Irgendwann hat sie damit angefangen, ihre Träume nicht nur "festzuhalten", sondern zu deuten. Die Einfälle, Erinnerungen und mögliche „Erklärungen“ aufzuschreiben. Auch das ist schon lange her, und sie hat es seitdem beibehalten. Sie beschäftigt sich mit ihren Assoziationen und Erinnerungen, die sich aus ihren Träumen ergeben. Und mit Traumsymbolen un uralten Mythen. Sie begann die Werke des Psychoanalytikers C.G. Jung zu lesen, dessen Gedanken über die Archetypen des Unbewussten sie faszinieren. Und schließlich gehörte zu jedem Traum nicht meh nur, dass sie ihn aufschrieb, um ihn nicht zu vergessen, sondern dass sie ihn durcharbeitete, mit allen überraschenden und erschreckenden Entdeckungen, die dabei zu machen sind. Seitdem fragt sie: „Was will der Traum mir sagen?"

Und sie ist sicher, dass jeder Traum etwas sagen wil.
Ein Traum setzt dabei den anderen fort. Und jeder Traum reicht zurück bis in die Zeit der frühesten Kindertage. Er reicht zurück zu allem, was je geschehen ist, weit hinter die Dinge unseres bewussten Erinnerns. Zugleich weist er einen Weg in die Zukunft, auf das, was kommen könnte. Einen Weg, der oft nur mühsam zu (er-)kennen ist. Das Aufschreiben derTräume hilft, weiß Dörte Oppermann. Und dieses Aufschreiben und Durcharbeiten ihrer Träume ist fraglos auch zu einer Art Selbstbehandlung geworden Ein mit vielen Nebenwegen versehener Pfad, auf dem sie eintaucht in die verschlungenen Gärten ihres Seelischen, und wo sie sich selber besser kennen lernt. In dem, was ihr bekannt ist, und in dem, was ihr unbekannt und unverständlich entgegentritt. In diesem undurchsichtigen Gelände, in dem Höhenflüge und Abgründe, Schrecken und Freude, Vertrautes und Fremdes, Aufregung und Besänftigung, Wünsche und Ängste, Leben und Tod so nah beieinander liegen und nahezu ununterscheidbar sind. Und wo sich zeigt, dass alles mit allem in einem unauflösbaren Zusammenhang steht, und der Mensch bei weitem mehr ist als dieses Wesen, zu dem er so selbstverständlich „Ich" sagt. ,Ich ist ein anderer," stellte der französische Dichter Arthur Rimbaud fest. Und Sigmund Freud erklärte: der Mensch ist nicht Herr in seinem eigenen Haus, das er Ich nennt. So bringen unsere Träume jede Nacht zum Ausdruck, welche bekannten und unbekannt-undurchsichtigen Regungen in unserem Seelischen im Gange sind. Welche Möglichkeiten jenseits unseres Wissens in uns stecken, Kuriositäten, Groteskes, Schreckens- und Lustgespinste. Und dazu gehören auch Dinge, die man sich im taghellen Bewusstsein der Vernunft nicht einmal ausmalen könnte.

Vor ihren Träumen steht Dörte Oppermann wie wir alle vor unseren Träumen, gleichermaßen erschreckt und fasziniert Vor allem vor den Träumen, die sie aufwachen ließen. In denen sie in einen Abgrund stürzte oder aufgefressen wurde. In denen sie nicht schnell genug weglief und ausgelöscht wurde. Träume, die mit Angst zu tun haben: Angst vor dem Tod, Angst vor dem Leben, Angst vor der Explosion der Lust, Angst vor dem Nichts. Alle Träume haben zweifellos mit der unendlichen Zirkulation des Begehrens zu tun, der unerschöpflichen Gier, alles zu wollen und alles zu werden. Darin zeigen die Träume jede Nacht, was und wer man unterhalb seines bewussten Wissens noch ist: Königin und Bettler, Folterer und Opfer, Mörder und Schmetterling, erregtes Stück Fleisch und sphärischer Flügelfisch, leerer Eimer und Riesenluftschiff, und das alles zugleich. Widersprüche und Gleichzeitigkeiten sind in Träumen kein Problem. Und schöne und schreckliche Träume, so die Erinnerung, wechseln einander ab.

Als Dörte Oppermann vor rund zehn Jahren anfing, aus den aufgeschriebenen Traum-Geschichten Bilder zu entwickeln, wusste sie nicht genau, wohin ihre zeichnerischen Malereien sie führen würden. Manchmal beginnt sie mit einem einfachen richtungsweisenden Strich; andere Male mit einer prägnanten Gestalt oder einer Farbe. Nicht selten träumt sie in Farbe, so dass die Farbe des Traumes die des Bildes bestimmt. Auffallend ist das zeichnerische Element, das ihren Figuren und Räumen gleichermaßen Schemenhaftigkeit und Leichtigkeit verleiht. Bei aller Klarheit bewahrt die Darstellung auf diese Weise etwas Intuitives und den Hauch des Schwebens. Dörte Oppermann will der bewegt-ungreifbaren Leichtigkeit und seltsamen Zeitlosigkeit des Traumgeschehens bildlich gerecht werden, und immer wieder deutet sie das an durch serielle Strukturelemente, die leere Weite des (Bild-)Raumes und Wiederholungen in der Darstellung von Figuren. Ihr Bild-Vokabular ist schlicht und ohne übertriebene Schnörkel, mit Gespür für wenige Einzelheiten, doch ohne Detailverliebtheit, und auch das erweist sich als charakteristisch für die Bilder" ihrer und möglicherweise unserer aller Traume. 
„Träume sind Bilder," sagt Dörte Oppermann. Die gemalten Bilder ihrer Traumbilder ermöglichen ihr dabei, noch einmal in ihre Träume einzutauchen und zugleich ein Stück Distanz dazu zu schaffen .,In meinen Träumen geht es sehr chaotisch, sehr verwirrend zu. Die gemalten Bilder haben eine Ordnungsfunktion und geben dem Traum eine größere Klarheit," erklärt sie. Und jedes gemalte Bild ist die Entscheidung für einen bestimmten Aspekt des Traums. Damit verbunden ist der "Kunstgriff", das im Traum verdichtete Geschehen nunmehr nochmals in einem Bildmotiv zu verdichten: in einer zugespitzten Figur, in der Reihung von Figuren, der Konzentration auf eine merkwürdige Gestalt. Etwas aus dem Traum wird besonders hervorgehoben, wird zum Motiv, zum Symbol gemacht. Einige Beispiele: Die zum Baum verwachsenen Lederkraniche, die eine nackte, kauernde Frau wie eine Frucht umhüllen während ihre spitzen Schnäbel gefährlich in die halbdunkle Weite ragen. Ein Mann mit nackten Füßen zieht ein paar Schuhe an der Leine wie einen Hund hinter sich her. Ein Mensch schwimmt in einem Grasmeer, begleitet von vielen Rehen. Die boshaft-aggressive Tanzlehrerin zwingt nackte Menschen, die Wände hoch zu gehen. In einem runden Becken, um das schwarze Figuren wie um einen Tisch sitzen rudert eine ebenso schwarze Figur zu sich selber. Das Haus im Bauch des gefräßigen Tieres, das in einem eng abgesteckten Geviert Raubtieren Angst macht, und der Geschmack von Blut an seinem Maul. Eine schwimmende Hochgeschwindigkeitsdoppelkuh und Kinder, die auf dem Wasser Fahrrad fahren. Eine Straße voller sich bewegender Körperteile von geschlachteten Tieren. Der Kopf, durch dessen Gehirn eine Spinne kriecht. Ein Mann sitzt am Ende eines Ganges vor einer Tür, zwischen ihm und der Tür viele Spinnweben. Zwei von feinen Adern durchzogene Frauen - eine davon eine Vampirin, die der anderen im Kuss das Blut aus dem Körper saugt, und um sie herum klappern kleine schwarze Gestalten bedrohlich mit geschliffenen Scheren. Oder die Hand, aus der fortwährend unzählige neue Finger wachsen und davonfliegen.

Aus den komplex-komplizierten, schriftlich festgehaltenen Traumgeschichten hebt Dörte Oppermann einzelne zentrale Motive im Bild hervor, welche das Traumgeschehen wiederum ähnlich verdichten wie die Gestalten des Traumes zuvor bereits eine Verdichtung von Begebenheiten unsererVortagserlebnisse und früherer Begebenheiten waren. Oft sind es nicht Ereignisse vom Vortag, sondern vom Vorvortag, die in ihren Träumen als Anstöße auftauchen. So wie sie nicht genau sagen kann, warum ausgerechnet dieser oder jene Moment ihres Lebens in ihrem Traum auftaucht, kann sie auch nicht sagen, wie die Motive ihrer Bilder entstehen. Als ob die Bilder, angeregt und hervorgebracht durch ihre Träume, sich selber malten. Erschien ihr das Aufschreiben der Träume in ihre Notizbücher wie eine Fortsetzung des Traumes, ist für sie das Malen vor allem eine Form der Distanzierung vom Geträumten. Als müsse man, wenn man die Träume dem üblichen Mechanismus des Vergessens entzieht und in seinen Alltag hineinholt, schließlich doch einen Abstand zwischen sich und seine Träume bringen, um nicht den Boden unter den Füßen zu verlieren. Als sei es unmöglich, lange in der allgültigen Uferlosigkeit dieser komplex-komplizierten Paradoxien zu verweilen

Die Bilder ermöglichen mir, nocheinmal anders auf meine Träume zu schauen", sagt Dörte Oppermann. Was nichts anderes heißt, als anders auf ihr Leben zu schauen. Leben, Träume, das ist für sie längst unauflösbar miteinander verwoben. In der malerischen Sicht löst sie sich wieder ein stückweit von ihren Träumen, und es gelingt ihr, eine Art universelle Formel daraus zu machen. Tatsächlich ähneln die Figure und Formen ihrer Traumdarstellungen den Figuren und Formen, die man immer wieder in der Kunst sogenannter primitiver Kulturen und in der Bildnerei psychisch Kranker und künstlerischer Außenseiter findet, die ihre künstlerischen Ausdrucksformen jenseits der akademischen Kunststile entwickeln. Der Psychiater Hans Prinzhorn hatte dieses elementare künstlerische Schaffen in seinem Buch „Bildnerei der Geisteskranken" 1922 erstmals eindrucksvoll und systematisch in seiner ganzen seelischen „Wahrheitskraft" vor Augen geführt und gewürdigt. Indem er zeigte, dass Reihungen von Figuren, horizontale Gestaltanordnungen, Kreisstrukturen oder der Entwicklungs-Sog von Spiralen immer wieder in diesen Bildern auftauchen, wird sichtbar: es gibt eine grundlegende Struktur, deren psycho-logische Gesetze die zweckbestimmte Logik der Alltagsvernunft permanent überschreiten und unterlaufen, und die als bewegtes Gefüge derVerwandlung unaufhörlich auf Ausdruck und Gestaltanordnung drängt. Es gibt Listen des Unbewussten und paradoxe Zusammenhänge, die wirksamer sind als die Macht der Vernunft. Es gibt absurde Geschehnisse, die unserer Alltagsverfassung offenbar ständig zuwiderlaufen und ein Bein stellen, und die doch erst dafür sorgen, dass wir überhaupt vorankommen und im Gleichgewicht bleiben. Und genau das ist das Phantastische an unseren nächtlichen Träumen und an den Bildern von Dörte Oppermann: sie veranschaulichen, was wir nicht verstehen, und das sich offenbar doch immer schon von selbst versteht. Das Unaussprechliche: es zeigt sich.

Es besteht kein Zweifel, dass jemand, der seine nächtlichen Träume mitteilt, sehr viel Persönliches, Intimes preisgibt. Nicht zuletzt ist das einer der Gründe, weshalb viele Menschen ihre Träume nicht erzählen - neben dem Gefühl, dass es sich dabei bloß um dummes Zeug handelt. Dörte Oppermann verrät somit einiges über sich in diesen Träumen, ohne sich allerdings zu verraten. Die persönlichen Traumgeschehnisse, die aus dem Stoff einer individuellen, von Kindesbeinen an geprägten Lebensgeschichte und -dramatik entstanden sind, werden in ihren Bildern zu allgemeinen Projektionsflächen, die ähnlich den alten Märchen und Mythen von den grundlegenden existentiellen Dramen des Lebens erzählen: vom Menschlich-Allzumenschlichen, vom Menschen als Helden und als gefallenem Engel, als Windhauch im Universum, als krummem Stück Holz, als tanzendem Vogel in der Luft oder als blind kriechendem Wurm tief unter der Erde. Da kommt Sexualität vor und pflanzliches Wachstum. Unheimliches und Witzig-Skurriles. Und immer wieder tauchen tierisch-menschliche Mischwesen auf, Urfische oder Haartierchen, die den Menschen in Übergang und Verwachsung mit dem zeigen, was wir Natur nennen.

Nicht erst seitdem die künstlerische Bewegung der Surrealisten zu Beginn des Zwanzigsten Jahrhunderts in ihren Manifesten die (Sur-)Realität der Träume programmatisch zur ,eigentlichen“"Wirklichkeit erhob, haben sich Künstler in der langen abendländischen Kultur- und Kunstgeschichte immer wieder mit der besonderen Kraft und Magie des Traumes beschäftigt. Surrealisten wie Max Ernst, Paul Delvaux, Giorgio de Chirico, Rene Magritte oder Salvador Dali brachten das rätselhaft-abgründige Geschehen des Traumes in faszinierenden Kompositionen auf die Leinwand, in denen zwischen erotischen Motiven und einer tückischen Doppelbödigkeit des Alltäglichen vor allem das Verrückte, Absurde und unerschöpfliche sexuelle Begehren die Szene beherrschen. Etwas mehr als ein Jahrhundert zuvor hatte der britische Maler und Dichter William Blake (1757-1827) in symbolträchtigen Motiven der vertrauten Wirklichkeit die Macht einer anderen Wirksamkeit vor Augen geführt, die des Göttlichen, Mystischen, Visionären. Ungefähr zur gleichen Zeit brachte der spanische Maler und Graphiker Fancisco Goya (1746- 1828) neben zahlreichen anderen Gemalden und Druckgraphken über die menschichen Schwachen, 
Grausamkeiten, Kuriositäten und Verwirrungen in einem Blatt seiner 1799 veröffentlichen „Caprichos" die Traum-Erfahrung auf die bereits erwähnte ebenso einfache wie treffende Formel. „Der Schlaf de Vernunft gebiert Ungeheuer." Und diese faszinierend-erschreckende Erfahrung des Traumgeschehens ist auch in den Gemälden des Niederländers Hieronymus Bosch (1450-1516) enthalten, der bereits Jahrhunderte vor den Surrealisten die erstaunlichsten Phantasien unserer Innenwelt im Blick auf das „Weltgericht" oder den „Garten der Lüste" zum Ausdruck brachte, beherrscht von Dämonen und spukhaften Gestalten und einem unerschöpflichen Verwandlungsgeschehen.

An diesen Bildwerken der abendländischen Kunstgeschichte kommt niemand vorbei, der sich für die bildliche Darstellung von Träumen interessiert. Sie zeigen, wie der gewöhnliche Alltag und das unstillbare Verlangen unseres Körpers unauflösbar miteinander verflochten sind. Sie zeigen, dass hinter unserer Schädeldecke ein explosives Chaos an Regungen und Möglichkeiten verborgen ist. Und sie machen sichtbar, wie eng, ja untrennbar die Alltagsrealität in der Weltanschauung einer Kultur und die „Botschaft" des Traumes miteinander verflochten sind. Es gibt keine unberührte, ,unverfälschte" Innenwelt, sondern unsere innere Welt ist untrennbar an das gebunden, was in der Außenwelt geschieht. Auch bei der Entdeckung unseres Selbst in der Innenwelt stoßen wir auf das, was uns draußen begegnet und unaufhörlich zu schaffen macht. „Nichts ist innen, nichts ist außen, denn was drinnen, das ist draußen, “ wusste schon Johann Wolfgang von Goethe. Nur dass diese Einsicht immer wieder vergessen wird. Und ganz besonders in Zeiten, in denen, wie gegenwärtig, die Reise ins unentdeckte Innere des eigenen Seelenraumes als Pfad des „Eigentlichen“ und als Ausweg aus dem Unbehagen in einer als eng, trist, zerrissen und sinnlos erlebten Gesellschaft sehnsüchtig beschworen wird.

Dörte Oppermann lässt die verklärte Traum-Philosophie des Surrealismus allerdings ebenso links liegen wie den mystischen Heilszauber zeitgeistiger Seelentaucher.Vielmehr hat sie in ihren schriftlichen TraumErkundungen und zeichnerischen Malereien eine ganz eigene Form- und Bildsprache gefunden, in der weniger Beziehungen zur abendländischen Malerei-Geschichte als Korrespondenzen zu außereuropäischen Kulturen auszumachen sind. Den Figuren-Schemen verschiedener afrikanischer Naturvölker, die mit wenigen Strichen das Geheimnis von Leben und Tod berühren. Den Zeichnungen der lateinamerikanischen Frühkulturen als eine in Stein geritzte Brücke zwischen dem Menschsein auf der Erde und den kosmischen Gefilden. Oder den Darstellungen der australischen Aborigines, deren aufs Äußerste abstrahierte Figuren und Zeichen in Gebieten farbiger Punkte und Striche direkt in die "Traumzeit" hineinführen, jener Seinserfahrung, in der für die australischen Ureinwohner Traum und Vernunft. Träumen und Denken eines sind. Das ist eine schöne Vision, auch und gerade für die verkopften Menschen der westlichen Kulturtradition.

Dass Dörte Oppermann mit dem Malen ihrer Träume in der Zeit einer persönlichen Krise begann, belegt nicht nur, wie bedeutsam die Träume bei der Bearbeitung unseres seelischen Geschehens sind sondern auch die in die Zukunft weisende Kraft derTräume. Die schriftliche und bildliche Beschäftigung mit ihren Träumen hat es ihr ermöglichst, sich selber zu verwandeln. In der Berührung dessen, was man an vergangenen und an möglichen Erfahrungen in sich trägt. Und in derVerbindung mit jenem großen, alles durchwirkenden Ganzen, welches das kleine, begrenzte Ich zu einem winzigen Staubkorn zusammenschrumpfen und zugleich über sich hinauswachsen lässt. Die Tagesreste in ihren Träumen sind offensichtlich, ebenso die Bezüge zu früheren, lange zurückliegenden Erlebnissen und das Auftauchen unerwarteter, bis dahin unbekannter Perspektiven. „Im Traum erfährt man Neues über sich,“ weiß Dörte Oppermann. Immer wieder stößt man in den Träumen auf ähnliche Themen, Ängste, Wünsche. Doch während man in diesen bekannten Schemen offenbar noch immer die alten Problemen wiederholt und scheinbar nicht von der Stelle kommt, ist das Gesetz der Entwicklung und Verwandlung längst in vollem Gange. Es ist sehr schwer, sich selber zu kennen. Und in diesem schwierigen Unternehmen, das nie zu einem wirklichen Abschluss kommt, bestätigen die Träume gleichermaßen unsere Geheimnisse wie sie einen Weg weisen. Allerdings, auch Wegweiser sind nicht einfach zu lesen, seelische schon gar nicht.

Die Träume betrachten heißt: sehen, was alles möglich ist - im Seelischen und überhaupt.Verstehen, was alles gleichzeitig los ist, während man glaubt, nur mit einer einzigen Sache beschäftigt zu sein: Und dass man darin spürt, was an Früherem im Aktuellen noch immer wirksam ist, kann nach einem ersten Entsetzen eine sehr hilfreiche (Er-)Kenntnis sein. Unaufhörlich spülen die Träume die Bedeutung vieler unscheinbarer, im Alltag nicht beachteter Kleinigkeiten für einen kurzen Moment in den Bereich unseres Bewusstseins. Wir müssen nur, wie Dörte Oppermann, unser Augenmerk darauf richten. Der Traum ist der Königsweg zum Unbewussten und zum Verstehen der Funktionsgesetze des seelischen Geschehens, wissen wir seit Sigmund Freud. Träume wollen gedeutet werden. Und auch Dörte Oppermanns Bilder wollen gedeutet werden. Nichts steht darin auf Anhieb fest, und zugleich ist alles auf einen Blick zu sehen. „Allein der Traum gewährt dem Menschen alle Rechte auf Freiheit," schrieben Jacques-Andre Boiffard, Paul Eluard und Roger Vitrac im Vorwort zur ersten Nummer der Zeitschrift „,Die surrealistische Revolution“ im Dezember 1924. .Dem Traum verdanken wir, dass der Tod seine dunkle Bedeutung verliert und dass der Sinn des Lebens gleichgültig wird... Wir alle hängen ab vom Traum und sind es uns schuldig, seine Macht im Wachzustand zu ertragen." Oder, mit den Worten der Schriftstellerin Elfriede Jelinek: "Wer will nicht sein Begehren befreien, und wer hätte nicht Angst davor." 
TRAUMTEXTE 
Der sehr hohe Baum, auf dem ich sitze, schaukelt.

Die winzige Sitzfläche ist wie aus schwarzem Leder.

Als ich sie berühre, wird sie zu Vögeln, die ihre langen Hälse in sich selbst versteckt hatten Sie beißen mich. Es sind die Ibiche des Dr. Kranikus.

Mir beginnt zu schwindeln und ich lasse mich in die Tiefe fallen.

\section{SCHWARZES MÄNNERGESICHT}

In dem dunklen Haus am Meer gibt man ein Fest.

Ich mache Musik. Spiele Flöte und Geige.

Mein Spiel muß sehr gut sein, sonst fangen sie mich.

Ich klatsche zusätzlich noch in die Hände und tanze im Kreis herum.

Trotzdem wollen sie mich fangen. Mir gelingt die Flucht aus dem Fenster.

Als ich zurückschaue, sehe ich selbst aus diesem Fenster heraus.

Ich als ein übergrosses, verzerrtes, schwarzes Männergesicht.
Der kleine, schmale junge Mann sieht uns an und wir sind verzaubert.

Unsere Gesichter völlig deformiert und häßlich.

Ein Zauberer.

Als er und andere Zauberer ihre Zentrale verlassen haben,

schleichen wir hin und können uns wieder entzaubern.

Nur schnell nach Hause.

Da begegnen uns zwei Männer, einer dunkel, einer blond, mit hängenden Augenlidern.

Wieder der Zauberer!

Ich versuche, mich von seinem Blick abzuwenden. Zu spät - ich sehe noch,

wie seine Augen schwarz werden und glühen, dann spüre ich die ruckartige

Verwandlung in meinem Körper. Nein! Dunkelheit.

Ich erwache in einem fremdem Zimmer, auf einem großen Bett.

Mein Gesicht! Alles deformiert, schief

Kann ich jedenfalls noch sehen? Auch nicht richtig.

Draußen geht der dunkle Freund des Zauberers Patrouille.

In einem unbemerkten Moment entkomme ich.

Bin nun auf dem Bahnsteig einer U-Bahnstation. Aber wo?

Ich verstehe die Antwort der Frau nicht

Hilfesuchend sehe ich mich um. Zwei Männer mit Hüten. Sie lachen über mich.

Ich deute auf mein Gesicht, will reden - aber es ist unmöglich - wie hinter einer Glaswand.

Die Menschen. Wie entsetzt sie mich ansehen.

Unter ihnen ein Mann, mit sehr besonderen, sehr hellblauen Augen.

Flehentlich fasse ich ihn am Arm. Seine Augen. Seine Augen. Sie sind aus Glas.

Können Sie mit diesen Augen sehen? Ja.

Da weiß ich, daß er mir helfen kann.

Er kann nicht verletzt werden, nicht verzaubert, ist unverletzbar. 
Die Erde. Ganz klein, völlig nackt, wie unbehaart.

Keine Berge. Kein Wasser. Keine Bäume. Keine Häuser. Nichts.

Ein glatter, toter Planet.

Wie ein Gebäck mit durchsichtiger Glasur überzogen.

Auf dieser Erde fuhr eine Straßenbahn.

\section{SCHRECKENSKÄFIG}

Ich erwache in einem ovalen Drahtkäfig, der im Raum zu schweben scheint

In dem Käfig hängen verschiedene Dinge, die mich offensichtlich erschrecken sollen.

Auch eine Gummispinne.

Ich muß lächeln und setzte die Gummispinne unter leisem Zureden

auf eine Art Fensterbank. Ins Sonnenlicht.
Nicht schlafen können. Es ist sehr heiß, entsetzlich heiß.

Die Hitze nimmt unaufhörlich zu. Die Welt färbt sich rot

Alle Dinge beginnen zu zerfallen und sich aufzulösen, in Fetzen herunterzuhängen.

Ein großes Grauen. Hilflosigkeit. Fluchtgedanken.

Ehemalige Erdbewohner sollen aus der Isolierstation auf einem anderen Planeten entwichen und zurückgekommen sein.

Etwas haftet an ihnen, das eine tödliche chemische Veränderung der Erde bewirkt.

Die Familie und ich. Wir wollen auch fliehen.

Die Katzen. Ich muß noch die Katzen aus dem Keller holen.

Ich renne, obwohl mir die herabschmelzende Decke Angst macht.

Versehentlich stoße ich an eine angelehnte Schranktür. Sie schlägt auf. Ich weiche zurück.

Umsonst. Ein gelber Pavianaffe springt heraus.

Er fällt mich an - im selben Moment beginne ich mich aufzulösen

Gerade noch kann ich den Affen in den Schrank zurückdrängen, dann zerfließe ich in eine Art Nichts. Schmerzlos, gleitend. Werde durchsichtig, unsichtbar.

Eine unsichtbare, bewegliche Qualle. Auch die Armbewegungen sind unsichtbar.

Aber sprechen kann ich.

Wieder oben bei den anderen. Nicht erschrecken! Ich erzähle. Ihr müßt fliehen

Wir müssen alles stehen und liegen lassen.

Armes Kind. Meine arme kleine Tochter.

Sehr, sehr traurig steht die mit hängenden Armen und einer Puppe in der Hand. Du tust mir leid.

Aufbruch. Paßt auf! Wer einen Affen sieht, soll um sein Leben rennen.

Mein anderes Kind. Dummes Kind. Dummer Junge. Was machst Du!

Er turnt in Richtung Affe. Komm schnell mit mir. Schnell!

Wir hasten zu dem großen Tor im Garten.

Riesig und gelb ist der Hund.

Plötzlich ist er da. Streckt fletschend seinen Oberkörper durch das Tor und will töten

Als Ich mich ihm in meiner Unsichtbarkeit nähere, beginnt er zu jaulen,

zieht den Schwanz ein und robbt, platt auf den Boden gedrückt, zurück.

Zwei weitere riesige Hunde sind auf der Straße und weichen auch entsetzt vor mir zurück.

Ein altes Auto mit heruntergekurbelten Scheiben kommt. Nette, fremde Leute sitzen darin

Sie werden mein kleines Mädchen mitnehmen, weit weg.

In 36 Jahren sei die Gefahr vorüber, dann könne ich meine Tochter besuchen.

Dann lebe ich wohl nicht mehr. Nein, wohl nicht,sagt der Mann

Der Augenblick des letzten Abschieds ist da. Der Schmerz zerreißt mich.

Hilflos renne ich zu einem Auto, in dem mein Vater und meine Mutter sitzen.

Außen am Wagen ist ein fremdartiges Schmucksymbol angebracht.

ein vergoldeter Maiskolben. Niemand kann mir helfen. 
Der fremde Mann hat mich durch die niedrige Eingangstür in einen unterirdischen Gästegang geführt. Es ist fast dunkel.

Der Gang erstreckt sich lang in die Tiefe und auf der linken Seite sind Boxen aus denen nackte helle Füsse herausragen.

Wo ist der Mann?

Ich bin alleine in dem feuchten Gang und habe große Angst.

Totenstille. Wie in einer Gruft.

Als wäre ich für immer begraben.

\section{MAgERE KNOCHEN}

Der Professor, halb liegend. Alt. Wunderbar schmal und knochig.

Seine Knochen erregen mich. Ich möchte ihn berühren, wage es aber nicht

und lasse meine auf ihn gerichteten Bewegungen in der Luft zergehen.

\section{VERLAUFEN}

Ich wußte doch genau, wohin ich wollte.

letzt in der U-Bahn weiß ich die Fahrtstrecke nicht mehr

Und das Baby ist auch noch bei mir.

Ich frage die Menschen, doch alle sind schrecklich beschäftigt mit vielen winzig kleinen,

glänzenden, kompliziert aussehenden Maschinen.

Sie antworten nicht.
Ich sehe in einen winzigen Zahnarztspiegel. Mein Gesicht ist ganz klein. Ein Blutstropfen in dem Spiegel verdeckt das halbe Gesicht.

Ich arbeite als Sprechstundenhilfe.

Im Wartezimmer sitzt eine ältere Frau.

Sehr aufgemacht. Turmhohe Haare.

Neben ihr klingelt das Telefon. Der Hörer lässt sich nicht abheben.

Das Telefon ist eine buntbemalte Atrappe, wie eine Torte.

Die Frau wendet mir ihr Gesicht zu. Ich muß sehr lachen

Es ist höchstens handbreit - und dazu diese Turmhaare.

Meine Kollegin kommt und wir halten nun kleine, bunte Regenschirme,

etwas abgenutzt schon, in unseren Händen.

Wir tanzen. Wie leicht wir sind. Immer leichter werden wir. Schwerelos.

Wir können diagonal in der Luft schweben.

Glücklich singe ich wieder und wieder eine fröhliche Melodie.

\section{AUSHÖHLEN}

Mit einem Löffel habe ich meinen Körper ausgekratzt, ausgehöhlt.

Auch die Gliedmaßen. 
Ich gehe einen Feldweg entlang.

Von rechts nähert sich ein Mann mit einer großen, blaugrauen Kuh.

Das Tier rennt plötzlich auf mich zu.

Schnell flüchte ich in die Federdecken des Bettes, das auf einmal auf dem Feldweg steht

Kaum liege ich rücklings, da springt das Tier, nun ein Schaf, zu mir ins Bett.

Es liegt mit dem Rücken auf mir, wollig und warm. Ist ganz lieb und friedlich.

Glücklich lege ich die Arme um seinen Bauch.

Siehst du, sagt der Mann, es wollte nur Liebe.

ATMEN

Ein berühmter Künstler hat eine Menschenvernichtungsmaschine entwickelt.

Er fährt mit der Maschine, die aussieht wie eine Straßenbaumaschine

- mit Riesenscheinwerfern vorne und oben - in eine tief verschneite

im Schneegestöber liegende Straße.

Ihm entgegen kommt ein ebensogroßes baggerähnliches Fahrzeug

mit vielen Menschen darauf.

Der Künstler stellt die Scheinwerfer an, die einen Lichtbündelnebel auf die Menschen

zielen, und sagt zynisch: Ihr seid nichts. Ich denke euch weg. Ihr seid Punkte,

die sich auflösen.

Es ist eisig und die Menschen beginnen sich aufzulösen und zu pulverisieren.

Wir sind nur zu zweit auf der Straße, aber immer mehr Menschen stoßen zu uns.

Wir beide flüstern erst, werden dann immer lauter und rufen: Atmen. Atmen! Atmen!!

Gegen die Scheinwerfer atmen, gegen die Eiseskälte.

Alle, alle atmen und atmen.

Die Vernichtungsmaschine hat keine Macht mehr.
Aus Naivität sind wir in das große Schloss und das verbotenen Gelände geraten.

Dort herrschen ein König, eine Königin und ein Kind.

Sie werden uns töten. Nicht als Strafe, sondern einfach, weil wir da sind.

So war es immer. So ist die Sitte.

Der lange Gang ist sehr dunkel, aus schwarzem Ebenholz und Metall.

Links und rechts zweigen in kurzen, regelmäßigen Abständen scharfkantige Seitengänge ab,

am Ende verschlossen mit schweren, schönen Metallklappen.

Dahinter rauscht das Meer

Alles ist sehr kunstvoll und filigran verarbeitet.

Wir werden von dem Kind geführt.

Es zeigt uns alles - unserer Angst gegenüber vollkommen gleichgültig.

Am Ende des Ganges gibt es zwei Fächer mitTüren.

Ich öffne die linke.

Ein Stofftier springt heraus und schnappt nach mir. Es beißt und klammert sich fest.

Ich schleudere es zurück und drücke die Tür wieder zu.

Das Tier schreit schrecklich.

Ich weiß, daß es Liebe will. Dann tut es nichts.

HÖHLEN-HÜLLE

Ich höhle ein großes Schaf aus.

Alle Eingeweide hole ich heraus und krabble in die Hülle.

Fühle mich wohl und geborgen. 
Die mannshohe Mauer ist mit Glassplittern besetzt.

Einzeln muss man darüber balancieren.

Es ist weniger schlimm, als es aussieht.

Die Straße vor mir. Gerade. Schmal. Ein Schlauch. Links und rechts Häuser.

Wie gezeichnet.

Alles ist ein flammendes helles Rot.

Ich. Ohne Form. Ohne Gestalt. Ohne Gesicht.

Nur rote, geballte Energie. Kugelförmig.

Ich bin nur rote Wut

Wie eine Feuerwalze rase ich schnell und schneller auf das gleißend helle Rot

am Ende der Straße zu.

Langsamer, langsamer! Es geht nicht mehr.

Die rote Wut. Schneller. Immer schneller

Das Ende der Straße. Alles verschwimmt

Ich bin ein dickes Buch mit vielen Seiten

Fremde Menschen blättern darin.

Ich will das nicht und verlange, mich in das alte Bücherbord, wo mein Platz war zurückzustellen.

Ein Haus, darin ein Heizkörper, dunkel.

Die Frau möchte unbedingt das Haus verlassen, klammert sich aber an den Heizkörper

Er ist ihr Halt und gibt ihr Wärme.

Sie kann das Haus nicht verlassen, ohne sich vom Heizkörper zu lösen,

doch der gehört zum Haus und bleibt auch dort.

ROTE VAMPIRFRAU

Eine mir unbekannte Gegend. Hohe Häuser, enge Straßen.

Ich fühle mich fremd, einsam und einer ständig wachsenden Bedrohung unbekannter

Herkunft ausgesetzt.

Innen. Ein labyrinthartiges Gängegewirr. Enge. Viele Menschen.

Immer deutlicher spüre ich die Gefahr näher kommen

Ich frage die Menschen nach dem Ausgang.

Keiner antwortet - als stünden sie unter einem Bann oder dürften nicht antworten. Panisch beginne ich den Ausgang zu suchen

Endlich erhalte ich Antwort. Von jungen Männern und Frauen. Eine sehr junge Frau zerrt mich in einen schmalen Raum - ich denke, sie will mir helfen. Zu spät - eine Falle!

Die jungen Männer und Frauen fesseln mich.

Man beginnt, mich mit kleinen Operationsbestecken zu löchern, zu stechen und zu schneiden. Es ist grausam und tut entsetzlich weh.

Eine andere junge Frau, sehr schön, mit langem, braunen Haar und einem engen,

blutroten Kleid, kommt herein. Ich kenne sie von früher, hatte ihr vertraut.

Ich sage: Du?, sie antwortet spöttisch lächelnd: Ja. und legt sich bäuchlings auf mich. Sie will mich vergewaltigen, denke ich, aber sie legt ihren Mund auf meinen Mund und beginnt, gierig und schlürfend mein Blut aus der Mundhöhle zu saugen und zu trinken Es gurgelt.

Die anderen quälen mich weiter

Ich weiß, wenn ich nicht freikomme, muß ich sterben. Sie wird mein Leben trinken!

Ich schlage um mich, reiße meinen Mund los und rufe um Hilfe - erst dumpf

dann laut und lauter.

Befreit stehe ich nun an der Terrassenbrüstung eines bestimmten dunklen Hauses.

Von hier oben sehe ich weit über das offene Land und die Stadt. Ich weine. 
Im Fischrestaurant.

Der Besitzer serviert. Riesenmengen von Fisch in Sauce.

Ganze Fische. Große, in denen jeweils noch ein kleinerer steckt.

Er serviert in einem rasenden Tempo, äußerst ungeduldig.

Nicht sovie!! Lieblos zerhackt er meinen Fisch in der Mitte, die Sauce spritzt,

und er reißt eine Hälfte vom Teller

Das Lokal sei aber noch eines von den alten und der Blick sei doch sehr schön,

meinen die anderen.

Verstört gucke ich auf das Fischmassaker

TIEFE KERBEN

Die nackte, junge, hellhäutige Frau wird von Männern festgehalten. Einer schneidet ihr mit einem Messer tiefe Kerben in den Körper.

Die Frau schreit und schreit.

Sehr ruhig schneidet der Mann die Formen zuende.

Es blutet nicht, und die Kerben sehen aus wie schmale, zieselierte Gräben.
Bevor man das Krankenhaus betreten darf, muß man eine Identifikationsmaschine passieren. Sie besteht aus einem lebensgroßen Spiegel, vor den man sich hinstellen

und möglichst natürliche Bewegungen machen muß.

Nur dann wird Einlaß gewährt.

Im Gebäude ist das Treppenhaus rund um einen sehr dicken, alten Baumstamm gebaut.

Ein junger Mann und eine alte Frau stehen am Treppenabgang daneben.

Die alte Frau greift mich plötzlich an. Nachdem ich sie abgewehrt habe,

attackiert mich der junge Mann mit einem großen Messer.

Ich kann ihn an den Handgelenken ergreifen.

Er wehrt sich heftig, aber ich lasse nicht los, sondern drücke seine Hand und das Messer voller Kraft gegen den Baum.

Das Messer beginnt von alleine, langsam und gleichmäßig einen scharfen und tiefen Schnitt in den Baumstamm zu schneiden.

Der junge Mann stammelt ganz erlöst: Jetzt ist der Bann gebrochen. Ich bin frei. Später stellt er mich seinen vielen Freunden als „Der Engel“ vor.

Erneut Einlaß in ein Krankenhaus.

Wieder wird man einer Kontrolle unterzogen.

Durch die äußere Flügeltür betritt man das Gebäude. Nach links erstreckt sich ein langer Flur. Aufgereiht stehen dort Männer und Frauen auf kleinen, rollbaren Podesten. Ich muß auf sie zugehen, würdevoll mit ihnen Kontakt aufnehmen und unbedingt ernst bleiben.

Jedoch stellt sich heraus, daß ich viele von früheren Jugendstreichen her kenne. Deswegen müssen wir immer mehr lachen, ja, wir brechen in lautes Gelächter aus und es wird immer lustiger.

Das verschließt uns seltsamerweise nicht den weiteren Zugang zum Gebäude - im Gegenteil - der Gang öffnet und weitet sich zu einem großen Saal hin, in dem viele Ausländer zu fremdländischer Musik tanzen.

Man ist freundlich zu mir.

Uberall bei diesen Menschen bin ich als „Der Engel“ bekannt. 
Ich soll meine Arbeit als Sekretärin beginnen.

Um den Arbeitsplatz zu erreichen, muß ich durch ein kirchturmhohes stacheliges

Geflecht klettern - und das mit meinen roten Stöckelschuhen und dem engen, roten Kleid.

Es ist so beschwerlich.

Oben.

Mein Arbeitsplatz ist ein Vogelhorst aus dünnen Ästchen, die rote Schreibmaschine

eingeklemmt im Geflecht.

Gefährlich. Unbequem. Aber hell.
Zwei Menschen in einer Küche. Mann und Frau. Wir sind Flaschenbürsten. Nicht mehr neu.

Ich bin ganz abgenutzt.

Wir drehen uns. Wir drehen uns.

In seinen Händen hält er mir ein in Papier eingewickeltes Buch entgegen. Das macht mir Angst.

Es scheint das Schuld-Buch zu sein.

All meine Schuld soll mir überreicht werden.

Eine Liege, direkt links daneben ein Hocker. Seine Sitzfläche ist ein zerknautschter, alter

Schulranzen, hart und mit scharfen Kanten. Auf der Liege übergroße, weiß bezogene

Steppdecken. Links und rechts an der Liege sind dunkle, schmale Haltegurte angebracht Auf dieser Liege kann man eine Mutprobe bestehen.

Gegen Bezahlung wird man von zwei älteren Frauen unter den Decken festgeschnallt.

Dann eine bestimmte Zeit lang in den aberwitzigsten Drehungen hin- und her-

geschleudert, bis man zu zerreissen droht.

Die Affenfrau IM KäFIG

Man erklärt mir alles genau.

Ich lasse mich versuchsweise auf die Liege schnallen und bekomme von der einen Frau die Anweisung, probehalber eine sehr schwierige Kopfverdrehung zu machen - damit ich eine Vorstellung davon erhalte, was auf mich zukäme. Und das sei nur eine kleine Probe. Auch auf den Hocker müßte ich achten wegen der harten Kanten - aber sie könnten nicht ausschließen, daß ich dagegen schlüge.

Und die Halteseile müßte ich gut festhalten und abstellen könnte man die Maschine zwischendrin nicht und Hilferufe würden nichts nützen - sie würden nicht gehört.

Mit Mühe bekomme ich meinen Kopf in seine normale Haltung zurück. Mir ist schlecht

Ich lasse mich losschnallen. Diese Mutprobe will ich nicht machen

Daran ist nichts Lächerliches.

Und mein Geld könnten sie behalten. 
In einer offenen, ovalen Hutschachtel sitzt ein sehr kleines Kind.

Es lacht: ich bin der König!

Mit den Händen schiebe ich die Schachtel und das Kind über eine riesige Fläche

aus klarem Eis.

Unter der gläsernen Eisfläche sehen wir tief unter uns eine große Stadt liegen.

NEUE FINGER

Aus der Mitte meiner Hand wachsen Finger.

Sie schieben und drehen sich, teils langsam, teils ruckartig heraus.

Es werden mir zuviele Finger. Durch Schüttelbewegungen schleudere ich sie ab.

Aber immer neue Finger wachsen nach.

kalt die leere Ebene von hoch oben.

In der Mitte stehe ich.

Einsam. Unendlich klein.
HIGH HEELS

Der Mann will seiner Frau dicke Socken bringen, damit ihre flachen Schuhe besser passen. Auf High Heels stöckelt die stark geschminkte Frau am Ende des Raumes hin und her.

Der Sockenbringer - fassungslos.

Wir sollen auf das stürmische Meer hinausrudern. Dazu müssen breite Riemen unter meiner Haut am Kopf befestigt werden, Hautlaschen geschnitten werden.

Nein. Ich will das nicht.

\section{MASKENTAUSCH}

Ich tausche bei verschiedenen Menschen die Gesichtsmasken aus.

Eine sehr dünne, sehr hagere alte Frau.

Und ein dünnes, flaches Tablett mit hochgewölbtem Rand. Es ist bräunlich wie alte Fotos. Auf der Oberfläche sind Köpfe abgebildet.

Aus der Mitte des Tabletts ragt mein papierdünner Kopf senkrecht nach oben in die Höhe. Das Tablett schwebt schräge im All. 
Der Leiter der Theatergruppe hält eine übermannshohe Meßlatte in den Händen. Vor sich. Vor uns.

Ich rufe: Aber ich kann es! Aber ich kann es!

Ich rüttle inn.

FREI SEIN

In dem Gefängnis liegen mehrere Zellen hintereinander, meine ist die letzte. Alle Gefangenen werden in die Freiheit entlassen und gehen.

Nur ich verkrieche mich in eine Ecke meiner Zelle.

Der Gefängnisleiter hat meinen Rückzug beobachtet.

Er will mir helfen. Das geht nicht, weil ich ihm nicht helfen kann

Auch wenn ich wollte. Ich kann nicht.

Böse starre ich die Frau an. Auf einmal sieht sie aus wie ein Röntgenbild.

Ihr Inneres leuchtet.

Sie beginnt zu einem unförmigen Klumpen zusammenzuschrumpfen.

Kugelartig. Ohne Kopf.

Als ich den Raum verlasse, flieht die Katze entsetzt vor mir.

Der wahnsinnige Herrscher arbeitet in einem Gebäude, das an ein Puppenhaus erinnert. Es hat keine Vorderfront und ist in viele Waben aufgeteilt.

Wir können in das Haus hineinsehen.

Der Herscher dekoriert die Waben, die Zellen, für neue Folterungen.

Er bemalt die Wände mit einem kleinen Muster. Malt viele, viele kleine, rosarote Tränen, freudig in Erwartung der blutigen Tränen von zukünftig Gefolterten.

\section{GANZ ZART GANZ STARK}

Lachend kommt von links der hübsche Neger, mit dem ich so schön tanzen konnte, auf einem Fahrrad angefahren.

Er ist sommerlich angezogen, nur im Unterhemd und schwitzt.

Höflich nickt er mit dem Kopf und beginnt dann, mit den Ohren zu wackeln.

Aus den Ohren fallen Mandeln und Nüsse heraus.

Immer wieder kann er Nachschub wackeln. 
Die Kommission hat eine Kommissarin entsandt.

Wir Frauen werden von ihr aufgefordert, uns in einer Reie aufzustellen

Die Kommissarin zählt die Reihe ab - ich bin die letzte, die sie mitzäht.

Wer in der Reihe steht, muß sterben.

In dem halbdunklen Raum befindet sich ein langes, dunkles Regal mit vielen Fächern - je einer Frau ein Fach gegenüber.

Wir Todeskandidatinnen müssen unsere Kleidung ausziehen und bekommen dafür bereits benutzte Kleider, jeweils aus dem gegenüberliegenden Fach des Regals.

Wir tragen jetzt Übergangs-Leih-Kleider für die verbleibende Zeit,

bis wir endgültig im Totenreich sind

Ich bin verzweifelt.

$\mathrm{Da}$ ich mich fraglos in die Reihe gestellt habe und nun sterben soll.

Man kann nicht fliehen. Das Gelände ist hermetisch abgeriegelt.

Ich wechsle letzte Worte mit der Familie, die zwar traurig ist,

sich aber schon damit abgefunden hat, daß ich sterben muß.

Es irritiert mich, daß die anderen schon wieder in ihrer Zukunft leben.

Ich gehöre nicht mehr dazu, obwohl ich noch lebe.

Meine Tochter berichtet mir, die Kommissionsmitglieder hätten eine Zeichnung von mir

ein Todesbild, so schön gefunden. Ich bin stolz, aber es ist kein Trost.

Ich will nicht sterben.

Kann mir nicht vorstellen und nicht einsehen, daß die Reihe schon an mir ist.

Viele Menschen, scheinbar auch Freundinnen von mir, sind in dem Restaurant,

in dem ich jetzt bin.

Lange Zeit halte ich mich dort auf, vielleicht hat man mich doch vergessen.

Aber das Todesflugzeug, ein seltsames, kastenförmiges, grünlich leuchtendes Gefährt.

fliegt immer wieder ganz nah und tief über das Restaurant.

Sehr langsam - als suchte es.

Es hat Augen und wirft einen riesigen Schatten, der durch die Fenster und

das gläserne Dach fällt.

letzt hat die Kommissarin mich entdeckt.

Freundlich will sie mir nun endlich die Todesmütze aufsetzen,

sieht aber meine Traurigkeit und meinen Wunsch, noch einmal wirklich zu lieben.

Sie lächelt und lächelt auch nicht

Ich darf noch leben.
Alles in dem Haus ist sehr heruntergekommen.

Wo ist das Zimmer, das ich suche?

Ich öffne rechts von mir eine Tür Es ist nur ein Gano dahinter.

Er ist sehr lang, schwach erleuchtet, schmutzig.

Und ganz verhangen und versperrt mir riesigen Spinnweben.

Am Ende des Ganges sitzt zusammengesunken eine Figur.

Ein Mann. Er ist lebendig.

\section{EIN HALBER MANN}

Der Mann hat nur einen Oberkörper, mit dessen unterer Stumpffläche er auf der Tanzfläche steht wie eine Schachfigur.

Ich setze mich auf meine Knie, um auf dieselbe Höhe mit ihm zu kommen.

Aber - wie soll man so Tango tanzen? 
Ein Haus. Ein Zimmer. Eine Party.

Plötzlich entsteht Chaos, eine gierige Unruhe.

Die Anwesenden sind meine besten Freunde. Sie fallen über alle meine Sachen her.

Wühlen in meinen Schränken, reißen die schönen, zarten Kleider heraus, plündern alles

und beginnen, es davonzuschleppen.

Alles, was mir gehört, ist schwarz. Ein schwarzes Chaos.

Entsetzen und Wut schleudern mich in die Luft

Ein Stück höher als die Menschen unter mir, drehe ich mich flach liegend

über ihnen im Raum.

Ich bin nicht nur schwarz gekleidet, ich bin schwarz.

Eine schwarze routierende Scheibe.

Ich drehe mich und aus mir drängt und würgt ein langer stummer Schrei.

Verzweifelt versuche ich, den Schrei hörbar zu machen.

Der stumme Schreikrampf löst sich. Ich schreie.
Wie ein Mädchen liege ich leicht bekleidet in meinem Bett. Am Fußende steht ein netter Mann, den ich kenne und mas.

Er steht bewegungslos und scheint doch näher zu kommen.

Auf einmal wirkt er sehr bedrohlich.

Fast traurig sagt er, es täte ihm leid, jetzt ein grausamer Kroate sein zu müssen Sofort bin ich mir der tödlichen Gefahr bewußt und fliehe.

Es ist eine lange Flucht in dunkler Nacht.

Durch Bahnhöfe, enge Häuserzeilen, verwilderte Gartenlandschaften

Ich schwebe durch nachtleere, schwach erleuchtete Straßen, schwebe über vereinzelte Passanten, gleite durch sie hindurch.

Die Gartenlandschaft wird bedrängender. Hohe, wilde Hecken säumen einen schmalen

Weg, der wie eine Rampe aufwärts führt. Ich muß über die hohen Hecken

und über eine hohe Pforte aus schwerem Holz klettern, um weiter zu kommen.

Vor mir ragt ein steil in die Höhe ansteigendes Kinogestühl auf.

Stühle und Kissen aus schwarz glänzendem Lack.

Im oberen Bereich sitzen einige dunkle Ausländer.

Sie sehen mich. Wieder bin ich in Gefahr und flüchte.

Links an einer hohen, großflächig schwarzweißgemusterten Leinwand entlang.

Die Männer dürfen keine Macht über mich gewinnen!

ch reiße das schwarzweiße Muster herab, reiße einen langen Riß diagona

von oben nach unten in die Fläche und stoße immer lauter einen

langgezogenen Schrei aus.

Der Schrei erschreckt die Männer.

Der Riß ist breit und wie aus Glas.

Durch den Spalt kann ich dahinter die Wirklichkeit sehen. 


\section{Ein Gesellschaftsspiel.}

Die Professoren stehen locker im Kreis.

Der erste zieht eine erschreckende Grimasse, der zweite sieht den ersten an,

verzieht sein Gesicht auch entsprechend fürchterlich, wendet sich dann zum dritten,

der macht wieder eine Grimasse und so fort.

Ich möchte mitspielen.

Breite die Arme aus und sage: Ich bin die Mauer.

Das will man aber nicht. Nein

Das sind die Tu Es Spiele.

In diesem Land ist es fast dunkel und man kann sich in feinsten, dünnen Netzen verfangen.

Sie lähmen mich.

Ich habe die Umwandlung des Landes in das Dunkelland der Netze zu spät bemerkt.

Neue Herrscher regieren jetzt das Land - sehr sanft,

solange man sich ihrer Herrschaft beugt.

Wächter haben mich in das obere Stockwerk eines Gebäudes gebracht.

Ich sehe nach draußen.

Bis auf eine Laterne ist alles dunkel.

Es regnet in Strömen von rechts nach links.

Ich sehe jeden einzelnen Tropfen.
Das Riesenhöhlenhaus lebt - wie ein Organismus.

Eine Aneinanderfügung und Durchdringung von Hohlräumen.

Halb gehe ich hinein, halb werde ich gesogen.

Diese Hohlräume, in denen und an deren Rändern sich auch große Gegenstände befinden,

senden eine magnetische, schlürfende Wirkung aus.

Wie in einer wild gewordenen Maschine werde ich hin- und hergeschleudert,

abwechselnd von allen Seiten und den mundähnlichen Räumen angesogen,

hierhin und dorhin katapultiert

Die Räume und die Gegenstände, auch ein großer halber Papierfisch dabei, schnappen nach mir und wollen mich wegschlürfen.

Mit all meiner Willenskraft konzentriere ich mich auf ein großes Auge,

das sich auf einer rechteckigen Platte am Ausgang befindet

Obwohl ich immer wieder in die Schlürfräume gesogen zu werden drohe

rettet mich das Auge.

Ich stabilisiere mich.

\section{SKELETTSPINNE}

\section{Der Kopf eines Mädchens.}

Nur ein verschlungenes Knochengerüst, lange, helle Haare.

In dem Knochengewirr bewegt sich schnell eine kleine, schwarze Spinne,

hin und her, auf und ab.

Der Mädchenkopf ekelt sich und gerät in Panik.

Ich rede beruhigend auf inn ein

Die Spinne sei völlig ungefährlich. 
Die Gefahr, daß die Wölfe kommen könnten, ist unterschätzt worden.

Ich dachte erst, die Wölfe schwimmen nur, aber sie kommen überall hin.

Weit hinten in der Straße kommt der erste Wolf angehetzt.

Wir fliehen.

Durch sehr lange, gerade, breite Straßen mit Schaufenstern auf beiden Seiten.

Viele verschiedene Mäntel und Kleidungsstücke sind dort ausgestellt.

Alle sind aus Fell, von den verschiedensten Tieren, vor allem Raubtieren.

Wir sind in ein großes Gebäude geflohen.

Viele Menschen liegen unter Bettzeug in Betten.

Sie haben sich selbst zum Sterben gelegt

Wir brauchen auch einen Platz, um in Ruhe sterben zu können

Aber es ist schon alles besetzt. jetzt sind die Menschen auf der Flucht. In den Straßen quellen die Massen.

Ich soll in ein rosafarbenes Kästchen verwandelt und in einem entlegenen Zimmer im obersten Stockwerk des hohen Gebäudes eingesperrt werden.

Der Direktor hat es so beschlossen.

Irgendwer verfolgt uns, greift uns an.

Wir sind in Not.

Da sehe ich ihn liegen, rechts, ein Stück von mir entfernt

Ein Riesenhandschuh, menschengroß - mit Fingerkuppen.

Die Fingerkuppen sind auch Augen

Plötzlich erheben sich diese Finger drohend,

bewegen sich auf und ab und verscheuchen die Angreifer

Das muß ich unbedingt den anderen zeigen

Aber da liegt der Handschuh schon wieder ganz ruhig da.
ROTES RÄTSEL

Leuchtend rote Blumen wachsen auf dem Boden des langen Flures.

Sie werden von einer alten Zauberin bewacht

Ich lobe die Schönheit der Blumen.

Wir sind jetzt auf einem Marktplatz.

Viele Tische sind in U-Form angeordnet und reichlich gedeckt mit rotem Geschirr.

Ich bin sehr aufgeregt, weil ich diese Szene von früher her zu erinnern glaube

und weiß, daß wir ein Rätsel werden lösen müssen.

Daß wir die Anordnung des Geschirrs deuten müssen.

Ich habe die Lösung vergessen.

\section{ROT CONTRA WEISS}

Ich probiere sexy Unterwäsche an, zum Schluß ein rotes, kurzes Mieder. Die Frau und der Mann blicken mich streng an.

Sie wickeln mich eng in weiße Tücher, hüllen mich vollständig ein

und lächeln beide boshaft dazu.

Ich ersticke. 
Über eine riesig ausgedehnte, wässrig glänzende, helle Steppe gleiten unzählige sich drehende, aufgespannte Regenschirme.

NACHGEBEN

Mit einem Stock tastet sich die Alte über den Boden.

Endlich gibt der Boden nach, sagt sie.

Ich denke: der Boden? Du gibst nach.

URFISCH

Ich blicke aus einem Fenster hinaus.

Draußen in der hellen Luft schwimmt ein riesiger, farbig schillernder groß gemusterter Fisch.

Langsam gleitet er wieder und wieder von rechts nach links vorbei.

Mit seinem großen, runden Auge sieht er mich an.

Es ist der Urfisch.
Unsichtbar und von uns unbemerkt hat sich eine tödliche Gefahr entwickelt. Von den Seiten her - aus dem Buschwerk - greifen sie nach uns.

Im Luftraum wachsende Pflanzen, fein wie Engelshaar, fast durchsichtig. Ein Hauch, aber klebrig.

Man bleibt an ihnen hängen und es werden immer mehr

Kein Durchkommen.

Vom Allerzartesten erstickt werden.

\section{DURCH EIN SCHLÜSSELLOCH FLIEGEN}

Ich fliege durch ein Schlüsselloch - dahinter gibt es mehr Kraft. kraftvolle weibliche Personen und Gesichter:

5I7 FITNESSGERÄTE GEGEN TRAUER

Die Fitnessgeräte sind extra für Frauen gemacht. Für trauernde Frauen.

Trauerarbeit mit großen Ganzkörperexpandern.

Kraftvolles Ausdehnen. 
Mein Körper ist sehr schmal und hat geschnitzte Kanten.

Ich bin ein Marterpfahl.

Das macht mich traurig und ich muß weinen.

Aber dann beginnen aus dem Marterpfahl zarte Triebe zu spriessen

Sie werden immer größer, zu grünen Blättern.

Der Marterpfahl hat senkrecht gestreckte, goldene Füsse.

\section{SCHATTENMUTTER}

Alles so leer - niemand da - ich kann die Schrift und die Zeichen unter Wasser nicht lesen. Über dem gläsernen Gang sehe ich nur einen riesigen Schatten liegen - eckig, mit ausgebreiteten Armen: meine Mutter

\section{DIE EISRÖHRE}

Ein starker Sog zieht mich in eine schneehelle, sehr lange und schmale Eisröhre.

In eine eisige Kälte.

Ich werde erfrieren. Erstarren

Mein Wille katapultiert mich wieder nach draußen
Das menschengroße Ei hat Arme und ist von einem Schuppenpanzer überzogen. Es ist mein Vater.

Vorsichtig löse ich vom linken Arm einzelne Schuppen, bis ein Loch im Panzer entsteht und ein Stück vom Arm zu sehen ist.

Sanft berühre ich die Haut und setze die Schuppen dann behutsam wieder ein.

\section{BraVo! BraVo!}

Endlich habe ich das Haus gefunden, in dem die Kunstausstellung sein soll.

Ich betrete den dunklen Gang und gelange von da aus in einen großen Raum voller

Menschen. Sie verharren bewegungslos - absonderlich verkleidet und darüber noch

mit dünnen Schleiern bedeckt - geisterhaft.

Musik erklingt.

Man bemerkt mich - die Figuren beginnen sich zu bewegen - und ich werde wohlwollend aufgenommen, ja wie eine Bekannte begrüßt.

Auch ich bin jetzt verkleidet und stürze mich in den nun stärker und stärker werdenden Festrubel.

Es ist wild und lustvoll, auch obszön.

Nachdem das Fest eine ganze Zeit lang gedauert hat, ertönt eine Stimme.

Sie kommt aus einem Karton, in dessen Nähe ich stehe.

In dem Karton liegen ein Ohr und ein Mund aus grauem Kautschuk - in feines Seidenpapier eingewickelt. Ohr und Mund bewegen sich und rufen:

Bravo! Bravo! Es ist der Chef, der ruft

Damit soll die Veranstaltung wohl zuende gehen

Ich beginne, die umherliegenden Schuhe einzusammeln.

Es sind zartbunte, geschmückte, fast durchsichtige Plastiksandaletten

Die erste wäge ich einen Moment lang in der Hand und werfe sie dann in den hinteren

Teil des Raumes, der sehr dunkel ist. Dann werfe ich einige andere Sandaletten hinterher und rufe dabei: Bravo! Bravo! Die anderen tun es mir nach. 
Die Familie und ich leben auf einem hermetisch abgeschlossenen Gelände. Unsere Feinde können nicht herein, wir aber auch nicht hinaus.

Bis auf das eine Mal. Die Familie muß das Gelände verlassen.

Diese Situation nutzen die Feinde, um einzudringen.

Ich bin allein und ihnen ausgeliefert.

In ihren Augen habe ich einen Verrat begangen und soll deshalb getötet werden.

Mit den Beinen noch auf dem Boden liege ich schräge in der Luft.

Ein langgestreckter, strenger Neger steht vor mir mit erhobenen Armen.

In seinen Händen hält er das Guillotinemesser

Ich wehre mich nicht und schließe die Augen.

Alles um mich wird dunkel. Das Nichts. Der Tod.

Meine Familie ist wieder zurückgekommen. Sie findet mich.

Ich bin nicht tot, aber nackt und voller großer, sehr dunkler Brandnarben.

Ich bin gezeichnet.

Und ich bin zur Ruhe gekommen.

DIE MÜNZE

Fast nebenbei entwickelt sich ein Spiel.

Fine Geldmünze wird hin- und hergekickt.

Jedesmal rollt sie von alleine wieder zu mir zurück.

Zum Schluß, alle sind inzwischen sehr erstaunt und belustigt, verwandelt sich die Münze

in einen kleinen, blassgelben Schmetterling mit hellbraunen Punkten und flattert davon.
Die sehr alte Frau ist winzig, püppchengroß.

Sie steht am oberen Absatz der steilen Treppe und möchte hinuntersteigen

Ich beuge mich zu ihr und gebe ihr die Hand, um ihr zu helfen.

Im selben Moment schlägt sie mir ihre Krallen in meine Handfläche, sehr schmerzhaft.

Ich reiße meine Hand zurück, und die alte Zwergin springt behende die geschwungene

Treppe hinab. Halb springt sie, halb fliegt sie. Sie berührt nur teilweise die Treppe,

weil sie sich von Geländer zu Geländer abstößt

Während dieses artistischen Aktes verwandelt sie sich in einen leuchtend gelben Ball.

\section{ZWERG OHNE CHANCE}

Ich hocke am Boden.

Das kleine Kind steht neben mir. So sind wir gleich groß.

Von rechts kommen schnell nacheinander viele rotweiß gekleidete Männer. Schauspieler

Einer ist ein Liliputaner. Er bleibt dem Kind gegnüber stehen und sieht es an

Genauso klein wie das Kind, aber erwachsen.

Tief traurig sagt er: Für mich gibt es keine Chance mehr. Für dich schon.

\section{GAUNERKOMMISSAR}

Mehrere Personen. Ein Platz. Ein paarTische.

Von oben, die Straße herunter, rollt plötzlich ein Ball, bremst und bleibt unter einem der Tische liegen. Scheisse, der Kommissar! sagen die Leute neben mir.

Der Ball grinst und zwinkert uns zu. Es war nicht der Kommissar, es war der Gauner. Kurz darauf kommt noch ein solcher Ball.

Keiner ist mehr beunruhigt, aber - dieser Ball ist der Kommissar

Scharf beobachtend äugt er in die Runde. 
Der Fisch ist tot.

Man hat ihn mir geschenkt

Ich werde ihn essen

Er liegt in meinem Handteller, hat die Größe und Form der Hand

und ist etwas nach oben gewölbt.

Sorgsam schneide ich ein Kreuz hinein.
Viele tiefschwarze, große Tiere und ein Neger lagern friedlich auf einer weiten Fläche. Die Haut derTiere ist so glänzend, daß sie nackt wirken.

\section{SCHNAUZENSCHNULERHUND}

In einem Graben liegt ein blauer Kopf mit Locken.

Ich beuge mich zu dem Kopf herab: Er soll sich bewegen!

Ich puste und puste.

$\mathrm{Na}$ endlich!

Er bewegt sich nach vorne.

Und die vielen Bäume.

Sie gleiten schnell durch die Luft, genau wie ich.

\section{TANZ UND TOD}

In einem Keller halten sich viele Männer auf.

Die Atmosphäre ist verschwörerisch, obszön.Wir müssen für die Männer tanzen und dazu genauso absurde Kleider anziehen wie all die anderen Frauen hier.

Die Männer selbst sind als Schwule verkleidet.

Wenn ihnen eine der Tänzerinnen nach einiger Zeit zu langweilig geworden ist, wird sie tot oder auch lebendig an die Wand genagelt - wie das Fell eines erlegten Tieres. Keiner schreit.

Wer sterben muß, ist rot und steht am Rand des teichgroßen Bottichs. Die Flüssigkeit in dem Bottich ist weiß.

Die roten Toten müssen hinein und lösen sich sofort auf.

Eine große aufrechte blonde Frau verquirlt mit einem langen Ruder das Weiß und das Rot.

Spiralförmige, rosa Schlieren entstehen.

Lh weil, daß ich hier nicht lebend herauskomme und will meinen schnellen Tod provozieren.

Ich fasse einen Kleinen, rosa gekleideten Mann ins Auge: er erinnert mich an einen General. Schon vorher habe ich getanzt, nun aber reiße ich mir die Kleider, die Verkleidung, herunter, nehme mir den Mann und tanze einfach überdreht und wild mit ihm. Ich führe beim Tanzen

letzt müssten sie mich doch eigentlich töten!

Aber mein Verhalten ruft nurVerblüffung und eine Art Achtung hervor: 
Ich bin alleine unterwegs.

Das Meer ist klar und ruhig.

Ich schwimme, dann wate ich im flachen Wasser umher.

Menschen, die lange Algen und Tang hinter sich herziehen, kommen mir entgegen.

Unter meinen Füßen schlängeln sich auch meterlange Algen.

Ich tauche, um sie mir besser ansehen zu können.

Es sind Seelen.

FLIEGENDES ROTES HERZ

Der Kommissar ist zu Besuch bei seiner alten Mutter

Es ist Winter.

Beide schaufeln Schnee.

Er ist glücklich - die Mutter, das Haus, der verschneite Garten.

Plötzlich läuft die alte Mutter sehr schnell ein Stück geradeaus, dann links um die Ecke

und verschwindet hinter dem Haus.

Sie ruft ihrem Sohn zu:

Ich muß aufpassen, daß, wenn ich sterbe, mein Herz auch mitkommt.

In dem Moment fliegt ihr Herz, leuchtend rot, auf dem Weg hinter ihr her.
Nur das Kind und ich sind noch da.

Hinter uns die Bäume.

Aus dem Wald wird ein Zischen und Knistern hörbar. Es wird lauter und wir erschrecken Zwischen den hohen, geraden Baumstämmen bewegen sich lange, silberne Blitze,

genauso hoch wie die Bäume.

Sie bewegen sich hin und her und kommen auf uns zu.

Aus den Blitzen werden hellgraue, weißliche Schleier, auch sie so hoch wie die Bäume.

Ich begreife, daß wir höheren Mächten begegnen.

Die Schleier verwandeln sich in helle Tiere, die groß und ruhig vor einem See lagern. Vorsichtig und respektvoll berühre ich sie.

\section{SÖHNE}

Drei Männer. Ein Vater und zwei Söhne.

Der Vater schlägt den ersten Sohn.

Der zweite Sohn greift ein, um den ersten Sohn zu schützen

und schlägt dann selber den Vater.

Daraufhin greift der erste Sohn den zweiten Sohn an

Der erste Sohn hat in seiner Verzweiflung viele lange Nägel in die Hand genommen und schlägt damit auf den zweiten Sohn ein

Dabei werden die Nägel in das eigene Fleisch seines Handinneren zurückgeschlagen. Das wiederum tut dem zweiten Sohn leid.

Krieg. Flucht.

Jeder muß einen Mantel mitnehmen, in dem er notfalls aussehen kann wie ein Schrank. 
Ich fahre mit dem Fahrrad durch eine hügelige, verschneite Landschaft.

Es geht bergauf. Der Schnee ist verharrscht, der Weg wird uneben und rechts

fällt es steil ab - es wird für mich zum Fahren zu gefährlich. Ich gehe zu Fuß weiter

halte mich nach links und gelange in eine schmale dunkle graue Schlucht.

In einer Felsen- oder Erdnische, etwas erhöht über mir, hocken und liegen

schmutzigweiße Vögel, einige von ihnen leben, die meisten sind tot.

Möwen oder Möwentauben.

Die lebenden Vögel hacken mit ihren Schnäbeln aus den toten und aus den noch

halb lebenden Vögeln Fleischstücke heraus.

Kein Blut. Alles in diesem cremefarbigen, schmutzigen Weiß.

Mich schaudert und ich gehe weiter.

Am Ende der kleinen Schlucht ist eine weitere Nische, größer und tiefer

Halb schräge, wie nach oben gekippt, liegen in ihr blasse, silbrig grauweiße Tiere.

Es sind Säugetiere. Schmal. Gestreckt.

Auf dem Rücken liegende Kühe und ein Tier, das aus einer Vielzahl von Tierfragmenten

besteht - gestaffelte Schweineteile.

Warum muß ich das alleine sehen?

Ich kehre um und weine.

\section{I3 DREIECKE}

Der tote Mann tanzt auf leichte, spielerische Weise über die glatte, große Wasserfläche. Er hat keine menschliche Gestalt. Er besteht aus weißen und blauen Dreiecken.

Separate Formen, die sich bewegen.
Alle in der Anstalt sind wahnsinnig.

Ich fliehe und bin endlich draußen.

Viele Personen, die Kinderwagen schieben, kommen mir entgegen

In jedem Wagen sitzt ein kindsgroßer Erwachsener - die Köpfe auf den dünnen Hälsen

sind viel zu klein, deformiert, abstoßend häßlich,

Merkt Ihr denn nichts?

In den Kinderwagen werden wieder neue Wahnsinnige in die Anstalt transportiert.

Es werden immer mehr, und es hört nie auf.

GEFÜHLE SCHLEUDERN

Man schleudert Gefühle und Gebärden auf entsprechende Objekte und Abbildungen. Teilweise mit geschlossenen Augen, um es selber aushalten zu können.

\section{ZITRONENSOCKEN}

Der orientalische Händler springt auf sein Boot und verdeckt schnell mit seinem dicken Hintern die Schmuggelware.

Eine alte Frau bietet ihm etwas an. Päckchen.

Darin sind winzig kleine, einlegbare Socken mit Zitronengeruch. Reisesocken. 


\section{Auf einem Schiff.}

Ein junges Liebespaar königlicher Herkunft ist zum Tode verurteilt worden.

Bis Sonnenuntergang muß das Urteil vollstreckt sein.

Vor der Hinrichtung dürfen sie noch eine Henkersmahlzeit zu sich nehmen.

Ihre Gesichter sind überdimensional groß, wie auf einer Leinwand, die unsichtbar ist, zu sehen

Eine männliche Stimme aus meiner Richtung macht Vorschläge für das letzte Menü.

Die junge Frau ist mit den Vorschlägen nicht einverstanden - immer ist ihr das Essen nicht

recht. Bei jedem Vorschlag überlegt sie etwas, verzieht dann auf komödiantische Weise

angeekelt das Gesicht, schüttelt den Kopf und dreht sich dann zu ihrem Geliebten

Auch er verzieht das Gesicht und beide schütteln energisch den Kopf.

Also ein neuerVorschlag. Und noch einer. Und noch einer.

Währenddessen gleitet das Schiff aus der Flußmündung hinaus auf das offenen Meer.

Die Abendsonne ist gerade versunken.

Nach einer langen Radtour erreichen der ältere Mann und ich eine kleine Ortschaft Über einen Fluss, rechts neben uns, führt eine zierliche Eisenbrücke auf die andere Seite.

Wir wollen zum anderen Ufer und schlängeln uns dazu zwischen vielen Tischen und Stühlen eines Cafes durch, auf denen Menschen sitzen.

Wir bewegen uns très élégant und ich rufe des öfteren aus: Oh, Honey! Oh, Chérie! Oh, Darling!

Beiläufig streichle ich einem alten Herrn über die Silbersträhnen, die seine Glatze halb bedecken.

Von der Brücke aus sehen wir auf ein Miniaturdorf, das mit einer gelblichen Schicht überzogen ist - wie eine Pizza.

ch wende mich an meine Begleitung und rufe entzückt aus:

Oh, Honey! Paris! Look! Paris.
Ein Mann setzt kleine, silberne Schalen mit lebenden Schnecken und Spinnen in eine Art Graben und sagt: Da können sie sich jetzt entwickeln und miteinander kämpfen.

Und später können wir zuschauen, was daraus wird.

\section{WEISS UND PLÖTZLICH}

Ein weißes Essen.

Ein weißes Pferd und eine weiße Kutsche.

Plötzlich bewegen sie sich vorwärts.

Eine weite, weißlich helle Ebene - an einer Seite eine Erhöhung, auf der ein weißer Mann steht. Durch die Ebene läuft ein weißerTiger.

Mit einem lauten Schrei springt der Mann auf den Tiger, reitet ein kleines Stück,

und springt dann ab.

DerTiger flüchtet erschreckt. 
Meine Tochter und ich wandern über eine begrünte, hügelige Hochebene.

Wir sind auf dem Wege nach Hause.

Unter uns liegt das Meer.

Etwas veranlaßt mich, nach oben in den Himmel zu sehen. Ich erschrecke.

Der Himmel leuchtet unwirklich blaß, wie aquarelliert, und über ihn rollt eine helle,

grünbläuliche Sonnenkugel schnell von rechts nach links.

Meine Tochter ist überzeugt, das sei wieder ein dummer Werbegag.

Das glaube ich nicht. Ich habe Angst.

Die Sonne rollt vom Himmel herab ins Meer

Inzwischen sind viele Menschen auf dem Hügel und am Strand. Sie drängen panisch zum Aufbruch. Wir starren auf die Stelle im Meer, wo die Kugel eingetaucht ist. Es beginnt zu blubbern und kreisförmige Ringe breiten sich auf dem schnell ansteigenden Wasser aus. Die Flutwelle wird uns bald erreichen

Wir gehen zum Steilufer und bleiben dann, die Arme gegenseitig um unsere Schultern gelegt, ruhig stehen, betrachten das Meer und überlegen, ob wir ins Wasser springen oder einfach abwarten sollen.

Wir werden nie mehr nach Hause kommen, nie mehr unsere Mutter wiedersehen.

Aber es könnte sein, daß wir in dieser bedrohlichen Situation schon life im Fernsehen sind, und so verabschieden wir uns von der Mutter.

Vielleicht sieht sie uns ja.

Wir stehen umarmt und sagen: Adieu, liebste Mutter.
In einem Restaurant wird Kaffee getrunken und Kuchen gegessen

Auf dem Tisch vor mir sind Tortenflecken.

Ich klappe die Tischszenerie einfach nach vorne - sie steht senkrecht wie auf einer Staffelei

Ich nehme ein Radiergummi und radiere die Flecken weg.

\section{LUFTKINDER}

Es ist, als würde alles ein wenig schweben. Ein Luftraum.

Ich stehe nicht, ich liege nicht, ich bin einfach in diesem Raum

- eine Anmutung von Rüschen und heller, pastellfarbiger Bettwäsche umgibt mich.

Um mich Leere, Helligkeit.

Tief unter mir in der Luft schweben, schwimmen ovale, kleine Behältnisse, den Körben von Babywiegen ähnlich. Auch sie sind pastellfarben, mit Rüschen eingefaßt - wie Blüten. In diesen Körbchen liegen Säuglinge.

Wie wundervoll, denke ich, als ich auf sie herunterschaue - als Säugling so frei

in diesem herrlichen Luftraum zu schweben, in dieser sanften Helligkeit.

\section{HAGELCLOWN}

Die aus Liebe untröstliche, verzweifelte junge Frau nimmt einen Anlauf, springt senkrecht sehr, sehr hoch und steht dann weit oben in der Luft. Sie brennt und leuchtet, blutrot, auch ihr Kleid.

Brennend rot, wie eine schmale, gerade Flamme, sinkt sie langsam in die Tiefe. In den Orchestergraben vor der Bühne.

Entsetzt und fasziniert schaut das Publikum zu.

Ich bin in einem Haus am Meer.

Das Wetter schlägt plötzlich um. Starker, weißer Hagel prasselt hernieder, peitscht waagerecht. Schnell, die Tür schließen! Das Zimmer liegt schon voller Hagelkörner.

Dann blicke ich hinaus.

Über einen leeren Platz fährt ein Mann auf einem Fahrrad.

Er hat einen großen Hut auf und eine lange Pappnase.

An dieser Pappnase hängt ein Bügel mit einem gestreiften Oberhemd. 
Eine junge Frau ist von einer Reise zurückgekommen.

Nun erwartet sie, von ihrem Mann empfangen und begrüßt zu werden.

Das löst Bestürzung aus bei den Menschen um sie herum, denn ihr Mann ist nicht mehr da.

Um das vorerst vor ihr zu verbergen, dreht ein Mann der Frau seine Vorderseite zu.

Er trägt ein T-Shirt.

Auf der für die Frau nicht sichtbaren Rückseite des T-Shirts steht gedruckt:

Michael $X$

Verschwunden in den Wäldern des Alltags

HALBER VATER

Die Tante, die Cousinen und der Vater stehen am Bahnsteig direkt vor derTür.

Die Frauen sind schwarz gekleidet.

Alle kommen in den Zug herein zu mir.

Die Begrüßung ist sehr zurückhaltend und ernst. Ich wundere mich und frage, was passiert sei

Dann sehe ich es.

DerVater ist auf die Hälfte seiner Größe geschrumpft zu einem dünnen, alten,

lächerlichen Kind.

Ich frage, was ist denn mit dir passiert?

Hilflos schweigt er.
Zuerst hören wir nur das hohe, kreischend laute Zwitschern.

In dem sehr niedrigen, breit ausladenden Baum bewegen sich tausende von winzigen Vögeln.

Das kleine Kind und ich müssen da hindurch.

Wir atmen ganz flach und tasten uns unter den tief hängenden Ästen

mit fast geschlossenen Augen vorwärts.

Vielleicht bemerken sie uns nicht.

Wir sind ihnen egal. Sie flattern nur ein bißchen zur Seite.
Karneval.

Das kleine Mädchen hat Angst.

Die Aufpasser sagen, man müßte den Kindern erklären, daß das Unheimliche nicht wirklich unheimlich sei.

Kinder, die das nicht begriffen, müßten vom Umzug entfernt werden.

Das Unheimliche ist nicht wirklich unheimlich?

Wenn etwas unheimlich ist, ist es unheimlich.
Aus der braunen Dielung des Holzbodens leuchtet ein Auge. Blau und groß. Es blickt mich an.

Ich kann durch die Holzdielen hindurchsehen, als seien sie aus Glas. Unter mir liegen hunderte von solchen blauen Augen. Nur kleiner. 
Die steinere Wendeltreppe führt tief unter die Erde in einen großen Keller. Ich betrete den letzten Raum.

Künstler spielen ein Spiel.

Ein älterer Mann fragt: Spielst du mit? Das Spiel heißt: Zehn Wünsche.

Ich soll meine zehn liebsten Wünsche nennen, die dann in Erfüllung gingen.

Begeistert unterbreche ich ihn:

Ich habe nur einen Wunsch!

Einfach nur glücklich sein.

Einfach glücklich sein

Einfach sein.

Im Restaurant.

An der linken Seite sind Tische aufgestellt. Eine Tischreihe; Leute unterhalten sich.

Sie sitzen unter feinsten, miteinander verbundenen Netzen.

Es sind Gesprächsdämpfungsnetze.

Sie schlucken den Schall, und alle Gespräche der Menschen klingen wie leises Gemurmel.

Wie eingenebelt.

Sehr sanft
Wie spannend - sich immer wieder in dem endlos großen Gebäude zu verlaufen. Aber jetzt habe ich Appetit auf Kuchen.

Wo ist der Ausgang, die Straße?

Ich sehe von oben in eine riesige Halle.

Sie ist voll überdimensionaler, hellblauer, zart gemusterter Säcke, gefüllt mit Bonbons. Neben jedem Sack ist ein Verkäufer postiert.

Würde ich auch Bonbons nehmen statt Kuchen?

Auf einmal aber scheint Geschäftsschluß zu sein: alle Säcke und alle Verkäufer setzen sich plötzlich gleichzeitig in Bewegung und rasen in meine Richtung.

\section{ROSA WaTte}

Was ist das für ein Telefon!

Erst lassen die Nummern sich nicht drücken und als das endlich funktioniert,

ist die gesamte Tastatur mit rosa Watte überklebt.
Es ist Nacht Unter dem Fenster des alten Hauses fließt träge der alte, flache Fluß vorbei. Das Wasser ist glatt und schwarz.

Im Flußbett stehen große Bäume, zwischen denen sich viele junge Frauen in dunkler Kleidung, die Unterkörper im Wasser, bewegen.

Alle Frauen drehen sich langsam um sich selbst. Sie tanzen.

Die Arme haben sie weit ausgebreitet und lassen sie wie Schleier um sich kreisen Es ist sehr still. 
In der Küche. Die erwachsenen Kinder und ich.

Meine Tochter steht vor dem Radio, mein Sohn sitzt auf einem der Holzstühle am Tisch.

Ich stehe am Tisch. Wir unterhalten uns.

Etwas seitlich, vor dem Fenster, steht noch ein leerer Stuhl.

Auf einmal sehe ich auf diesem Stuhl meinen Sohn als Kind.

Es dauert etwas, bis mir bewußt wird, daß mein Sohn zweimal im Raum ist.

Aufgeregt rufe ich ihm zu: Da bist du, du als Kind

Gleichzeitig habe ich Zweifel, daß die beiden Kinder den Kleinen überhaupt sehen können.

Ich starre auf den Stuhl am Fenster. Der Junge wird immer kleiner und auch immer

undeutlicher - bis er ungefähr im Kleinkindalter sich wieder auflöst und nicht mehr da ist.

Später liegen auf dem Küchentisch zwei Glasplatten, die mit abstrahierten Gesichtern

\section{linear bemalt sind.}

Sehr langsam schiebe ich sie übereinander - es ergibt dann ein Gesicht, aber mit einer Verschiebung, einer Art Unschärfe.

Zuhause.

Zwischen uns tritt eine zunehmende Distanz ein.

Ich fühle mich ganz fremd bei ihm und will ausziehen.

Verbissen und verzweifelt reiße ich die Decken vom Bett und nehme mir die schönen,

in Zeitungspapier eingewickelten Keramiken aus dem Bord heraus.

Aber dann weiß ich nicht, wo ich mit all den Sachen hin soll, wenn ich weggehe.

Er sieht meinem Treiben mit kalter Gleichoültigkeit zu, was meine Traurigkeit und

meinen Trotz noch verstärkt.

Ich gehe auf ihn zu und will etwas Erklärendes sagen.

Mir versagt vollständig die Sprache.

Mit aufgerissenem Mund scheine ich flach auf ihn zuzukippen, eigentlich schwebe ich eher und bin nur noch etwas wie eine helle Fläche.

Alles um mich verschwimmt, es ist totenstill - ich bin wie in einem Aquarium.

Absolut in dieser Stille gefangen, völlig kraftlos, aufgelöst und dabei mein eigener Zuschauer

Eine wache Ohnmacht.

Ein Land wie ein Kaufhaus, mit verschiedenen Ebenen und Abteilungen

Freischwebend wie eine riesige eckige Raumkapsel.

Ein Imperium in dem beherrscht und manipuliert wird.

Nichts stimmt wirklich: Aussehen und Habitus von Mensch, Pflanze, Tier und Gegenstand. Eine Freundin und ich erkennen das - wir verkleiden uns, um unentdeckt entweichen können. Zuerst sind wir zusammen, dann getrennt.

Ich treffe auf einen Mann. Wir gefallen uns sehr und suchen auch gemeinsam nach einer Fluchtmöglichkeit.

Unauffällig versuchen wir, zwischen den vielen Menschen und Dingen, uns aus dieser Gesellschaft, diesem Land zu entfernen - indem wir scheinbar das Spiel mitspielen Der Mann und ich befinden uns nun in einem zum Imperium dazugehörigen Außengelände. Die Gefahr, daß wir erkannt werden, ist sehr groß - auch Pflanzen und Tiere könnten uns erkennen und verraten.

Das Gelände ist flach und wie ein Stadion von einem sehr hohen Zaun eingefaßt. Vor uns ragt er senkrecht wie eine Wand empor, Maschendraht und oben Stacheldraht An einer Stelle ist er teilweise mit einem großen, grünen Teppich bedeckt.

$\mathrm{Zu}$ der Stelle laufen wir und klettern hoch, denn unten kommen schon uns verfolgende

Wesen. Ich vertraue darauf, mich nicht zu verletzten und greife unverzagt über den Zaun. Wir entkommen.

Sehr hoch sind wir nun. Hinter dem Zaun drängen sich dicht dunkelgrüne Baumwipfel aneinander. Halb schwingen wir uns, halb fliegen wir durch diese Wipfel und dann an den Stämmen entlang herunter.

Der Mann hat nun eine Tierfarbe - leuchtend rötlichbraun wie ein Pferd.

Es ist immer noch verzaubertes Land, eine Art Park.

Wir sehen einen Menschen, einen Jungen. Er steht halb nackt über einem Spiegel und pinkelt. Er darf aber nie zuende pinkeln, sondern der Spiegel wird immer jeweils weggezogen, wenn er noch nicht fertig ist und ein neuer Spiege wird untergelegt den er erst wieder bepinkeln darf, wenn er ganz mit Urin angefüllt ist.

Wir gehen weiter bis an den Rand des Parks.

Dahinter ist die Welt, die Realität.

Aber wir wissen:

Diese Realität sieht zwar anders aus als das verzauberte Land, aber das ist eine Täuschung. Es ist genauso ein Zauberland, nur spiegelverkehrt. 
Ich bin mit einer Freundin unterwegs.

Schon zum zweiten Mal verfolgt uns ein Tier, ein schwarzer Stier.Wir rennen.

Der Stier kommt schnell näher, auf mich zu. Ich versuche, auf eine erhöhte Sandfläche

zu kommen - sie ist quadratisch und von niedrigen Steinen und sehr kleinen Grasbüscheln

eingefaßt, an denen man sich schlecht festhalten kann.

Da ist der Stier! Gerade noch kann ich mich auf die Fläche rollen.

Aber das erboste Tier greift mich an

Ich fasse ein Horn, kann ihn aber so nicht zurückhalten

Plötzlich sehe ich, daß auf dem hellen Sandboden viele große Gabeln liegen.

Der Stier hat sich nach oben gereckt. Seine über mir hochgestreckte Brust sieht nun aus

wie die weiche Unterseite von einer riesigen Schildkröte.

Ich ergreife eine Gabel und steche sie in die Brust. Doch das Tier greift weiter an.

Wieder steche ich eine Gabel hinein und noch einmal. Da sinkt es um.

Als ich mich zurückwende, lehnt hinter mir an einem hohen Zaun eine junge Frau

in einem hellen Mantel. Sie war der Stier. Sie hat lange, schwarze Haare und sehr intensive,

schwarze Augen.

Ich weine sehr und stammle: Ich wollte dich nicht töten, aber ich mußte es tun.

Eher spöttisch und verächtlich winkt sie ab:Was soll das denn jetzt?

Gedemütigt, verwirrt und traurig gehe ich.

\section{A LEINE MIT DEM SPIEGELBILD}

Ein großer Reisebus. Von der Seite zu sehen

Er steht und ist leer, bis auf eine Figur, die in der Mitte sitzt.

Es ist meine Mutter.

Sehr jung, sehr schön, mit langen, glatt und dunkel über den Rücken fallenden Haaren.

Sie sitzt allein dort. Ernst und traurig sieht sie in einen Spiegel. Regungslos.
Der alte Mann fällt, rollt halb aus dem Bett.

Mit seinem Gesicht auf den Teppich.

Neben eine Puppe.

Kann man helfen? Nein.

Alles geht rückwärts. Dem Kinde zu, dem Tode.

\section{SCHLANGENSCHLÄGE}

Ich scheine ein Kunstprojekt machen zu wollen und brauche dazu präparierte Schlangen. Es ist abend, wohl eher schon Nacht

Im Zimmer ist es fast dunkel, nur in der Küche brennt etwas Licht.

Auf meinem Arbeitstisch stehen drei Töpfe, in denen Wasser kocht.

In dem linken schwimmt eine schon fast tote Schlange.

Aus einem Behältnis an meiner rechten Körperhältte nehme ich vorsichtig zwei Schlangen und werfe sie in den mittleren Topf.

Eine dritte, die ich auch herausholen will, wehrt sich und beißt mich etwas, was mich mit leichter Sorge erfüllt, obwohl ich weiß, daß die Schlangen ungiftig sind.

Fast panisch werfe ich sie in das kochende Wasser des dritten Topfes.

Es ist schrecklich, die Schlangen in dem kochenden Wasser langsam sterben zu sehen. Ich verlasse das Zimmer:

Aber ich höre, wie die Schlange, die ich zuletzt in den Topf geworfen habe, nicht sterben will, um ihr Leben kämpft.

Auch die Kinder hören es

Immer heftiger schlägt sie in ihrem Kampf von innen gegen die Topfwand - rythmisch sehr laut, sehr schnell.

Entsetzlich.

Die Schlange hat sich aus dem Topf geschleudert und kriecht halbtot auf dem Boden.

Sie tut mir leid.

Ich fürchte ihre Rache. Wo wird sie sich verstecken? 
Ein Mann hält einen großen Affen fest - vor seiner Brust.

Dieser Affe hält vor seinem Oberkörper einen Mann mit seinen langen Armen

umschlungen und dieser Mann trägt vor sich eine große Trommel, die er schlägt.

Eine zimmergroße Wunde mit einem riesigen rosa Pflaster

das aus dickem gepolsterten Plüsch besteht, bedecken 
TRAUMBILDER 


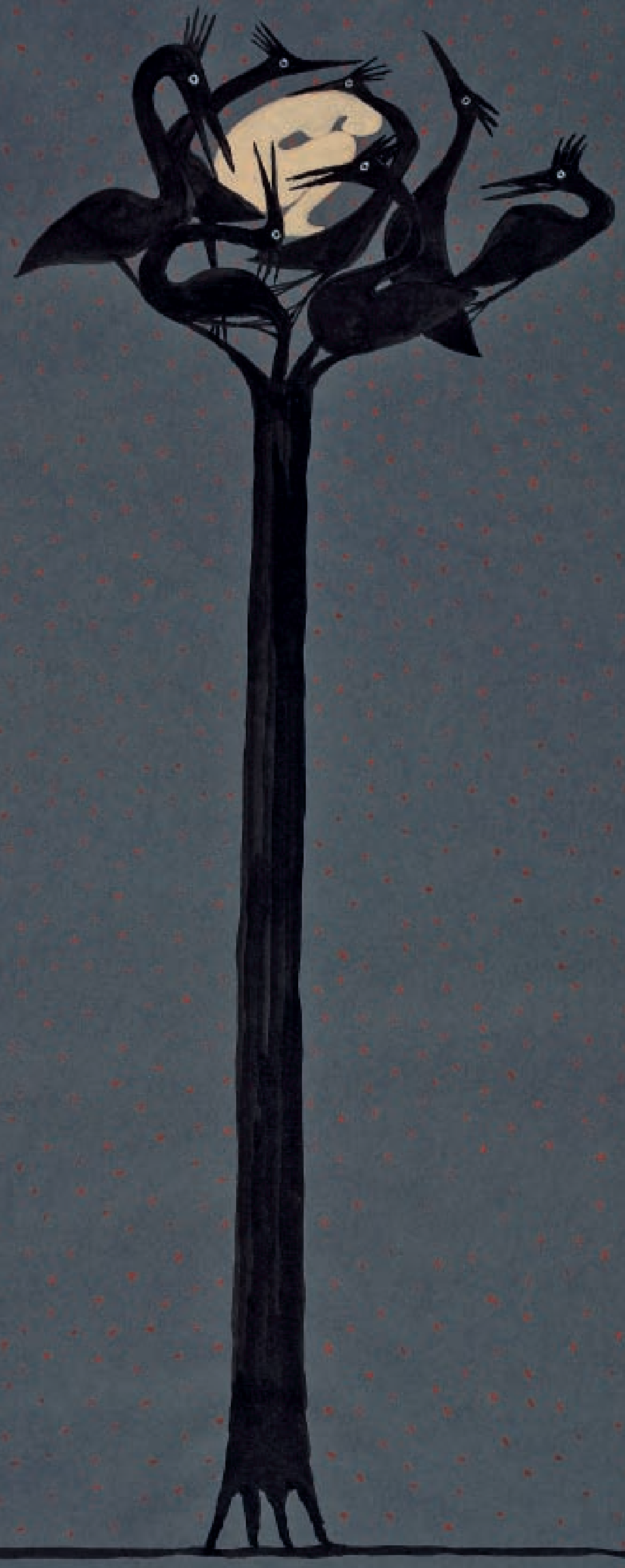




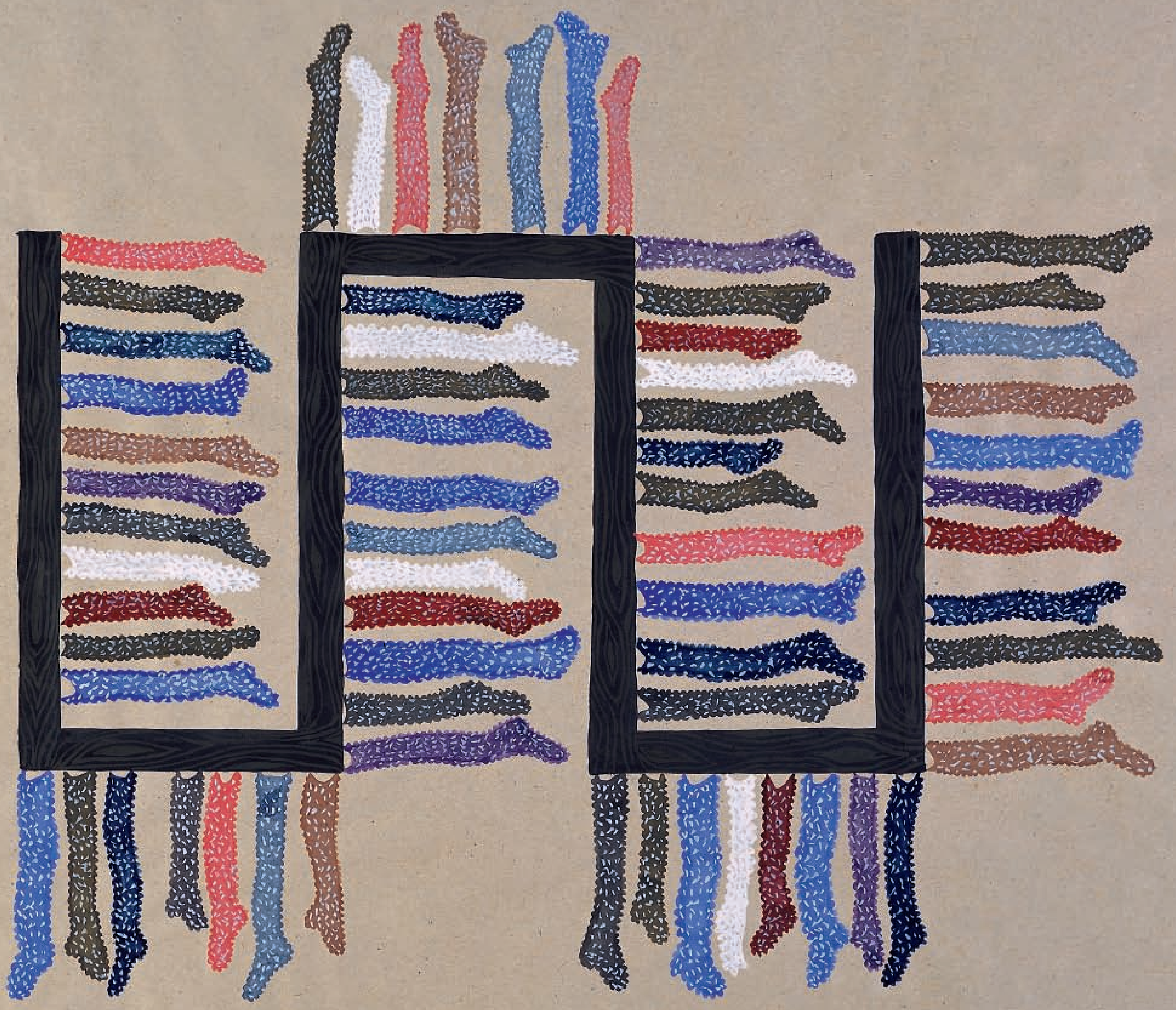




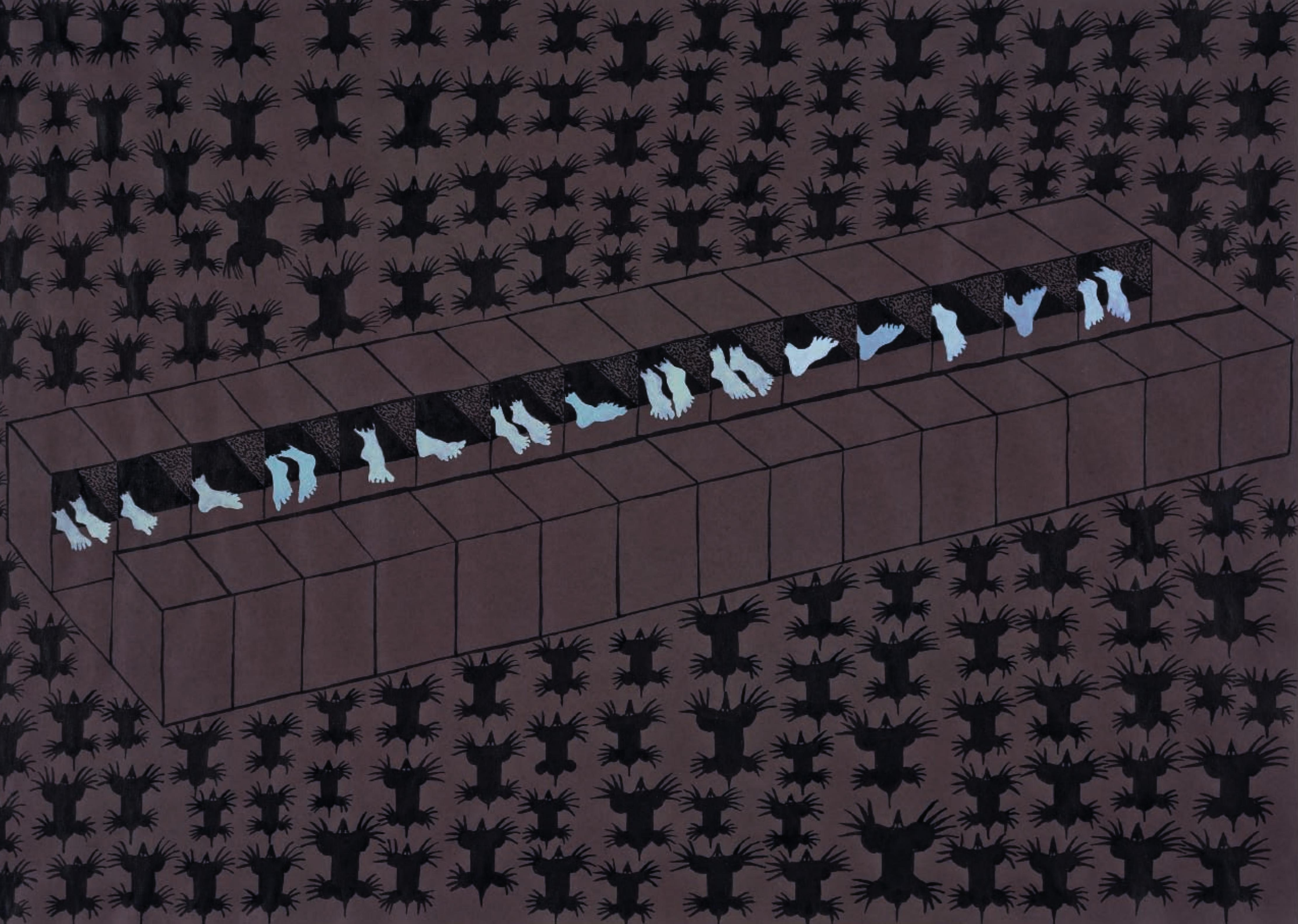




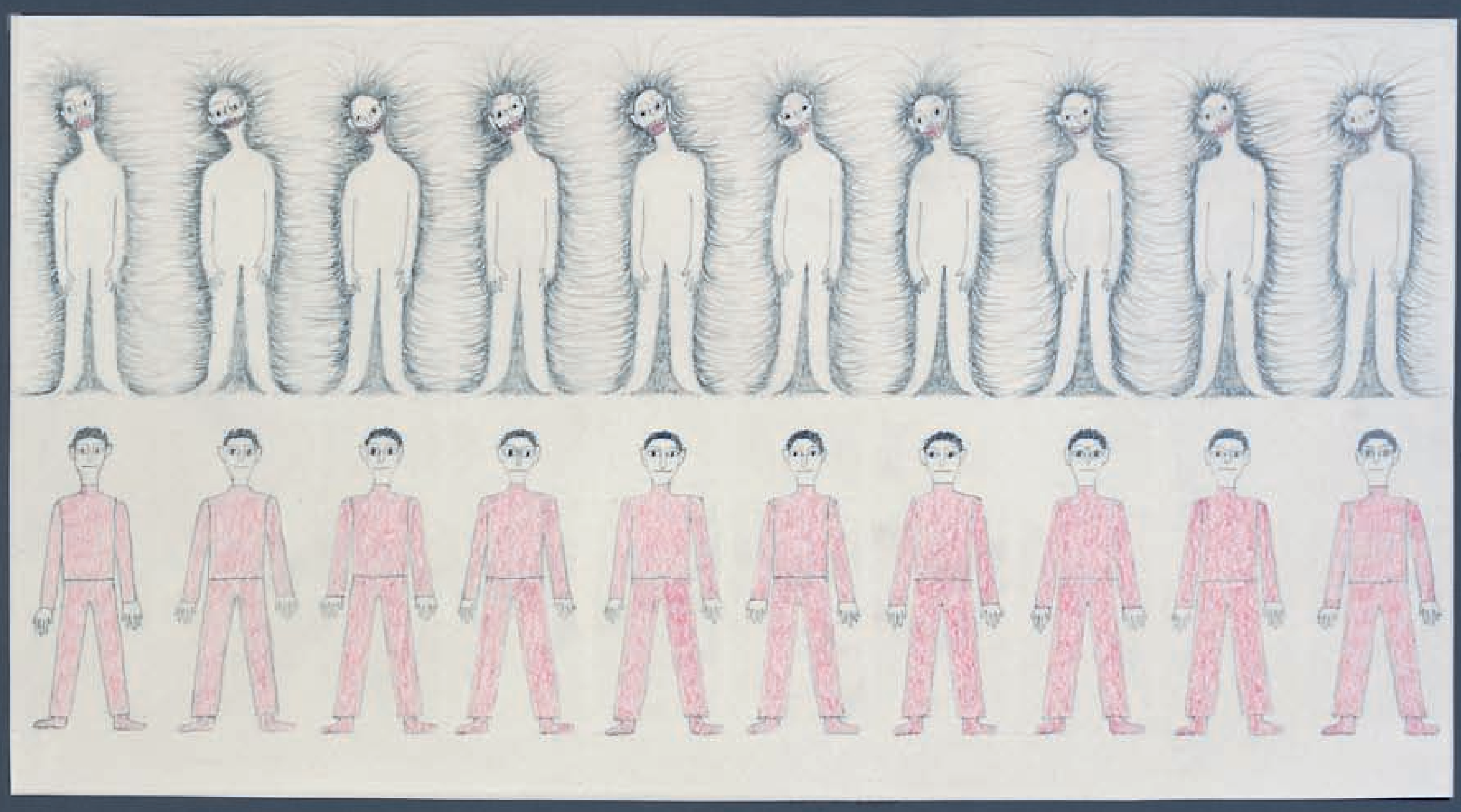




$$
\begin{aligned}
& 5353,5 \\
& 53515 \\
& 5 \$ 53
\end{aligned}
$$




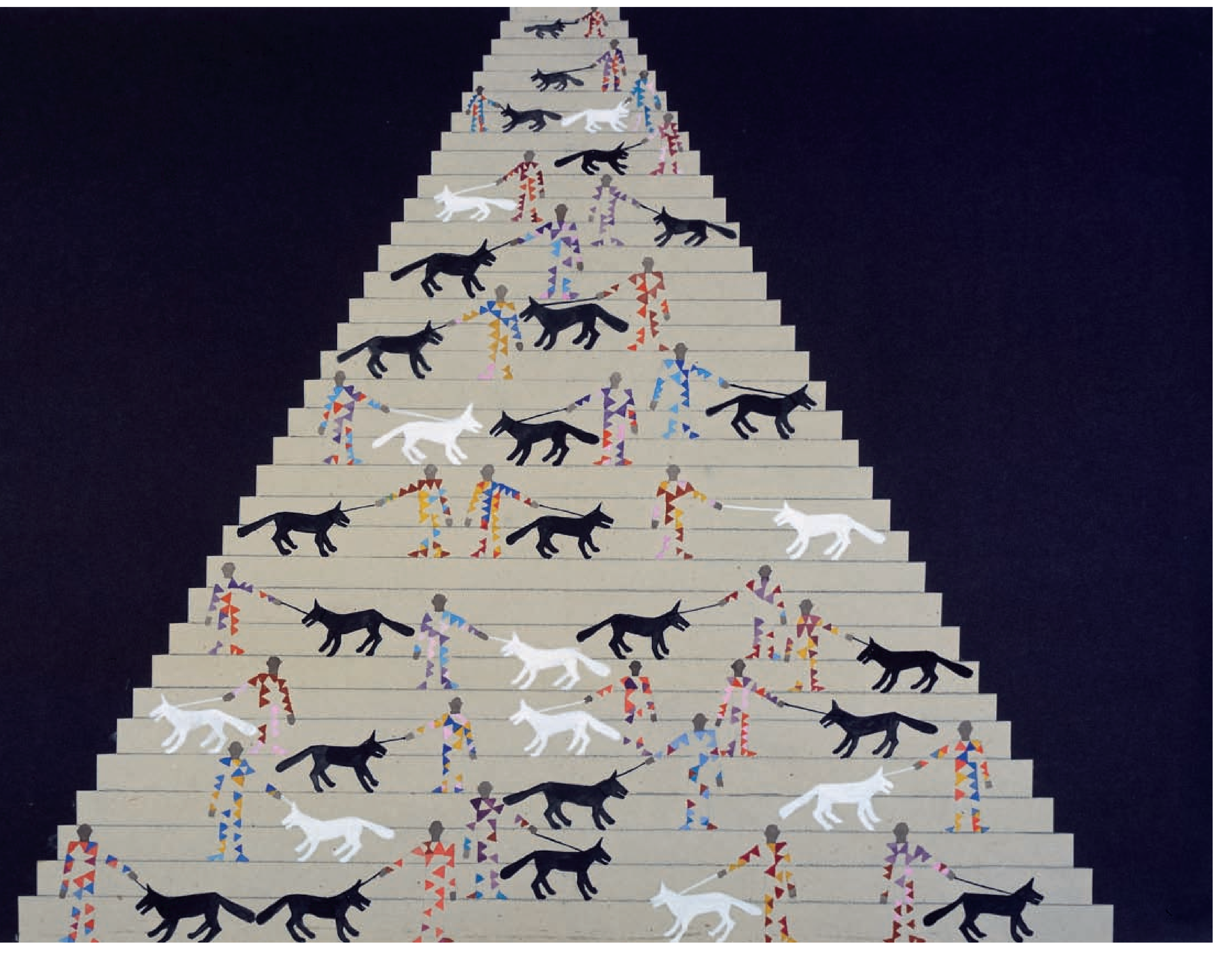




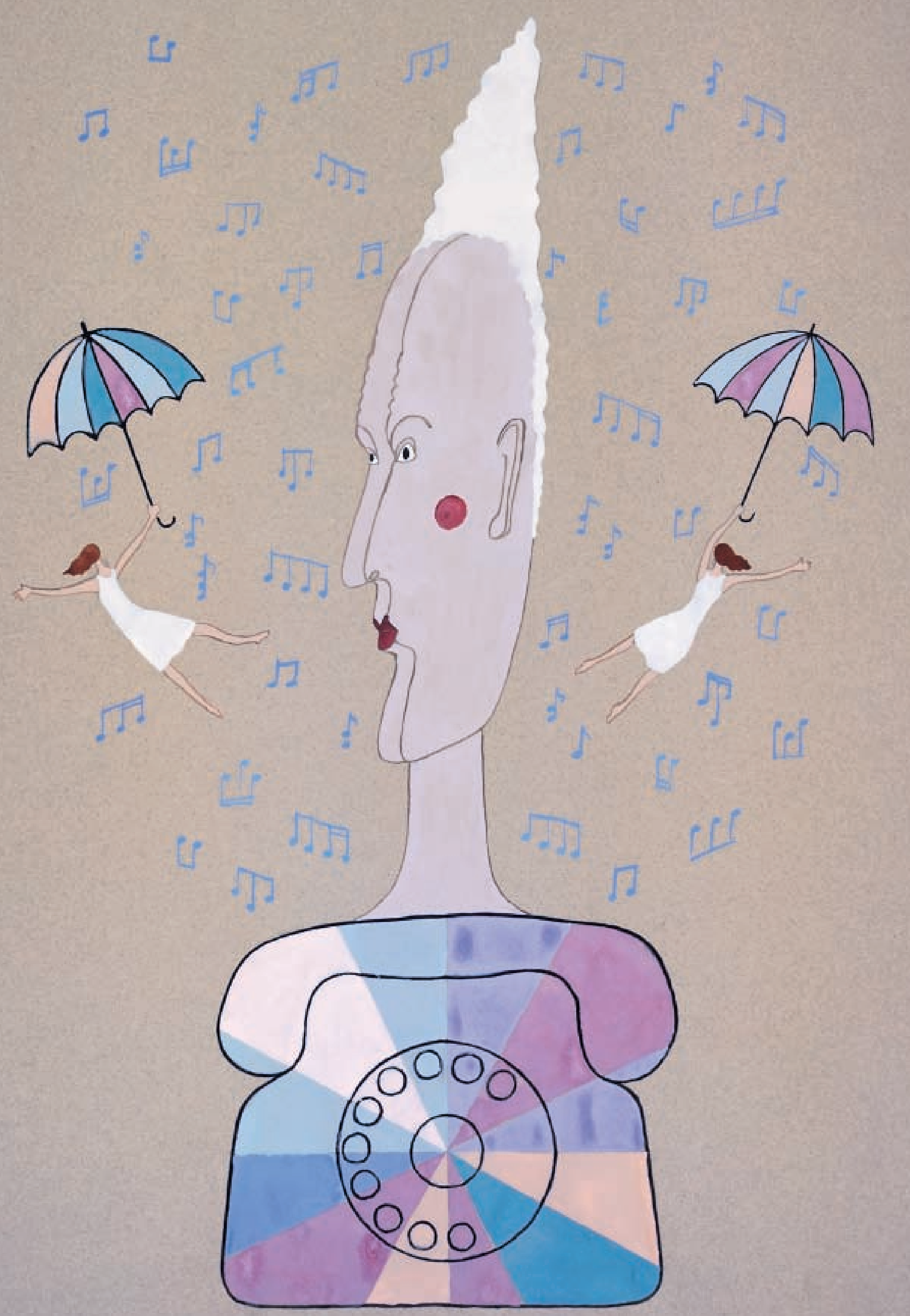




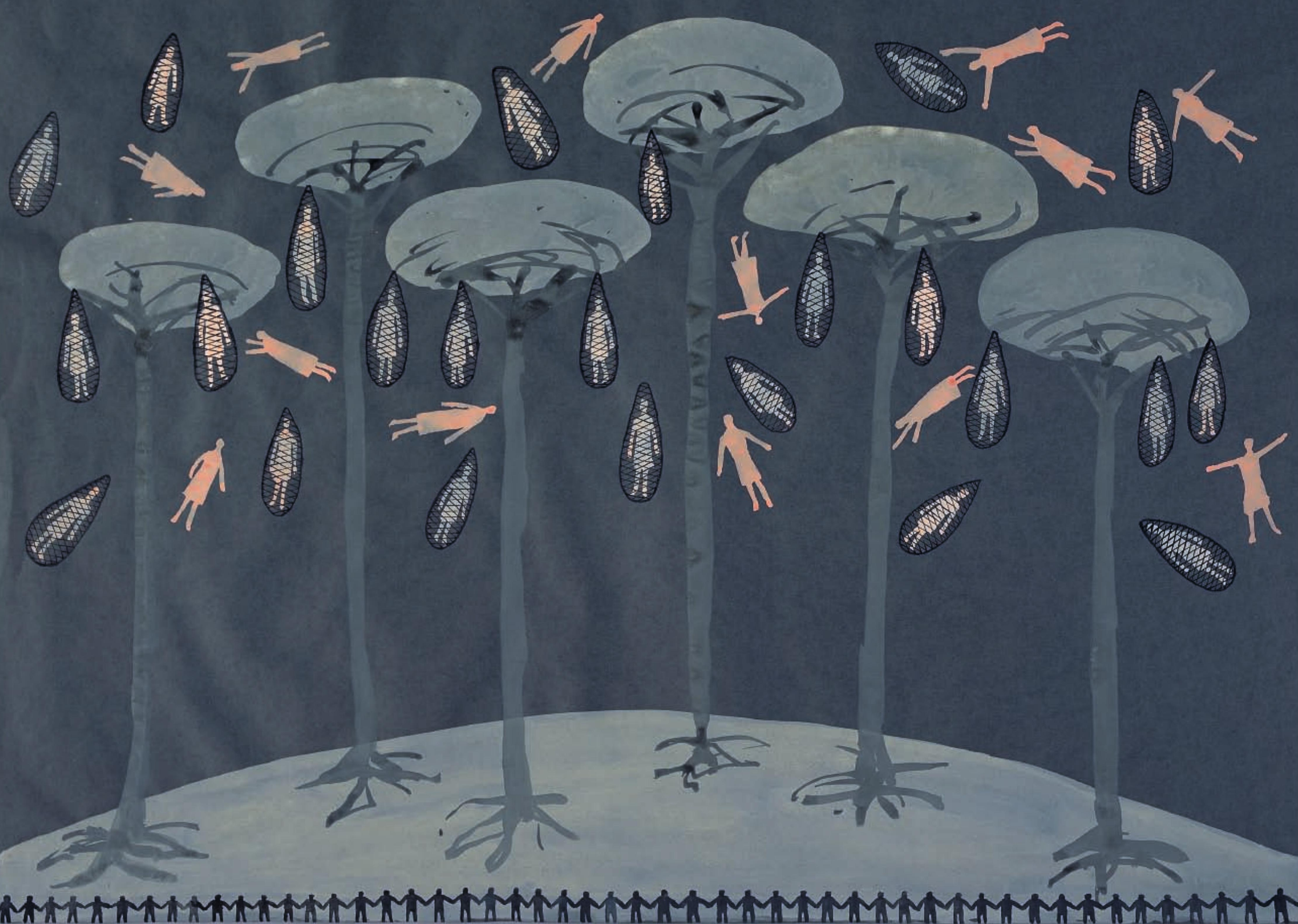




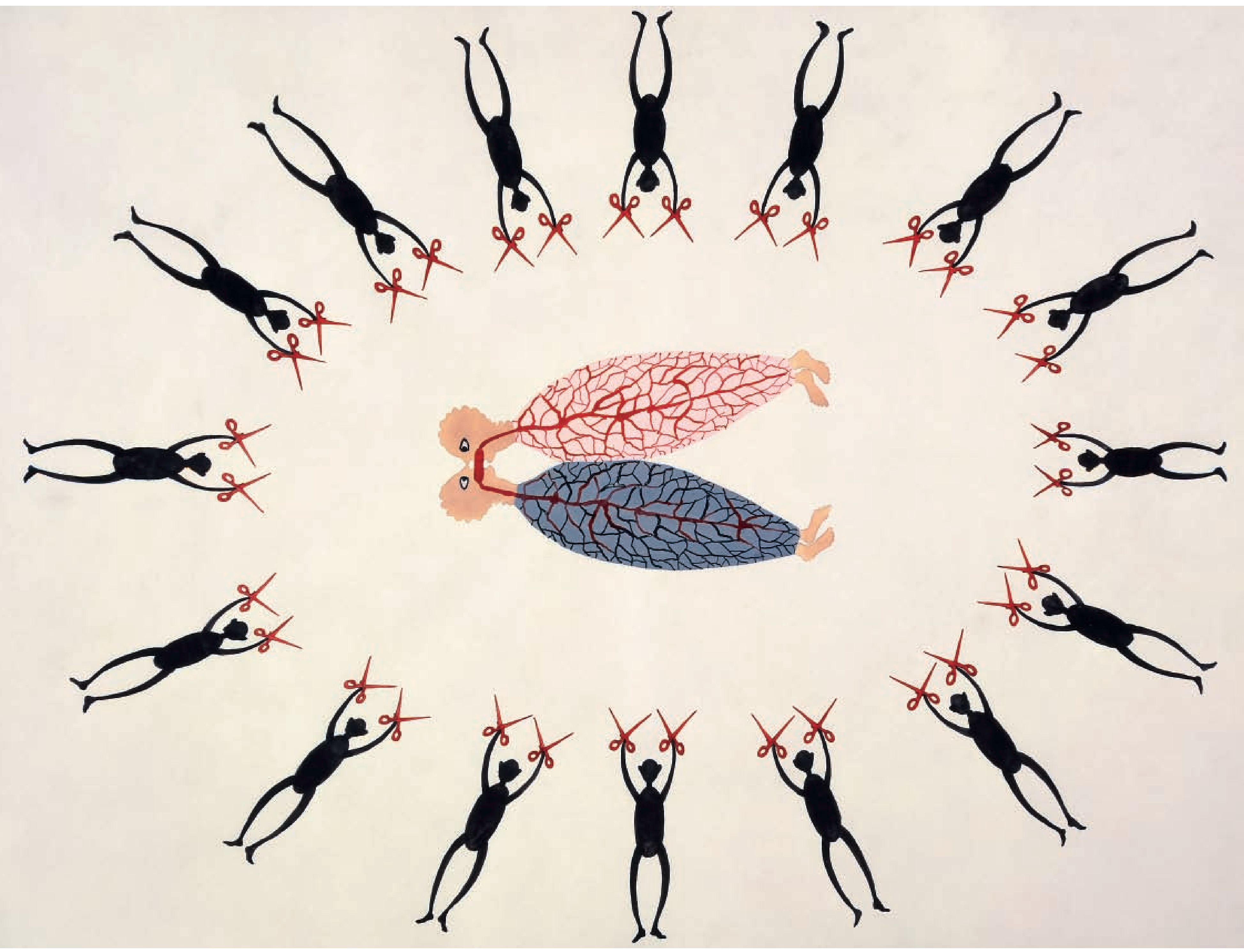




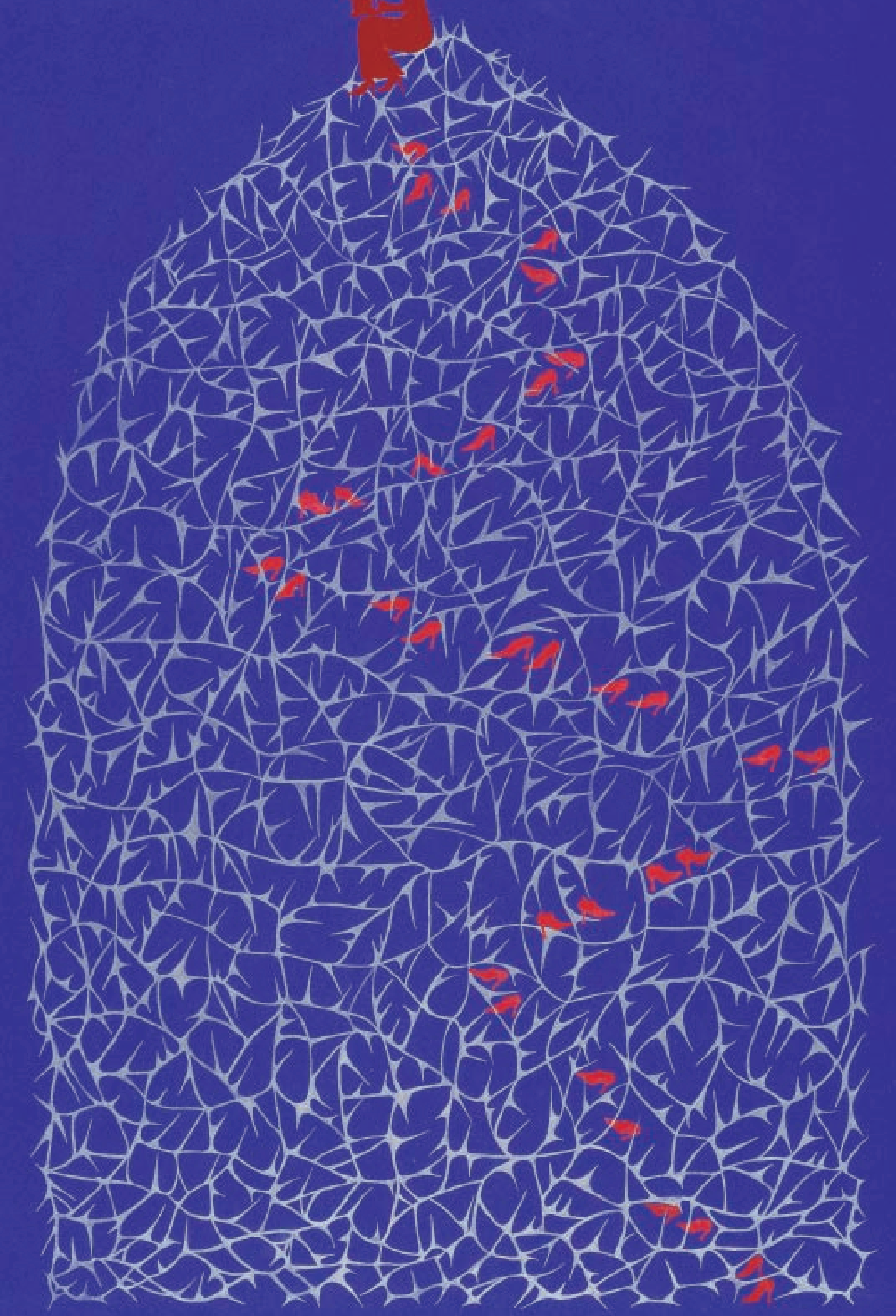




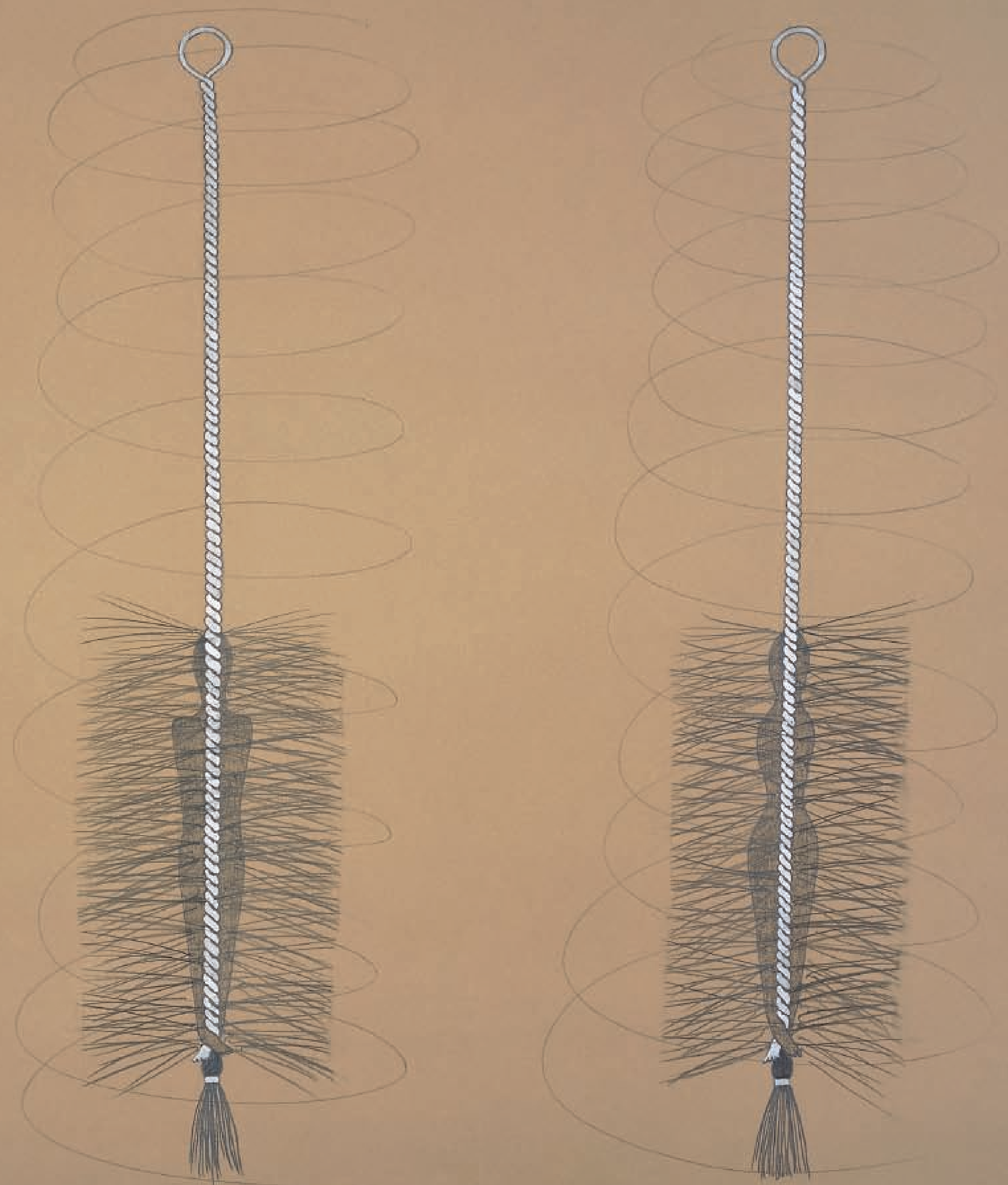




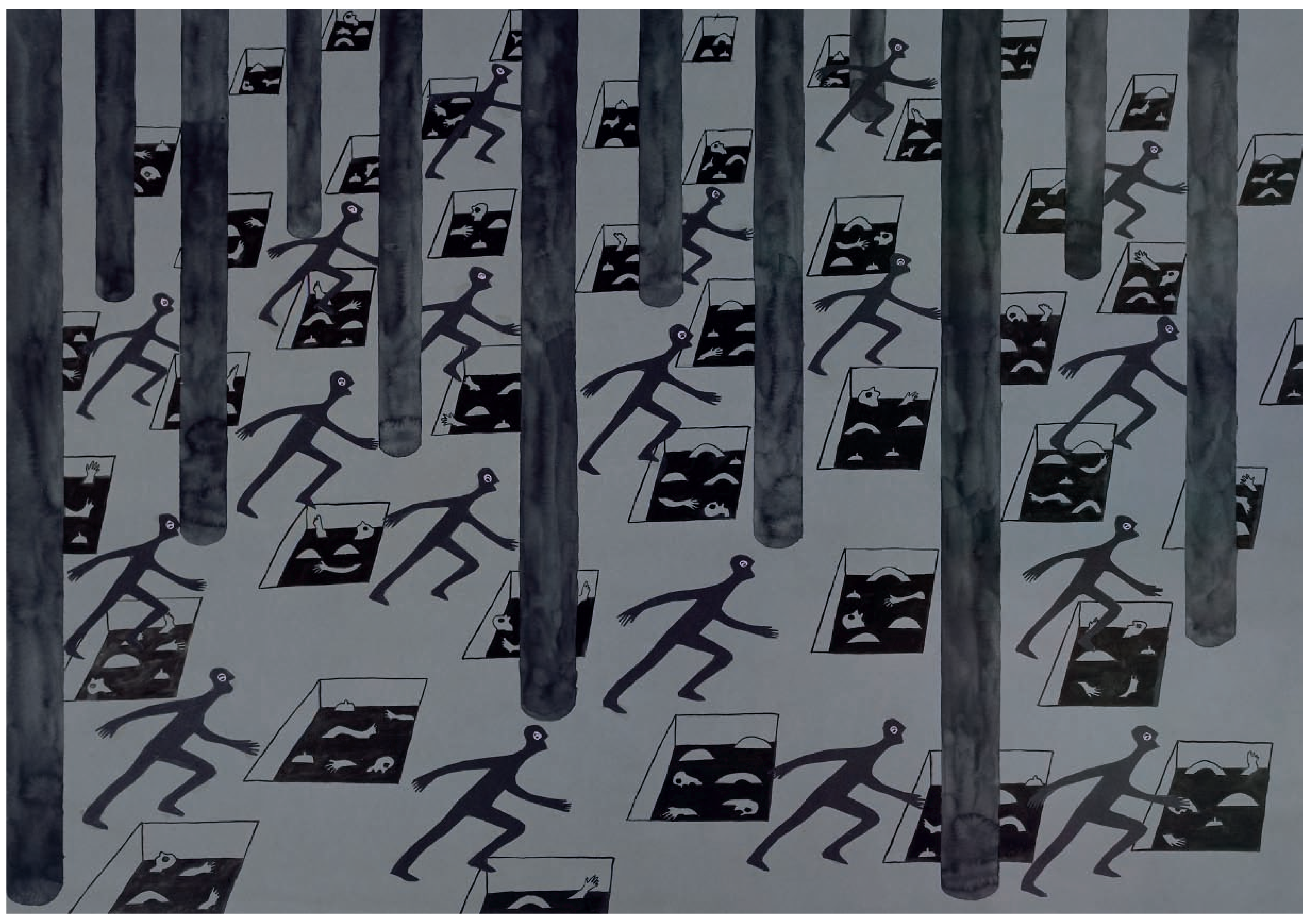




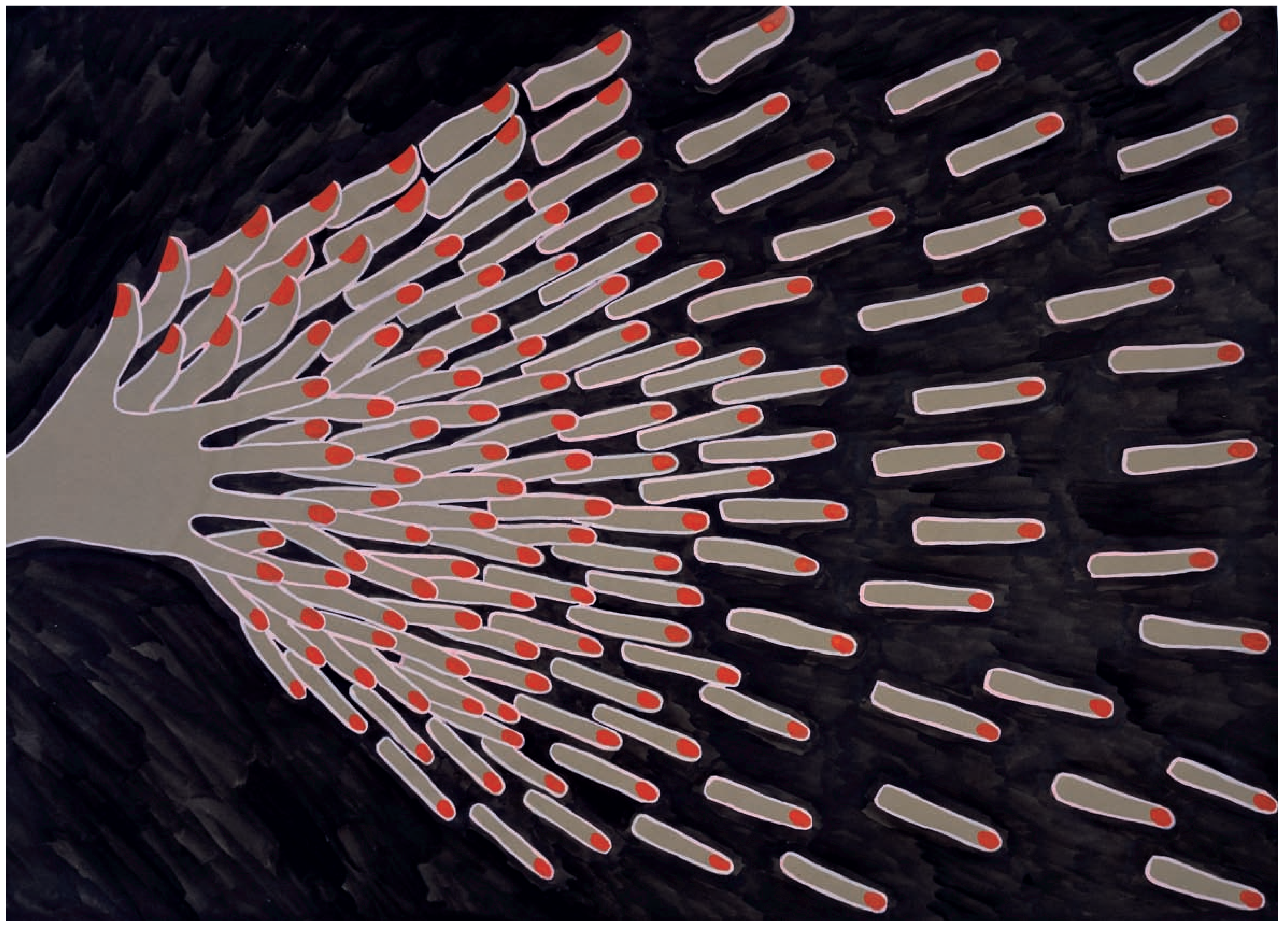




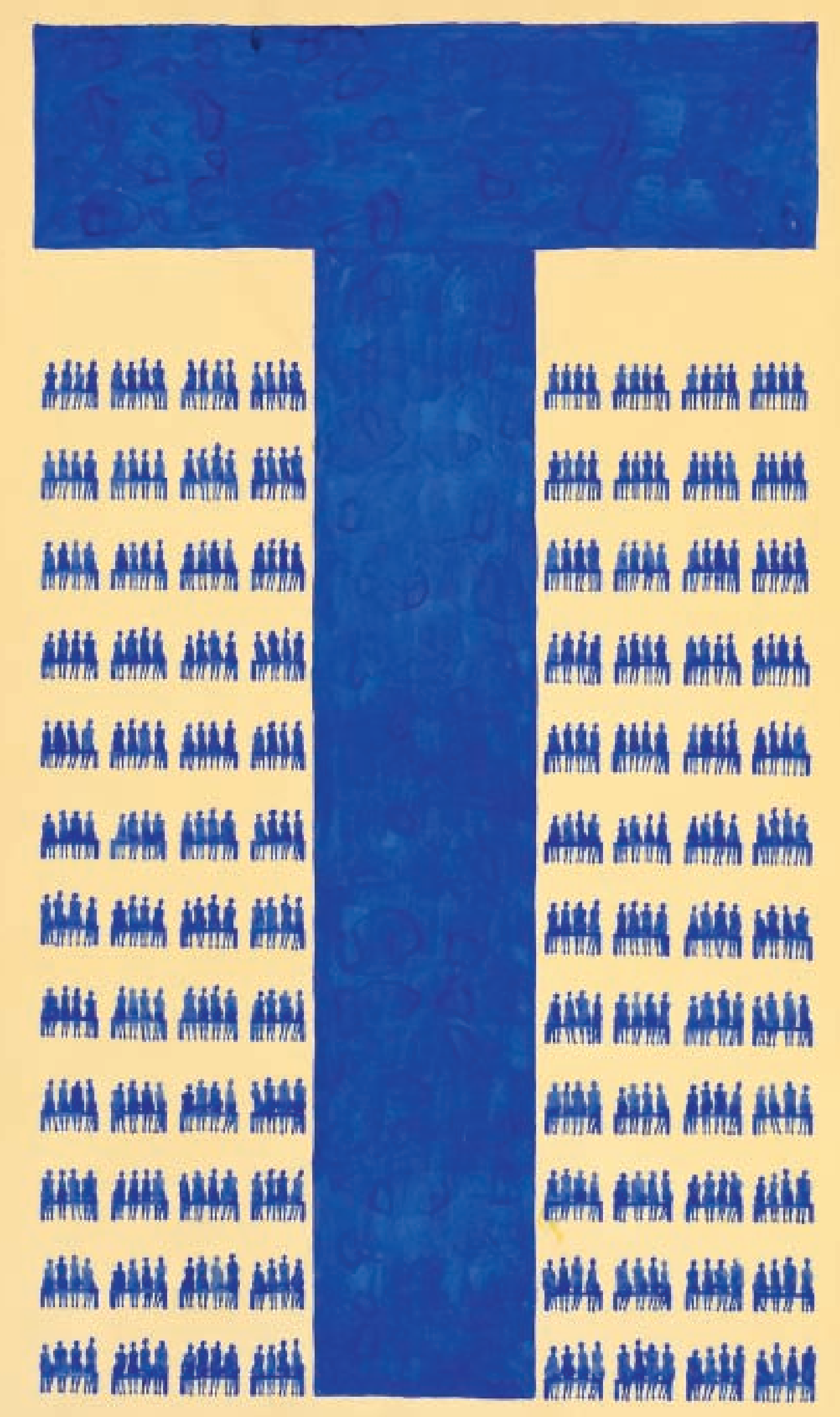



gerger

(20)

$0406060 \%$

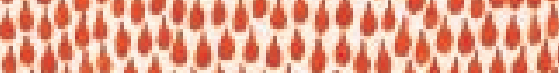

Brofer (1)

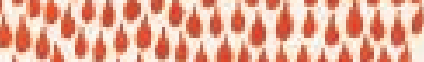

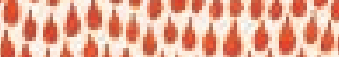
ope

c.
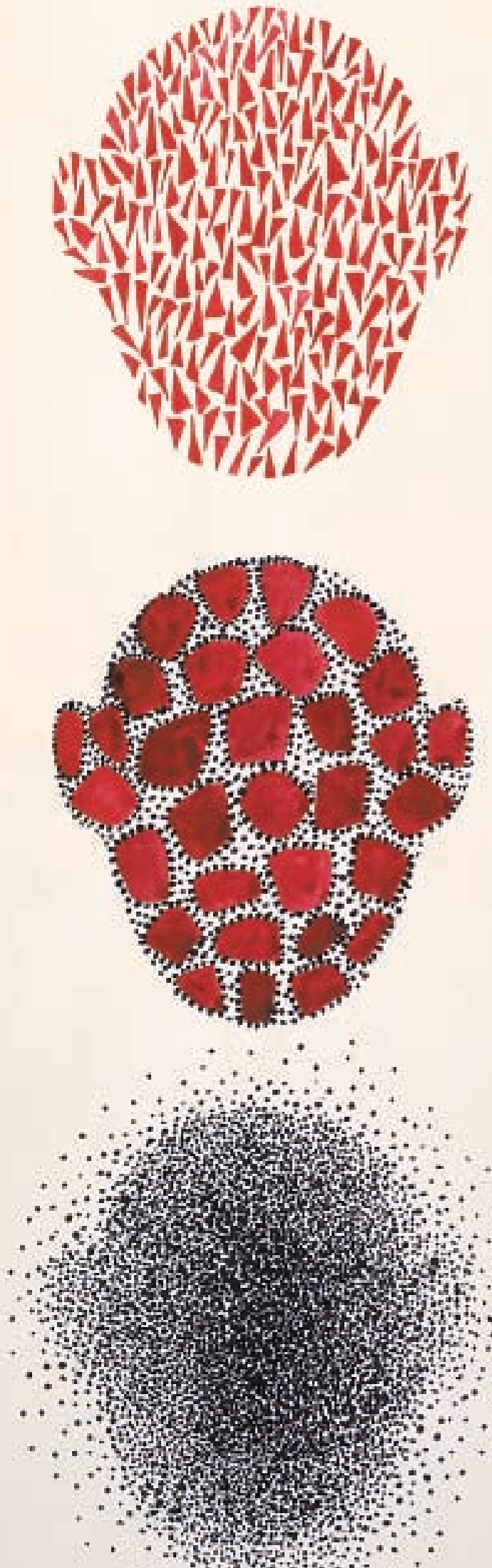

(1)

. 


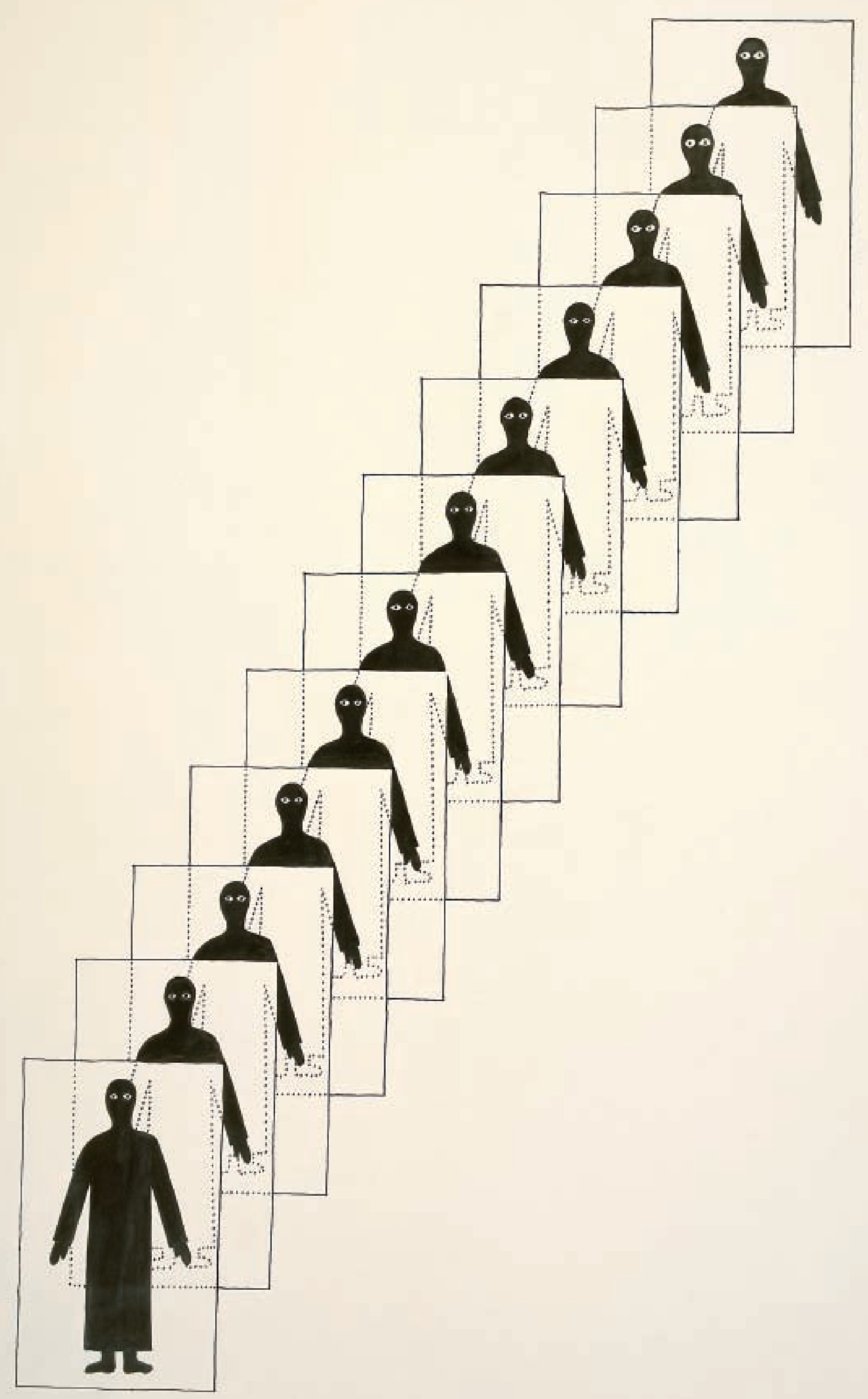




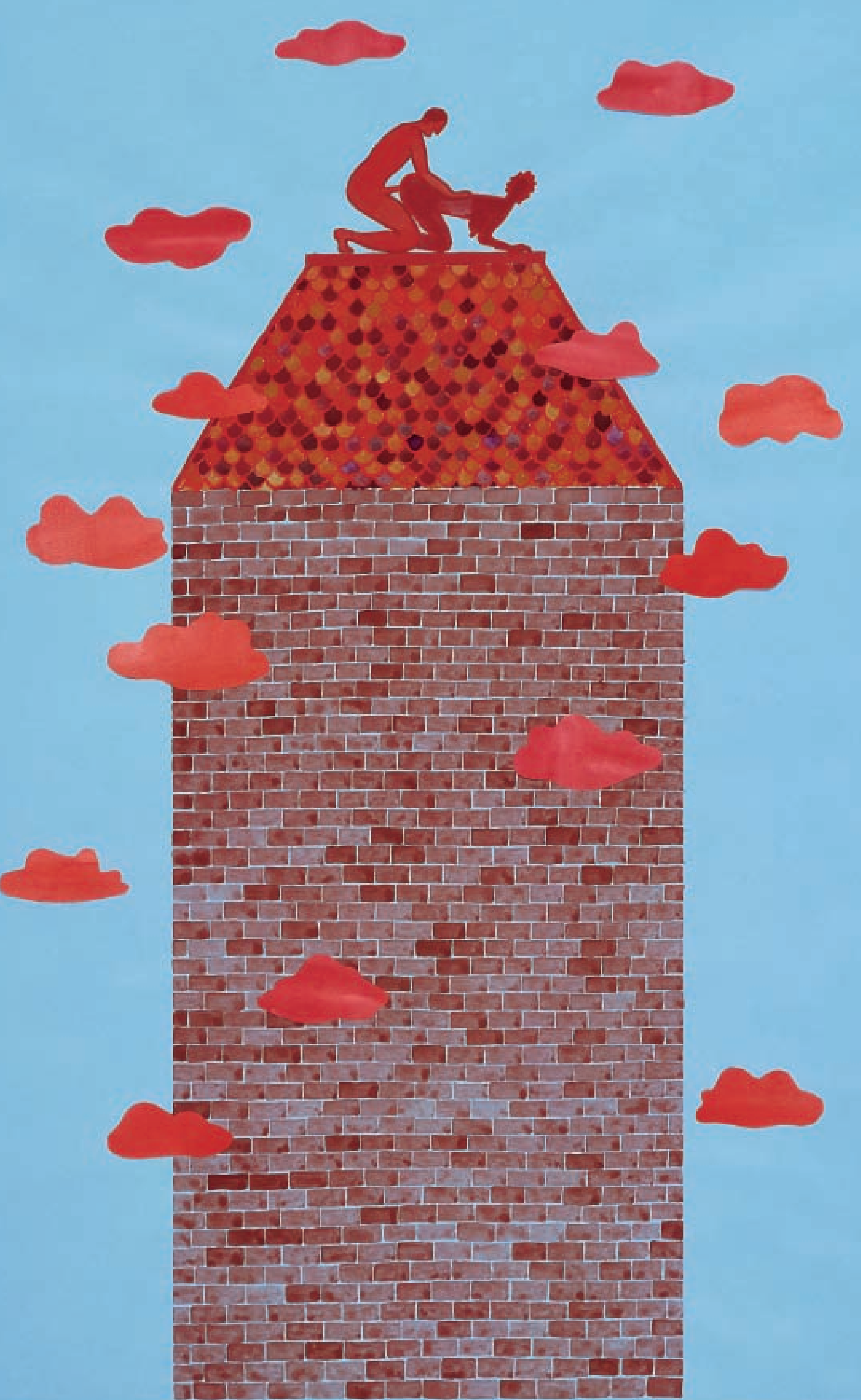




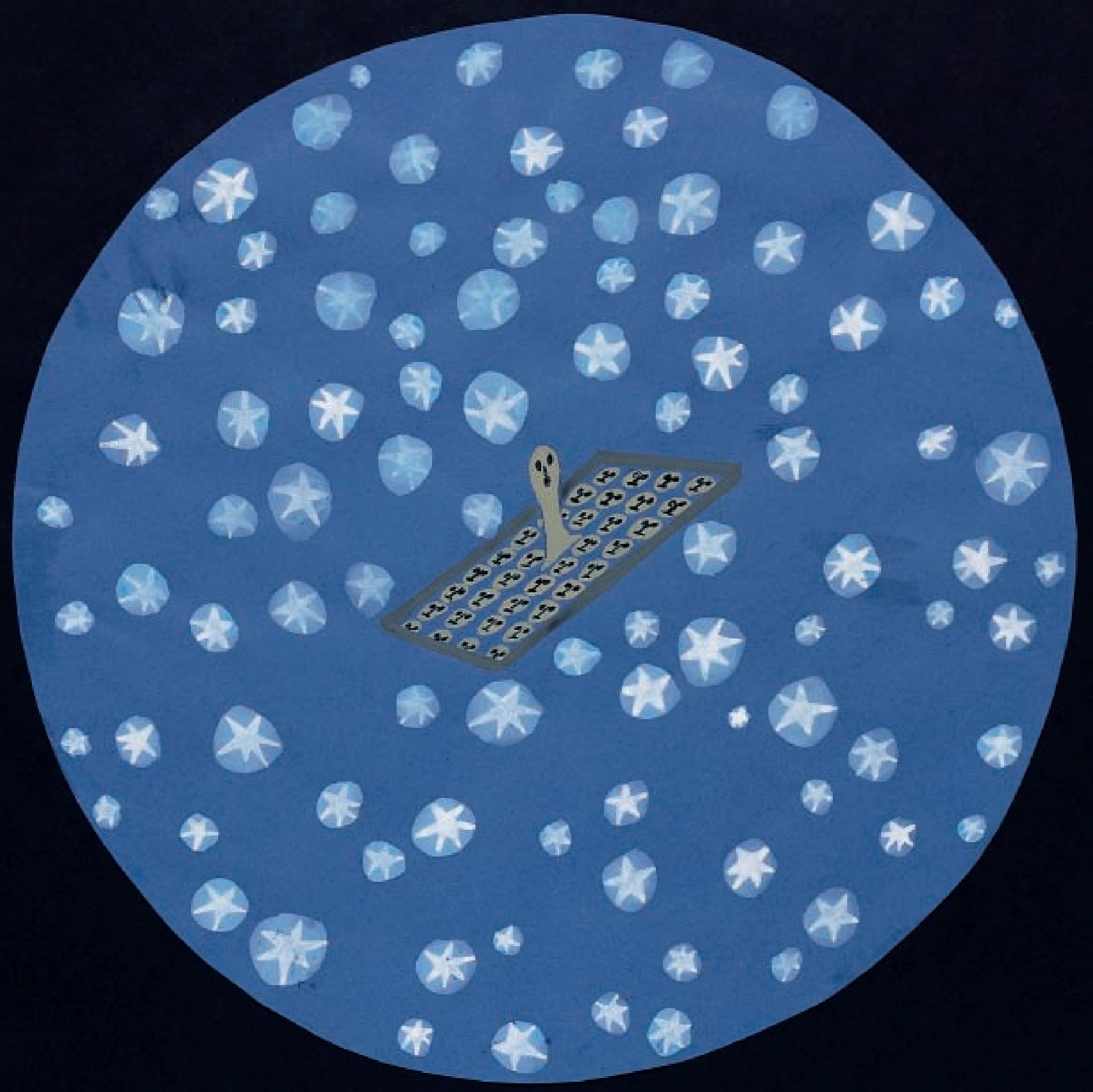




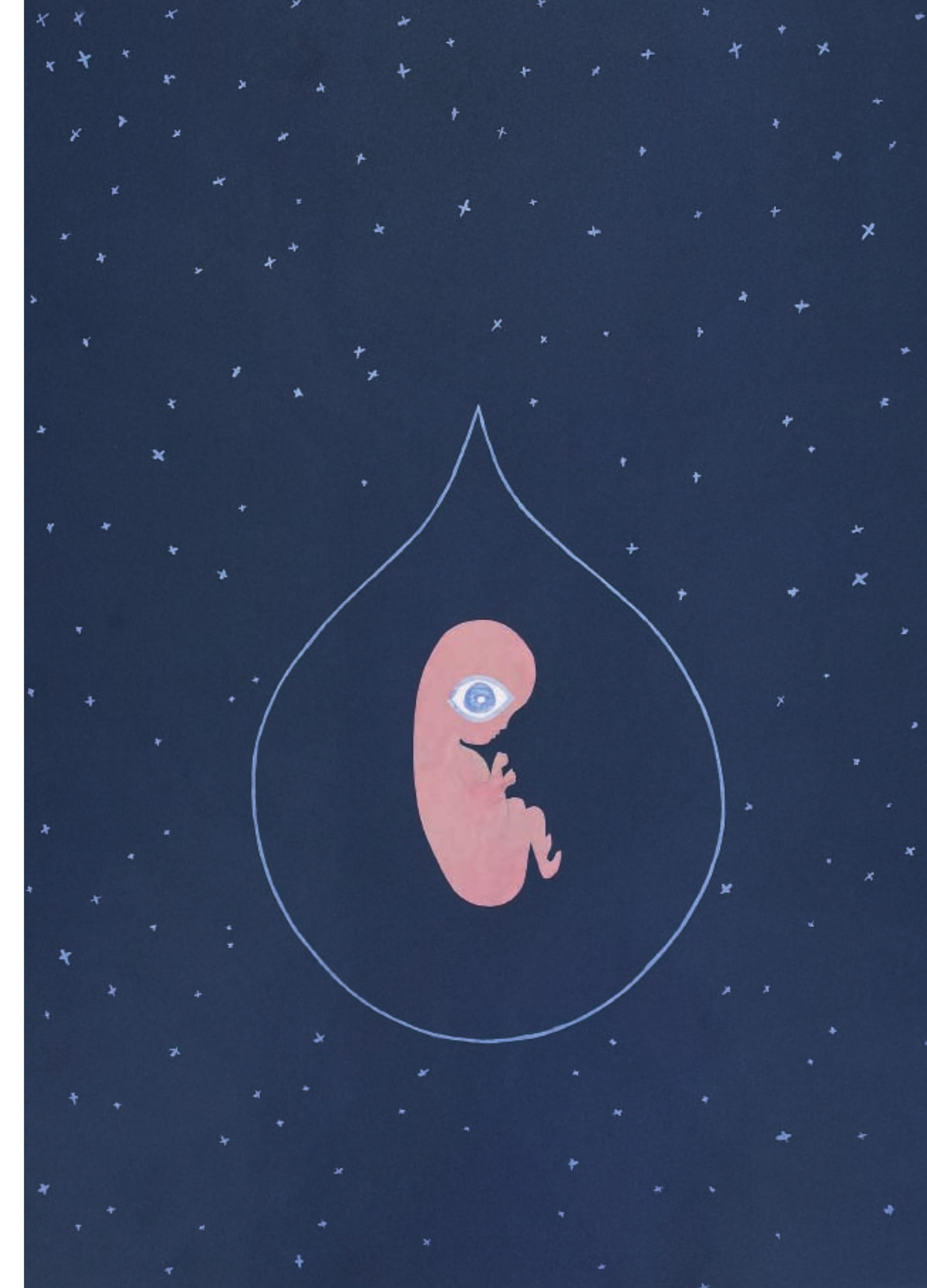




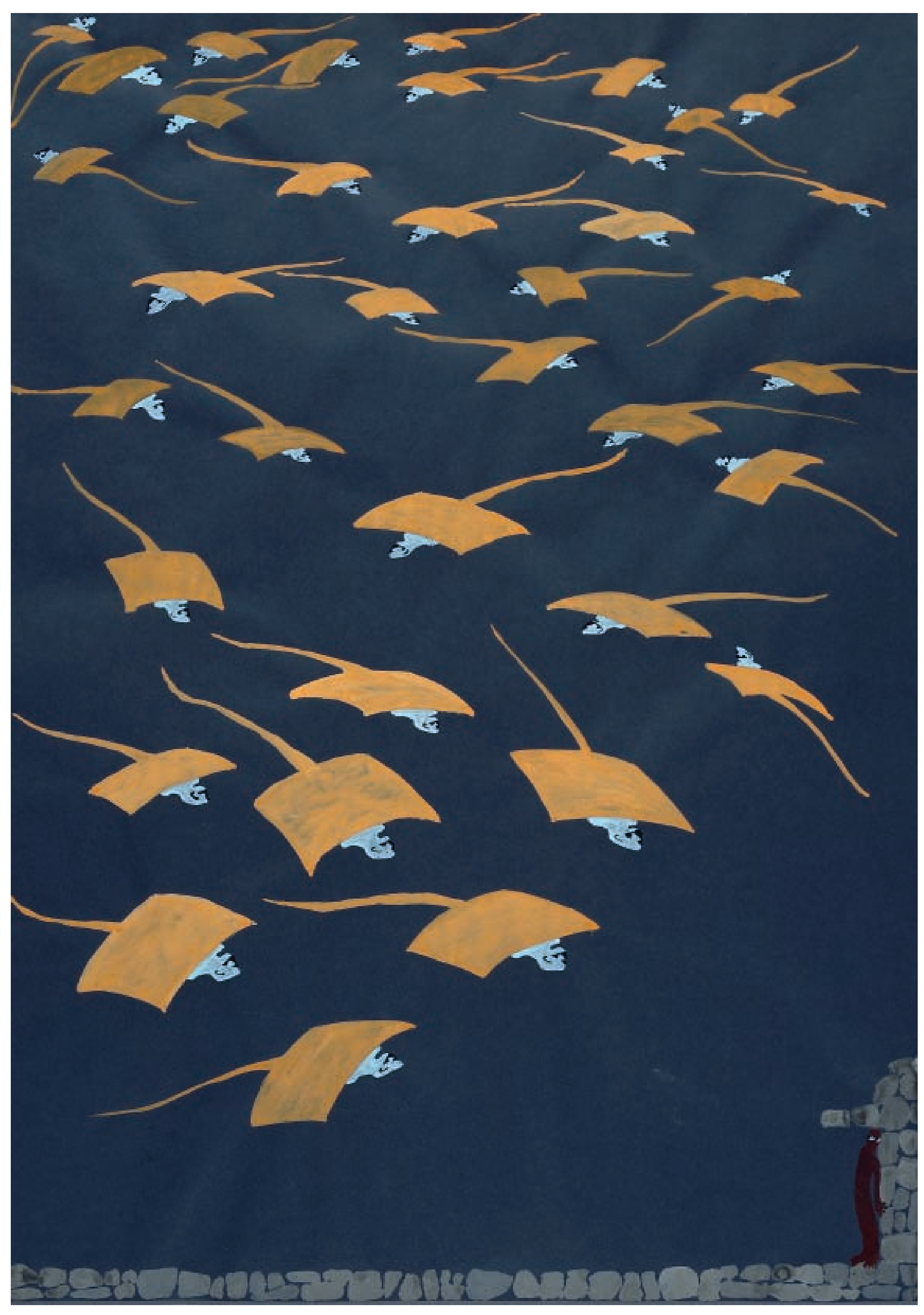



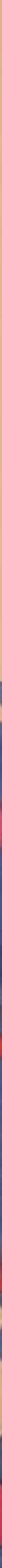


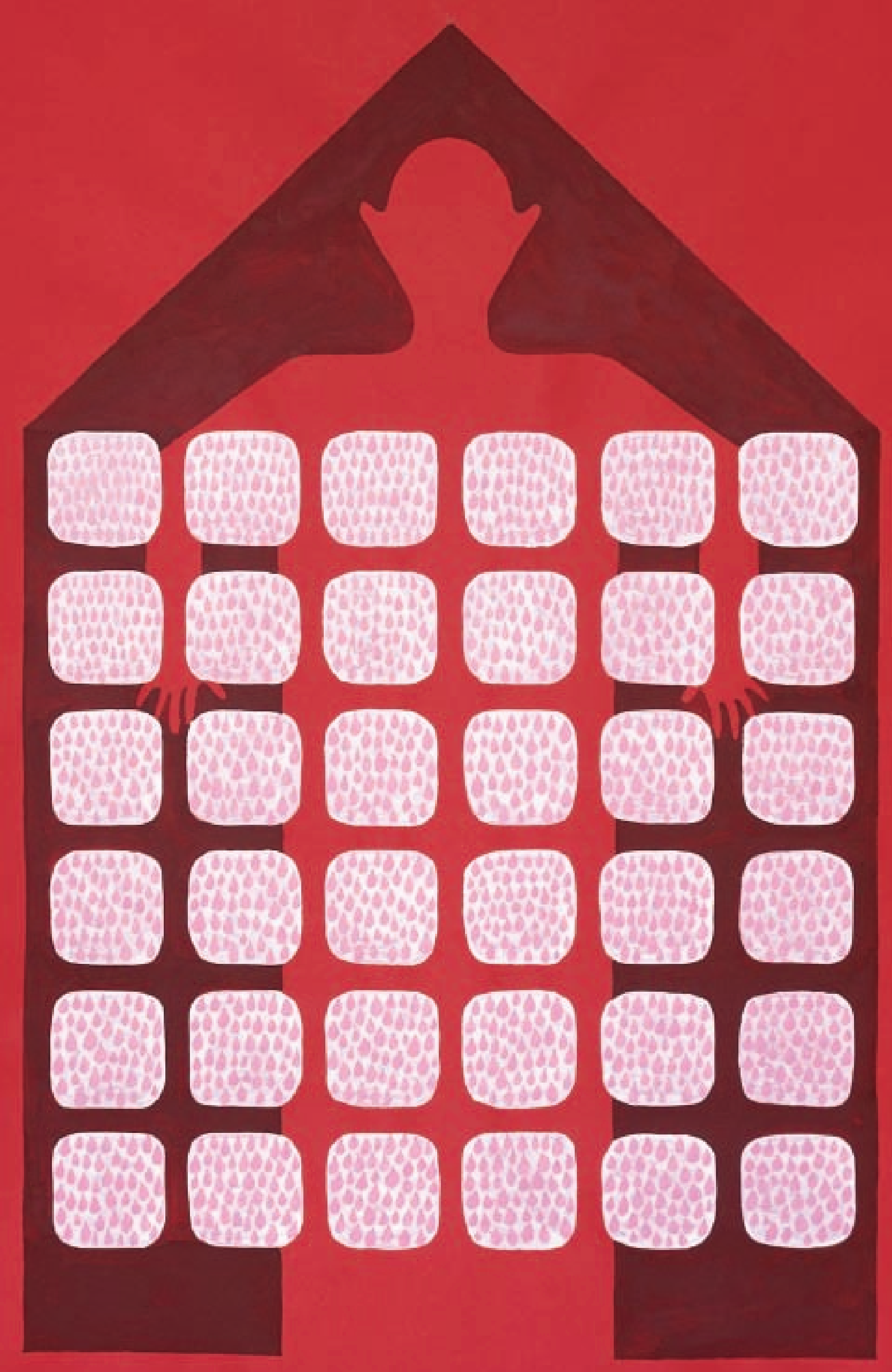





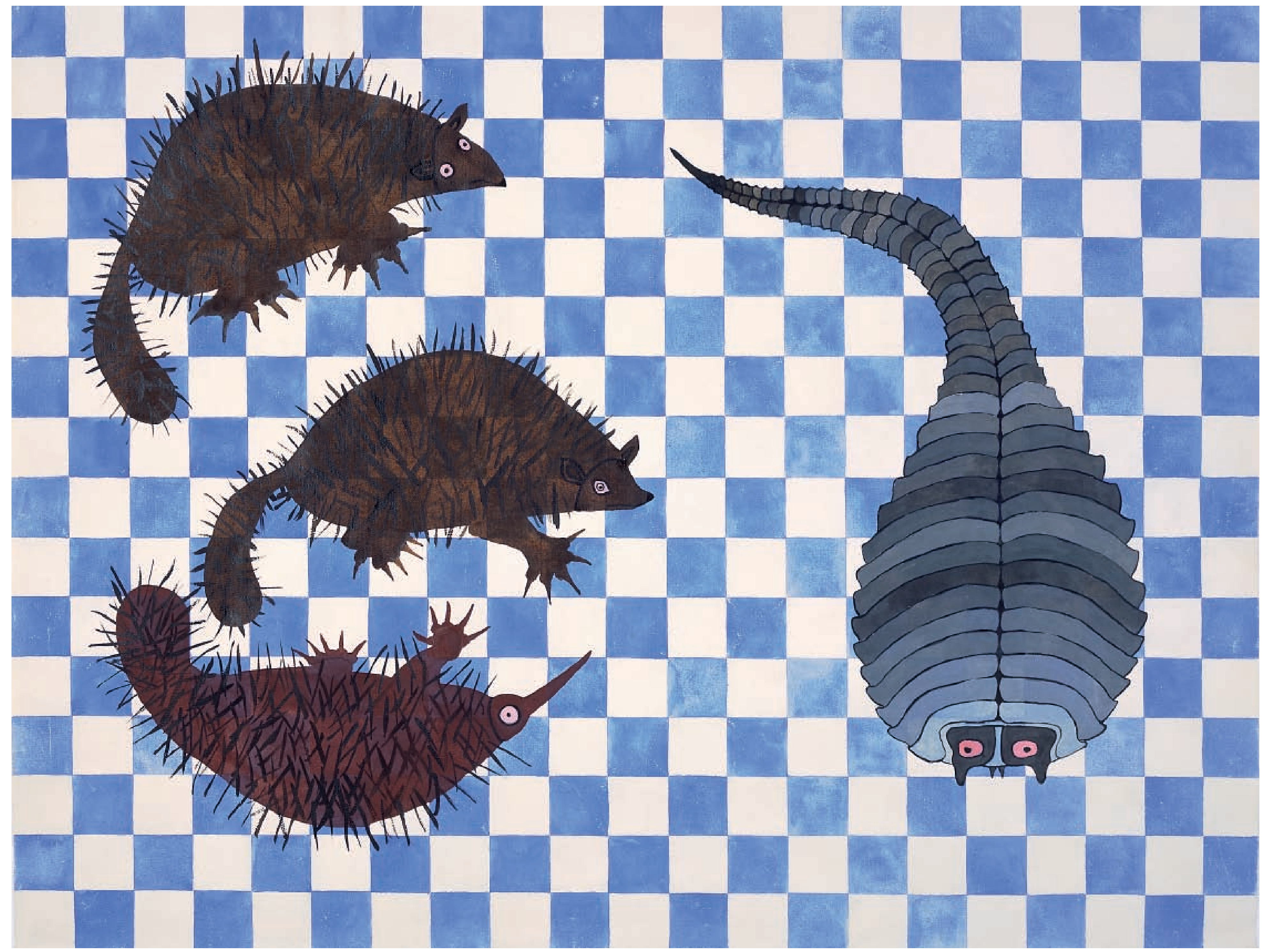




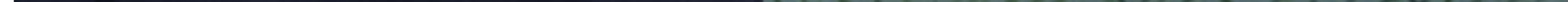




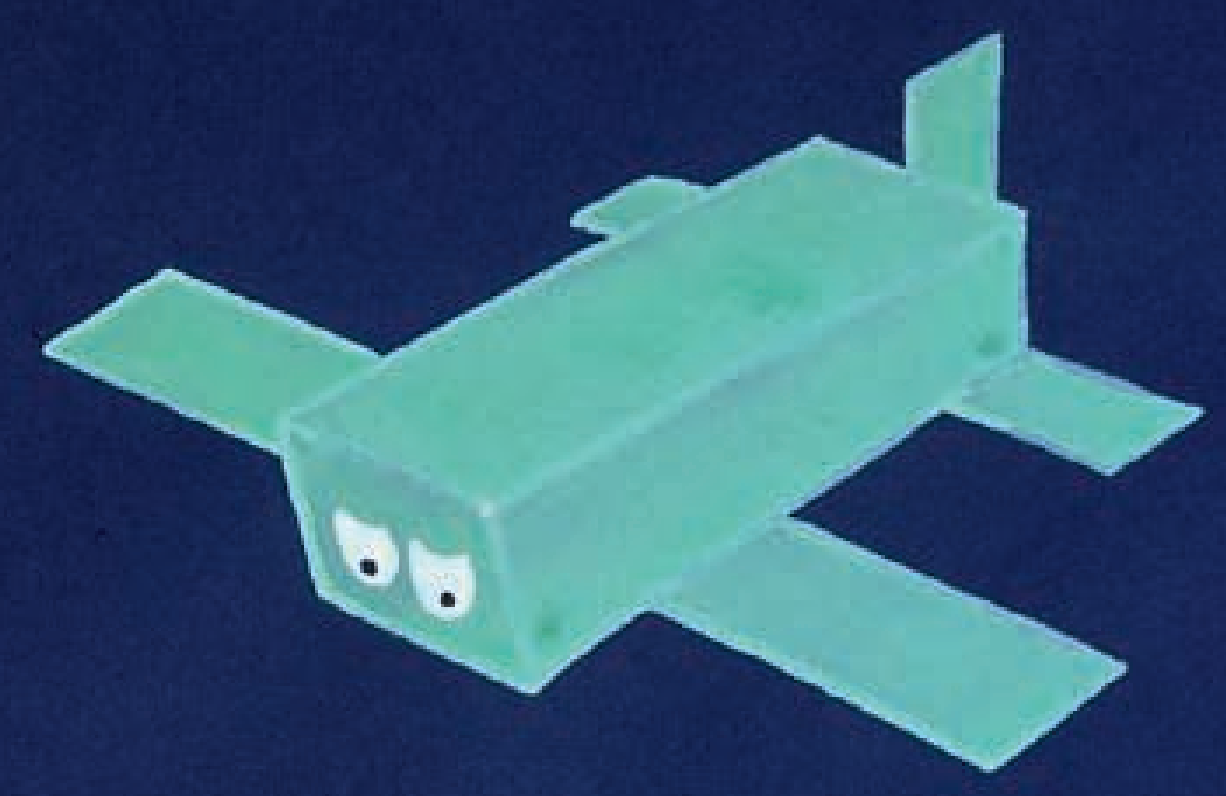

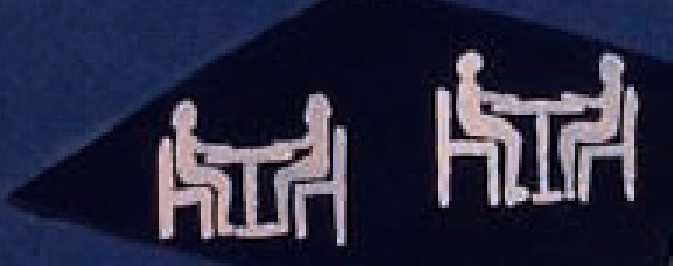

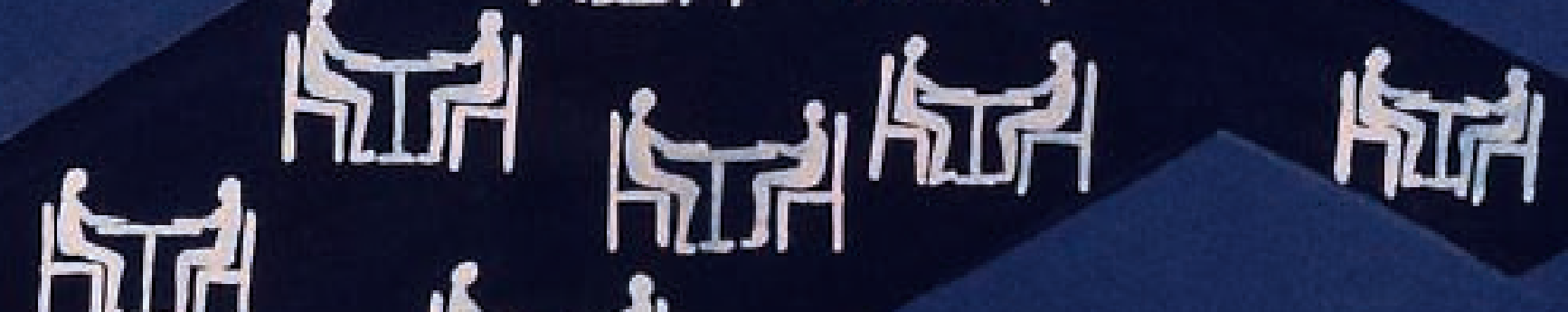

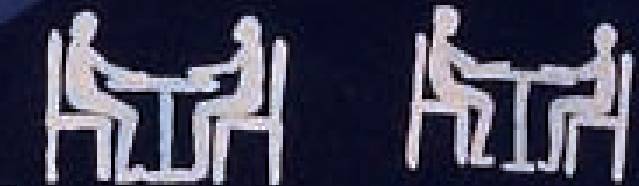

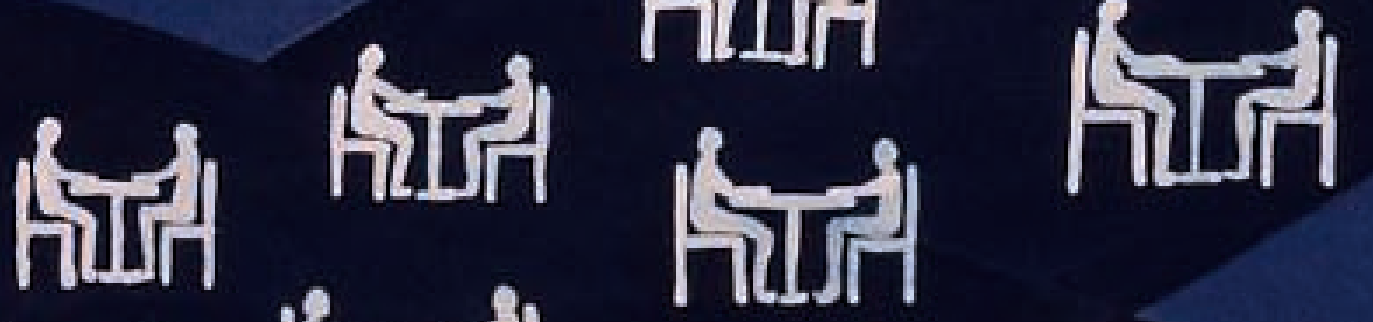

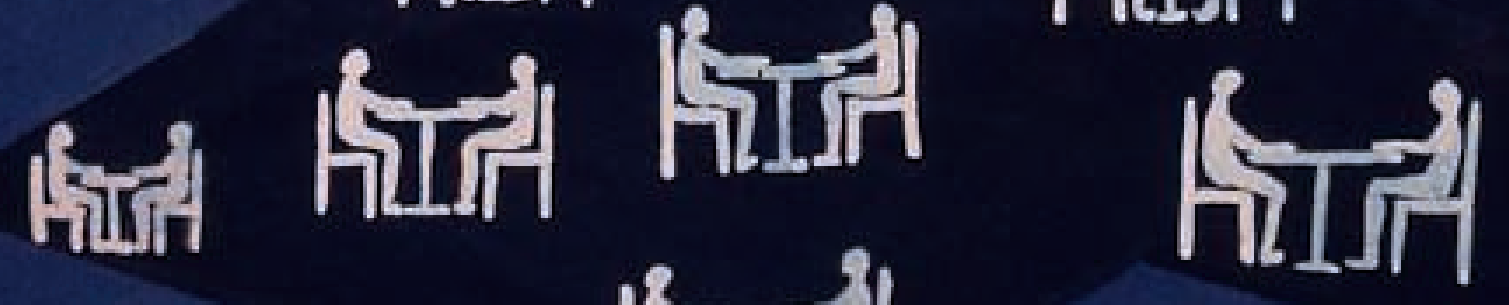




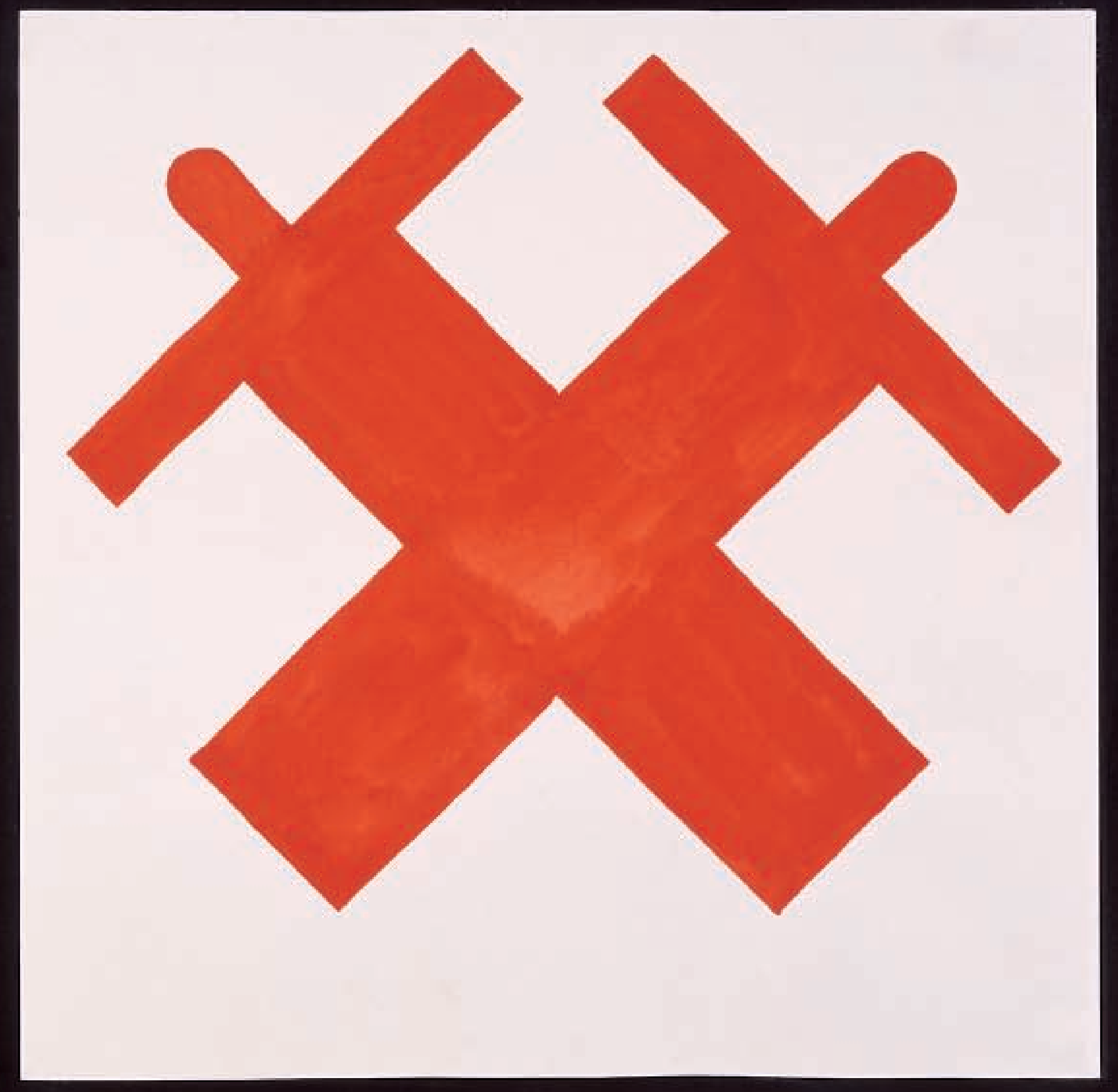



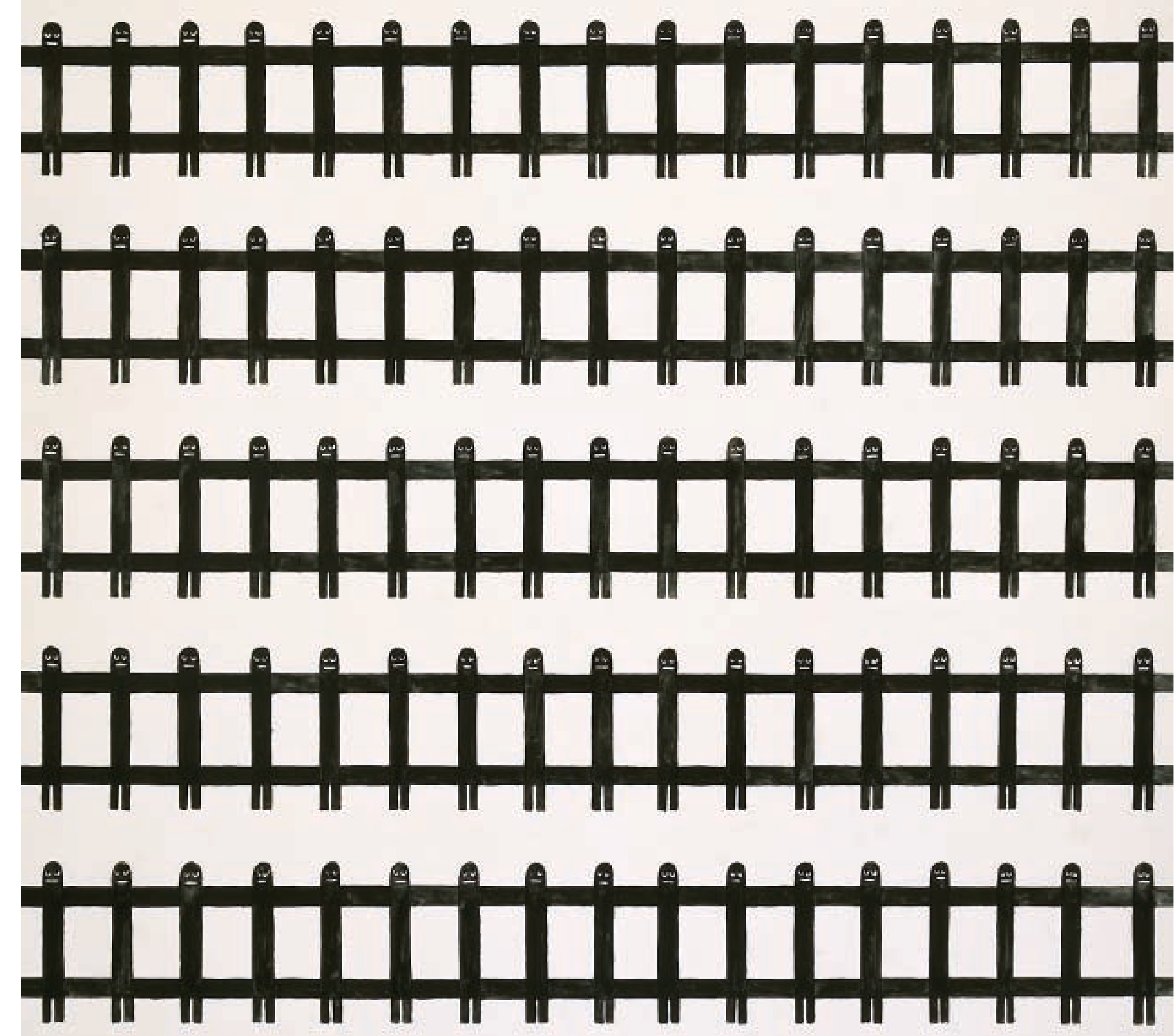



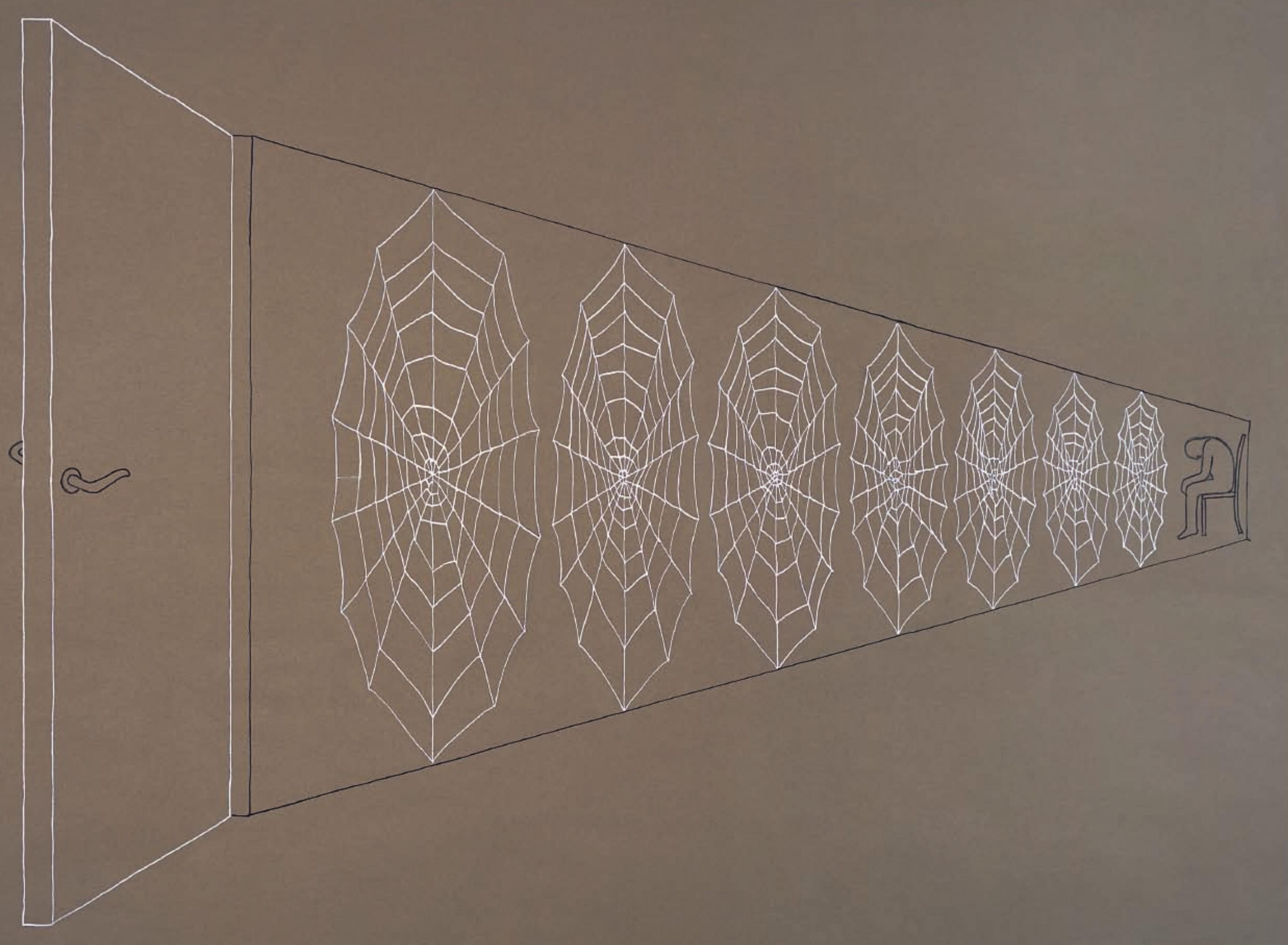





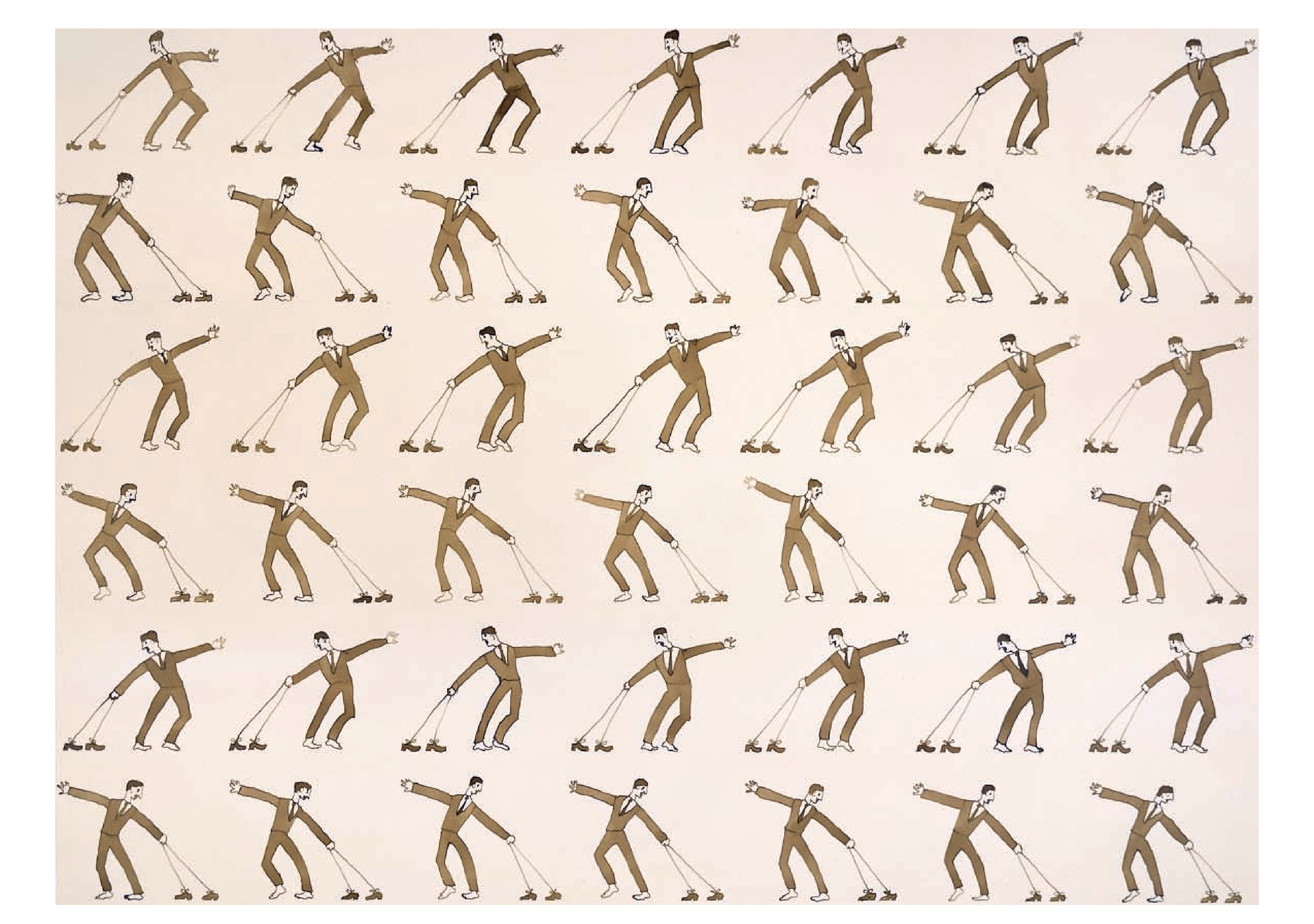




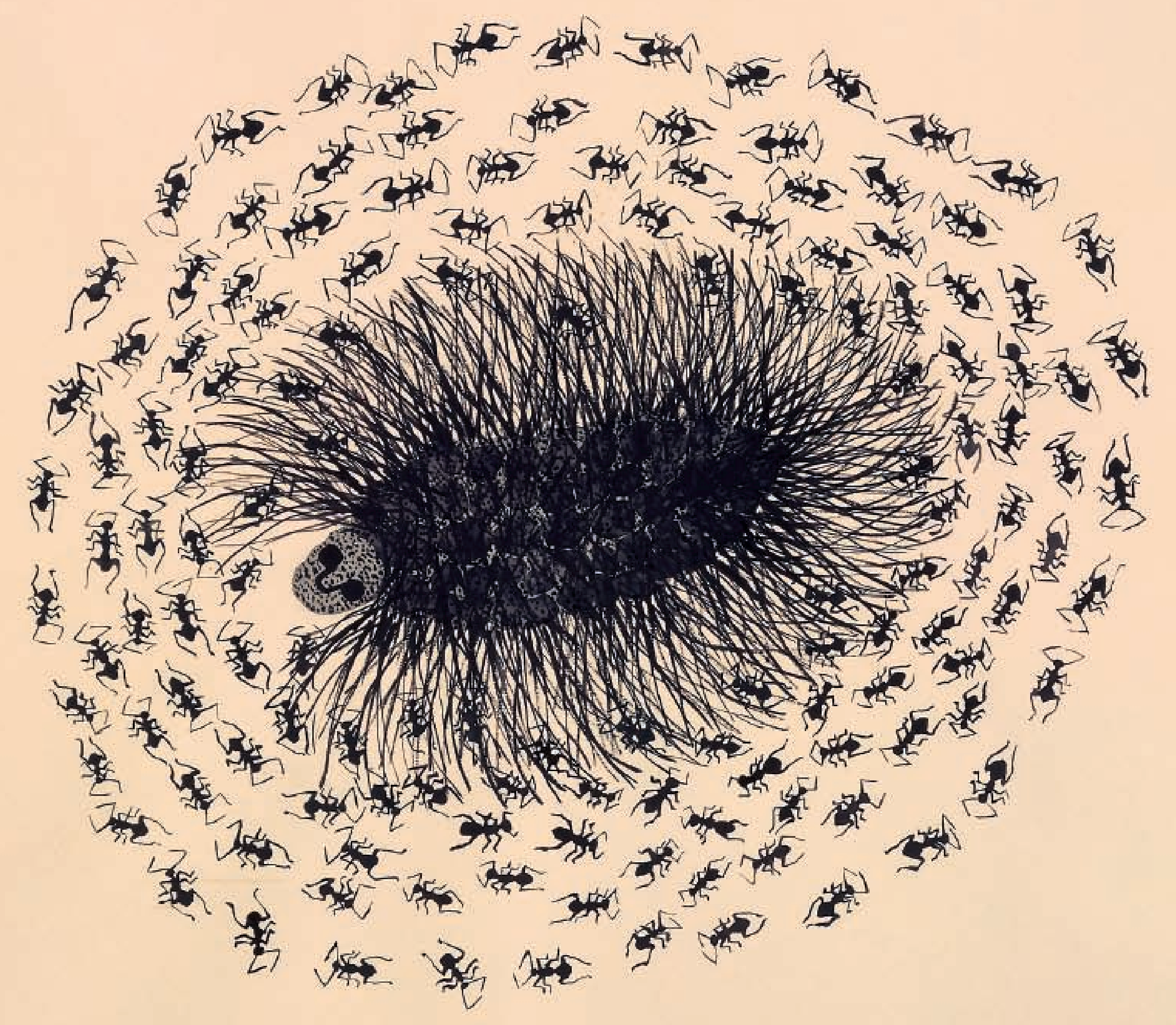




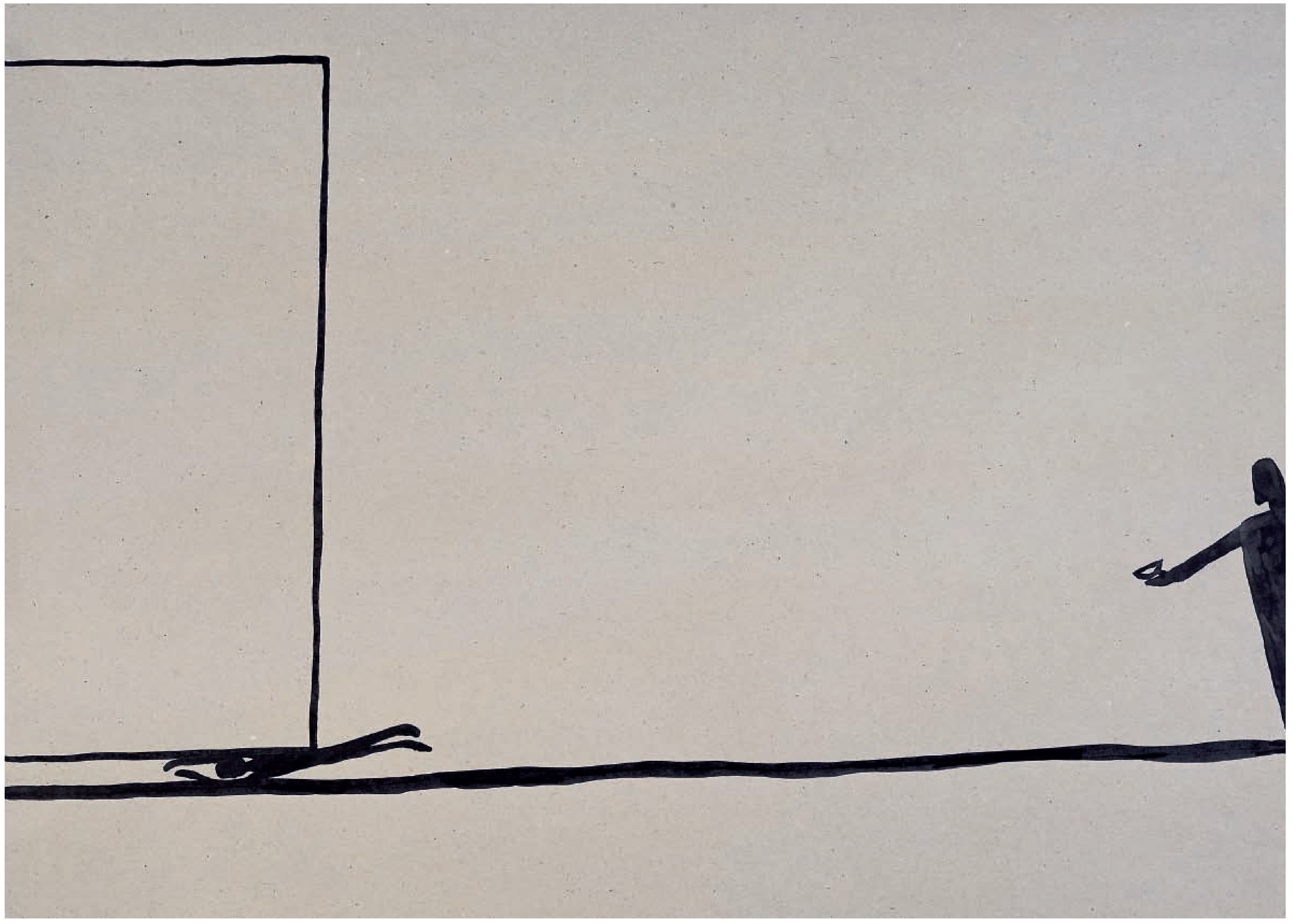




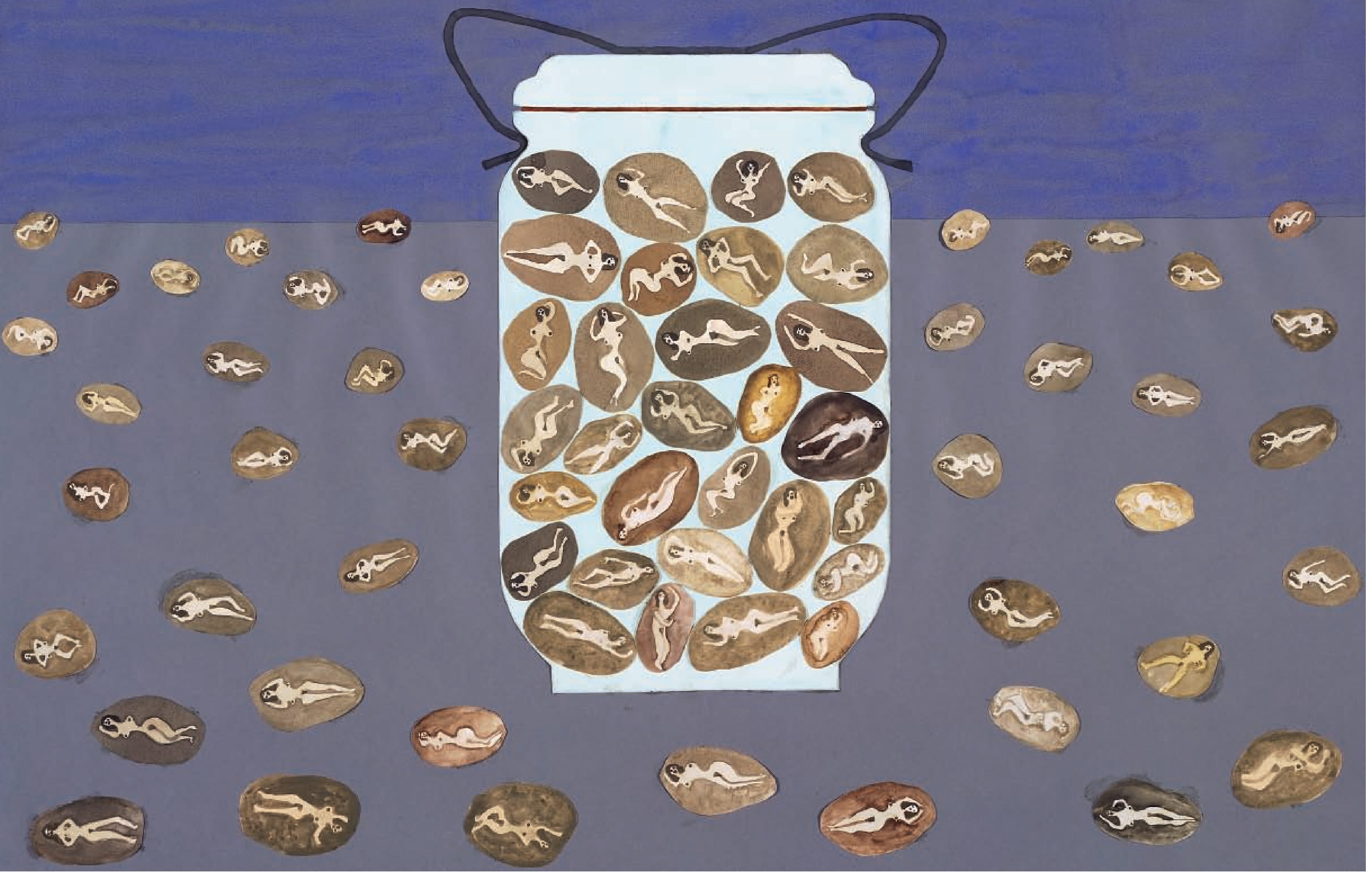



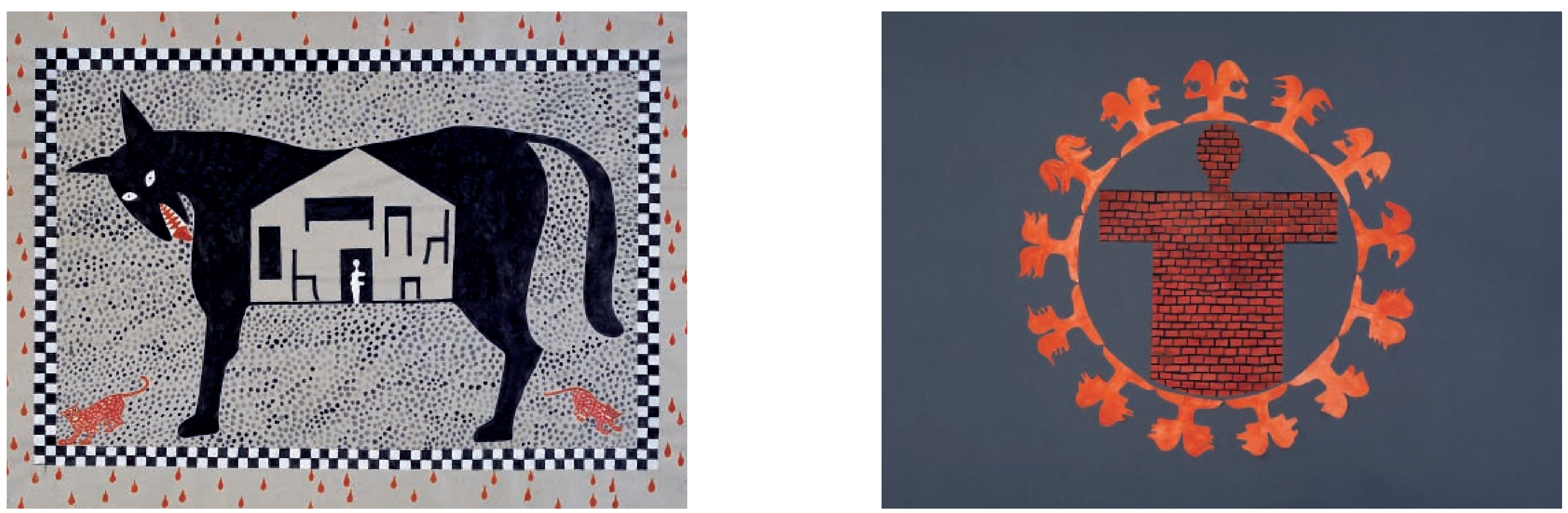

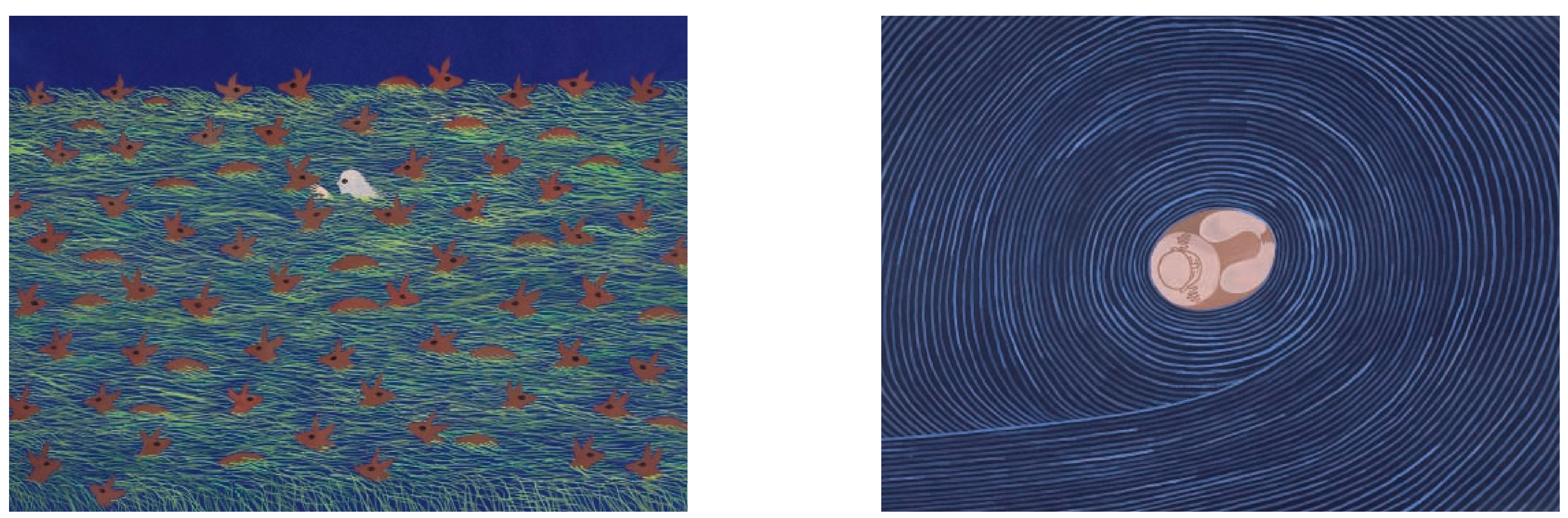



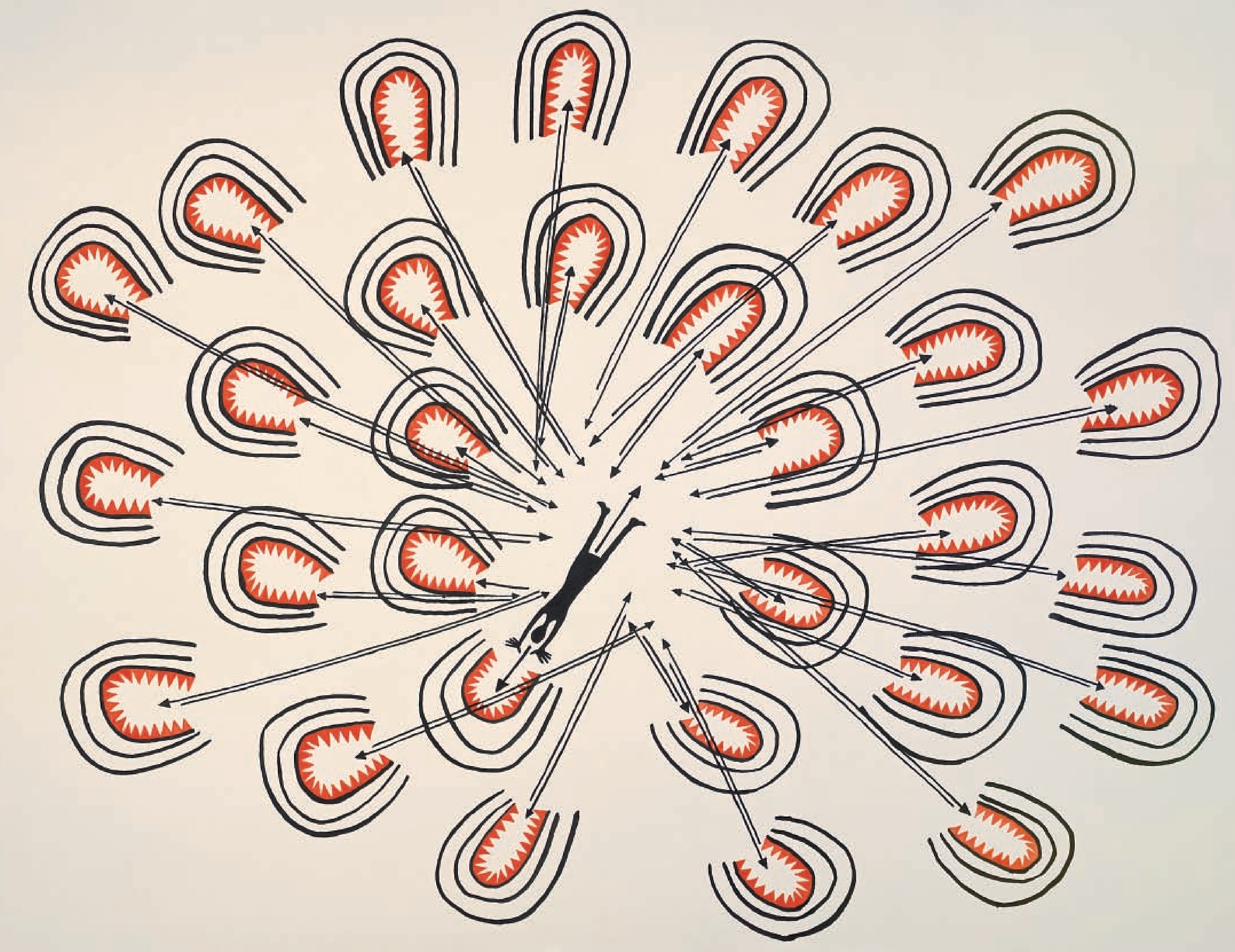




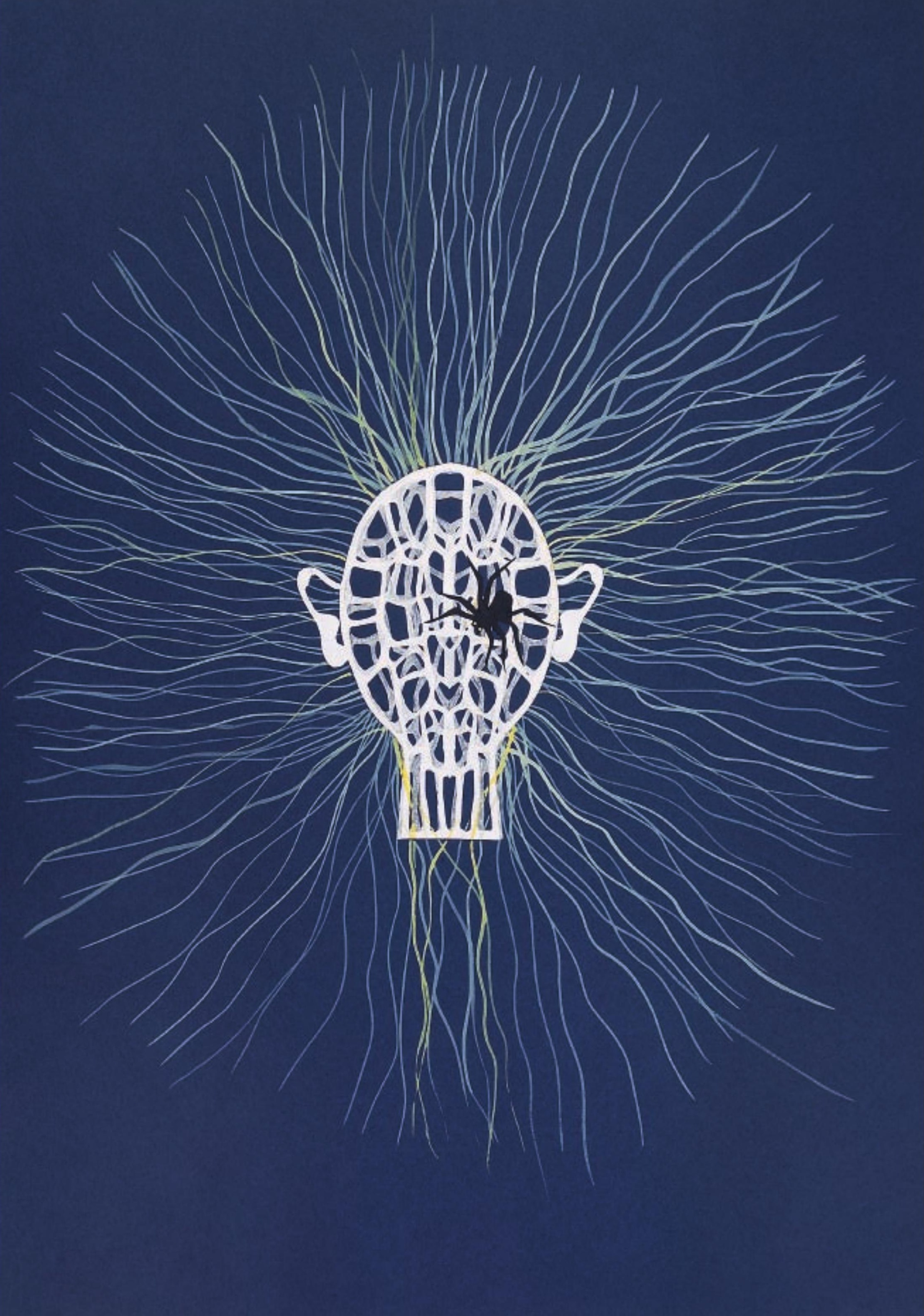




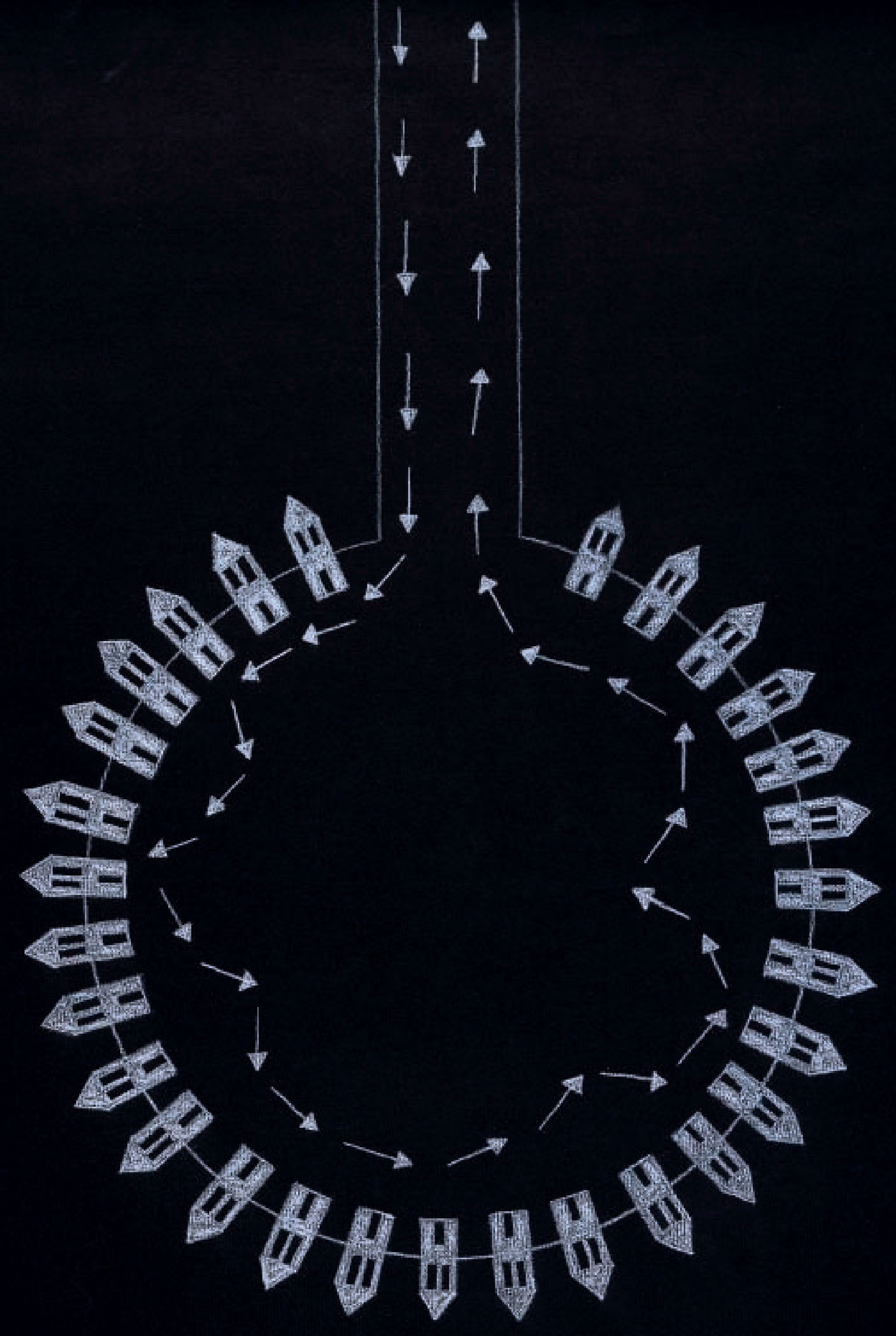




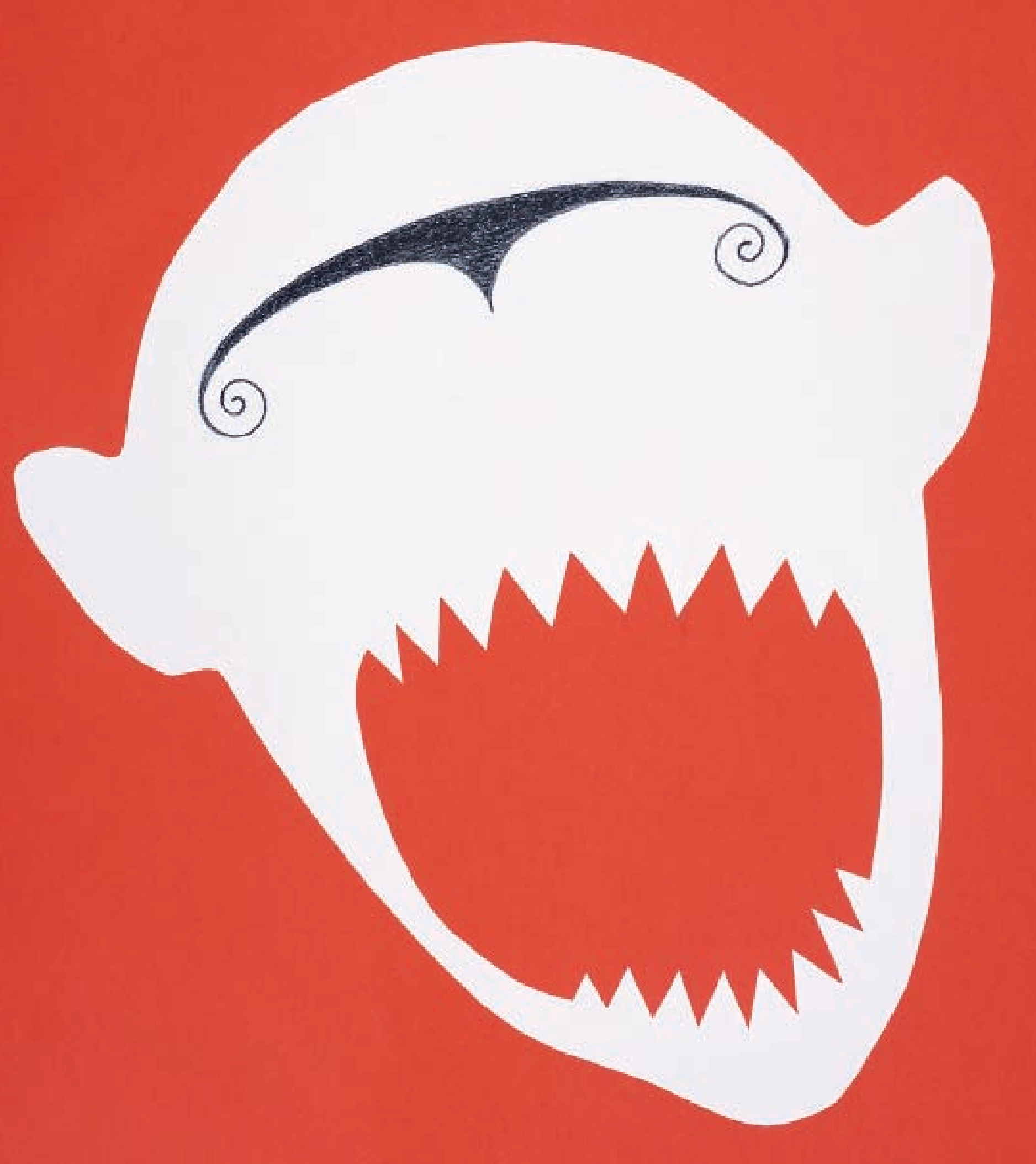




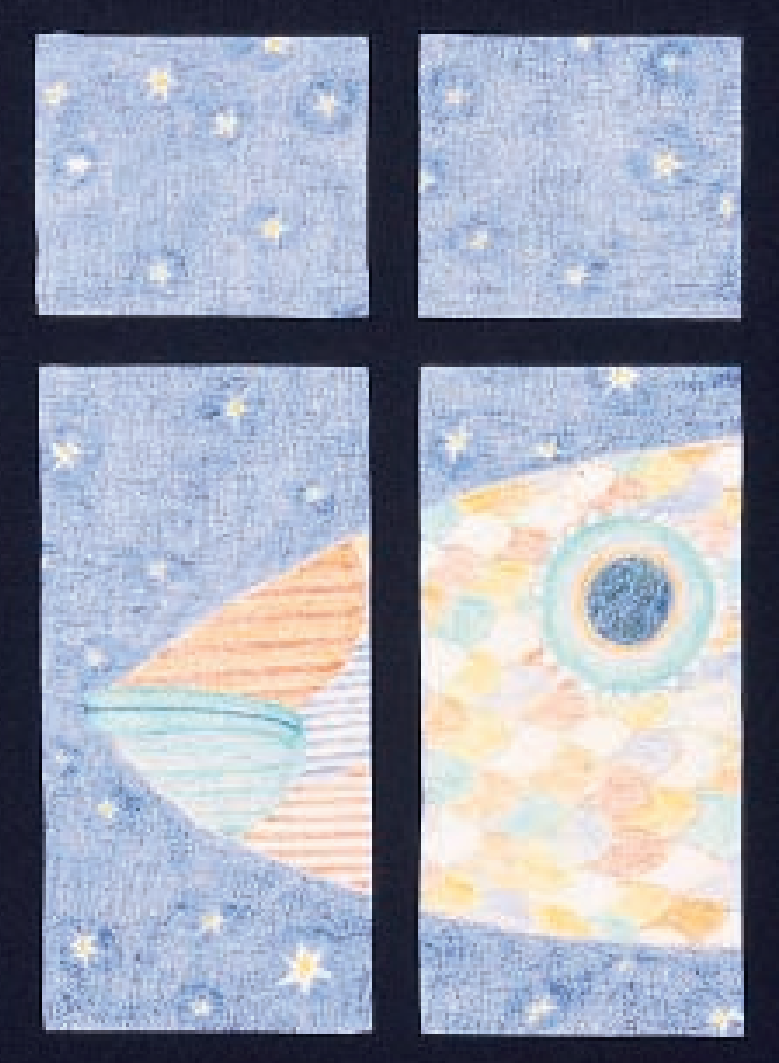




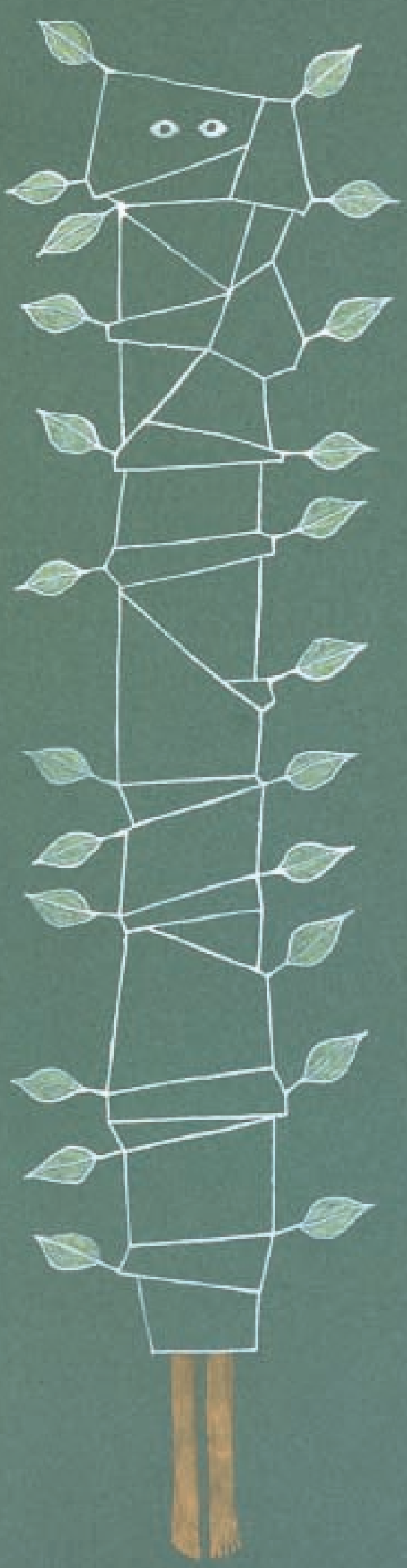




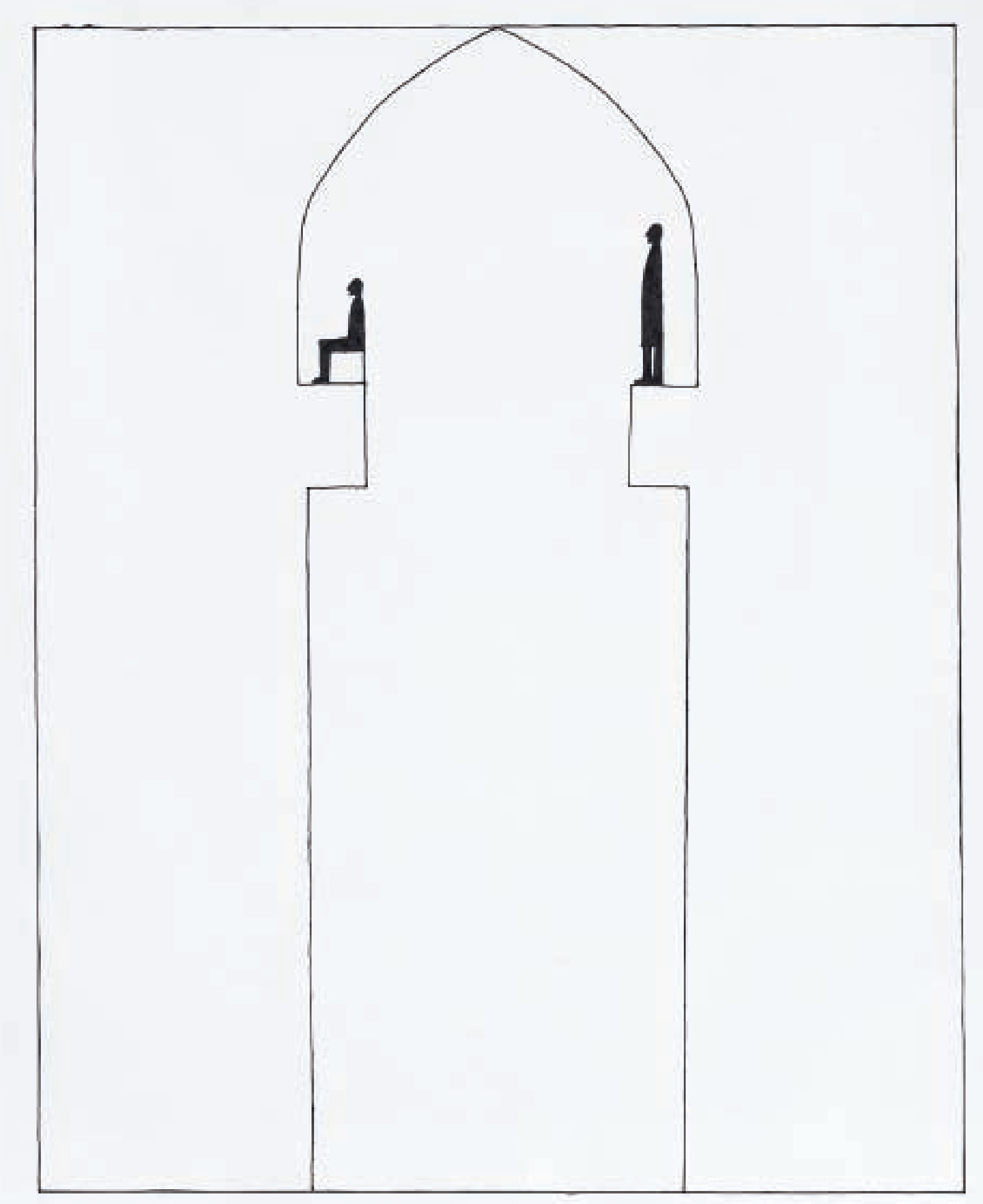




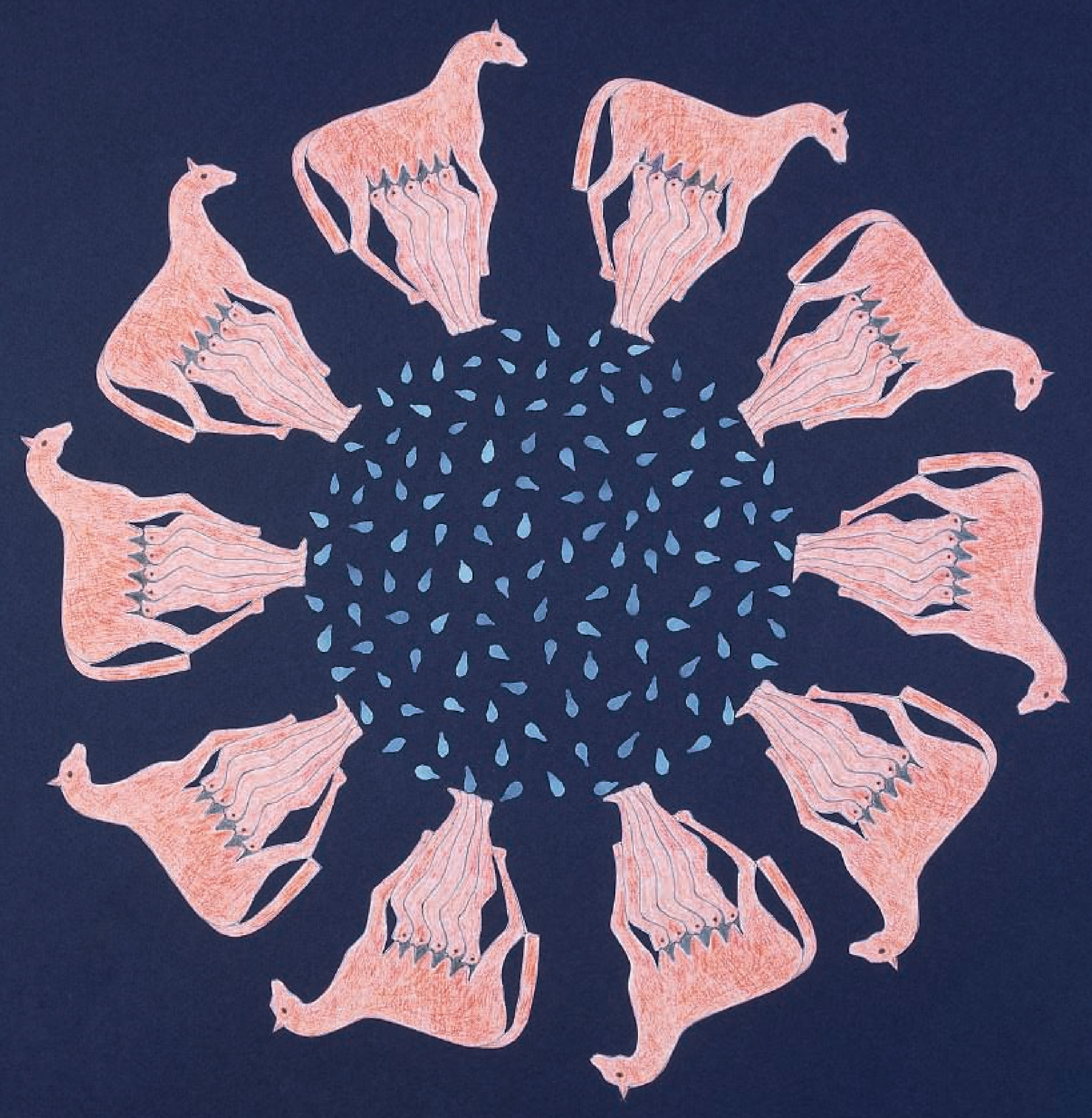




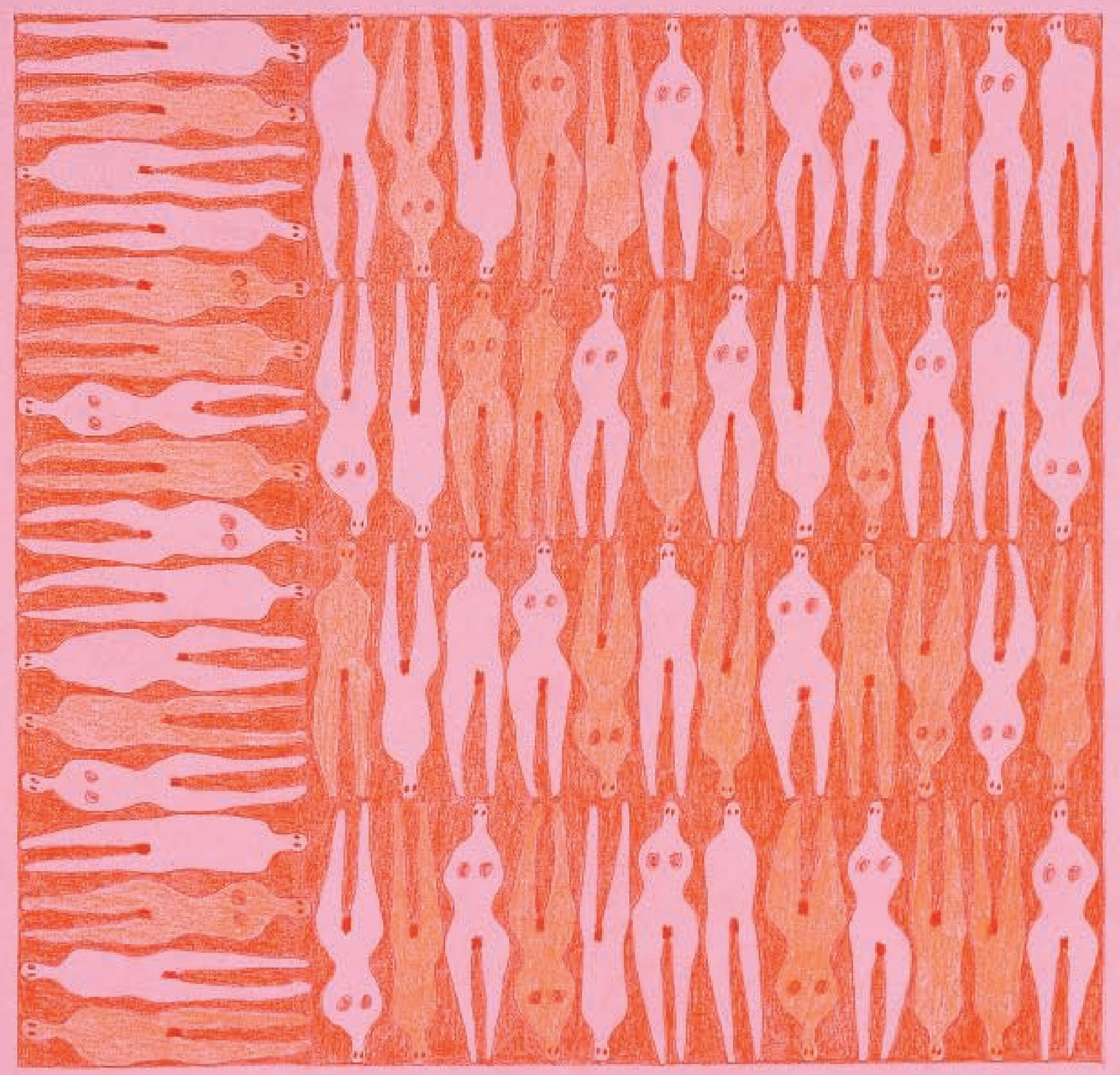




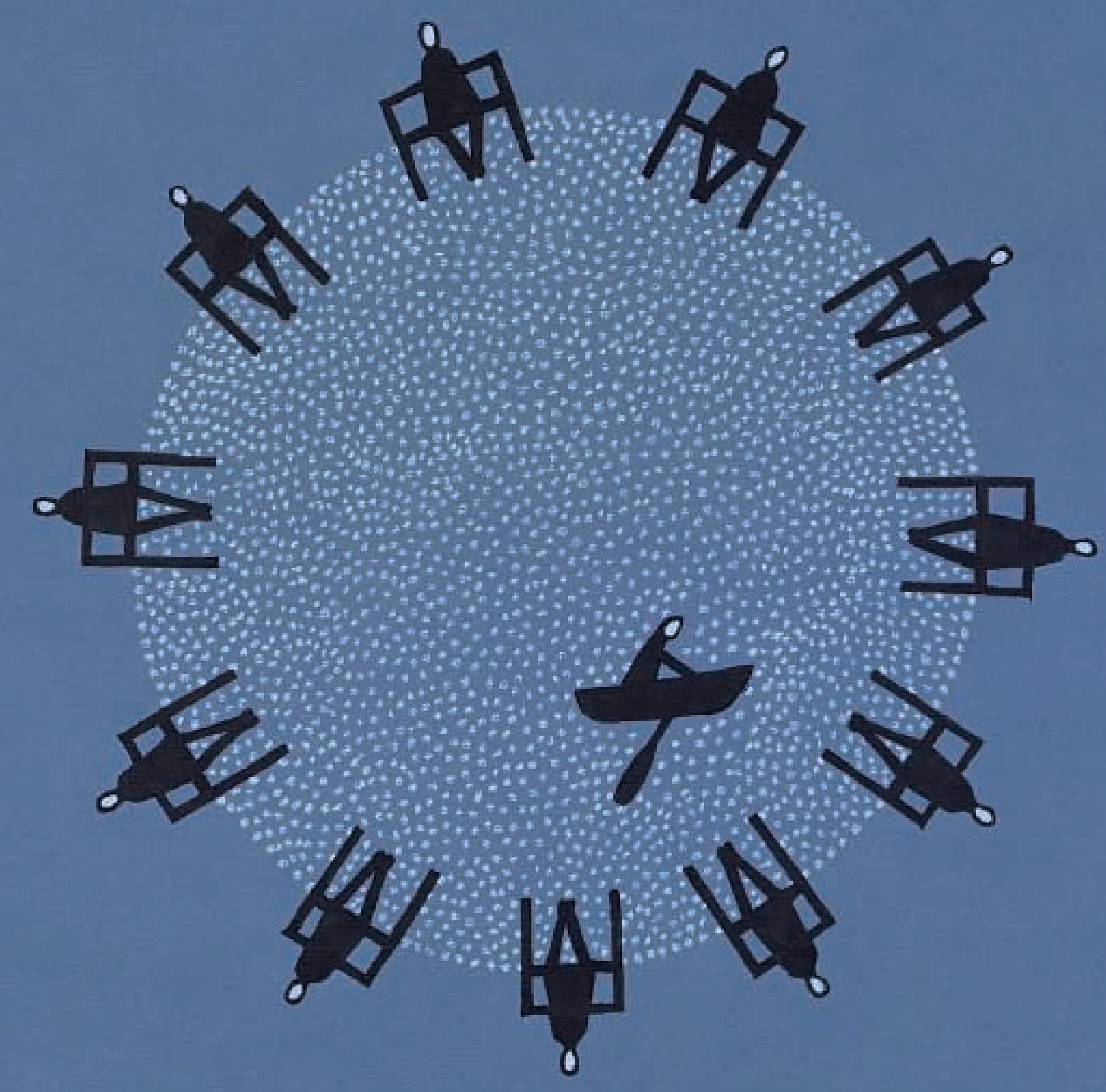




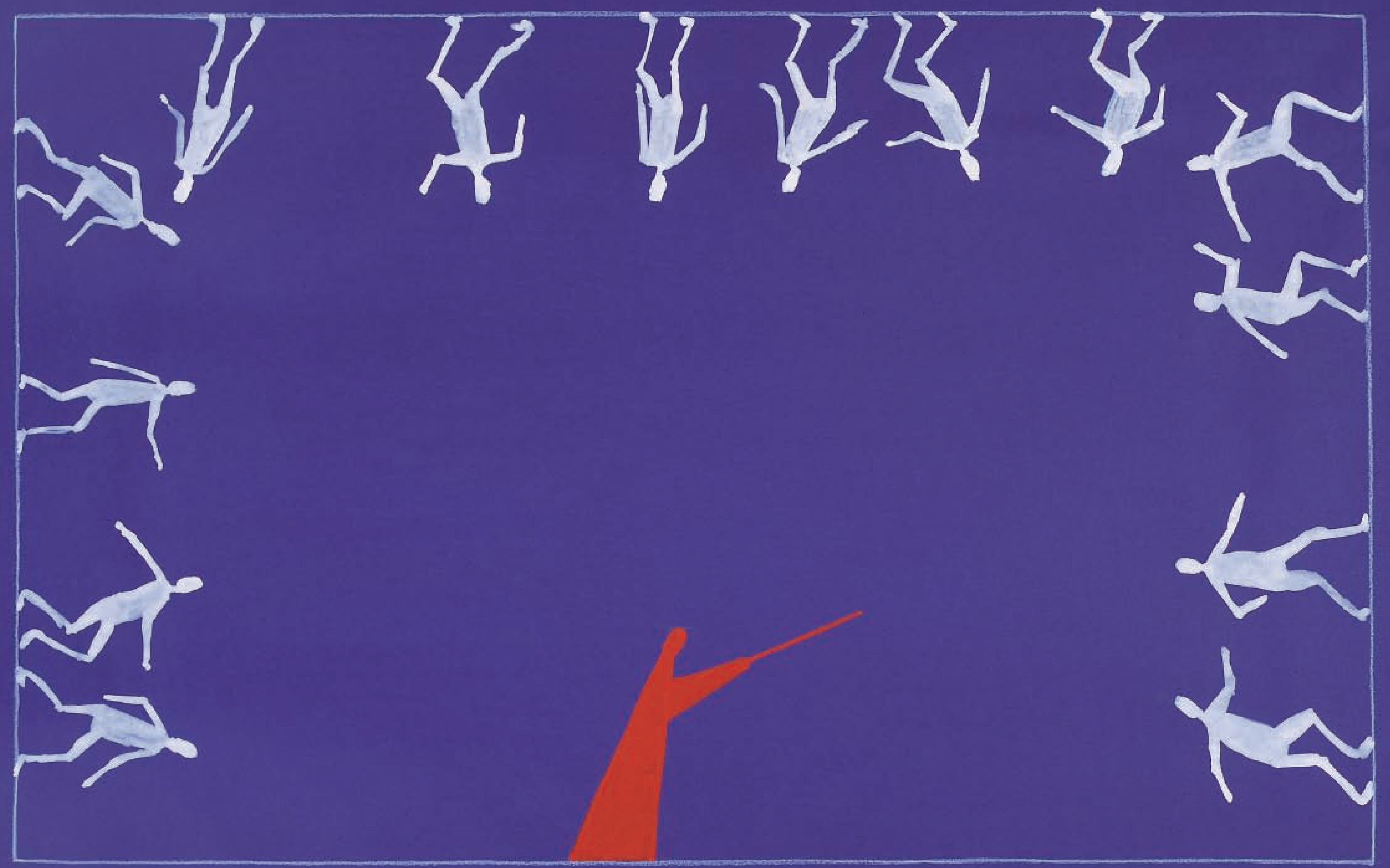




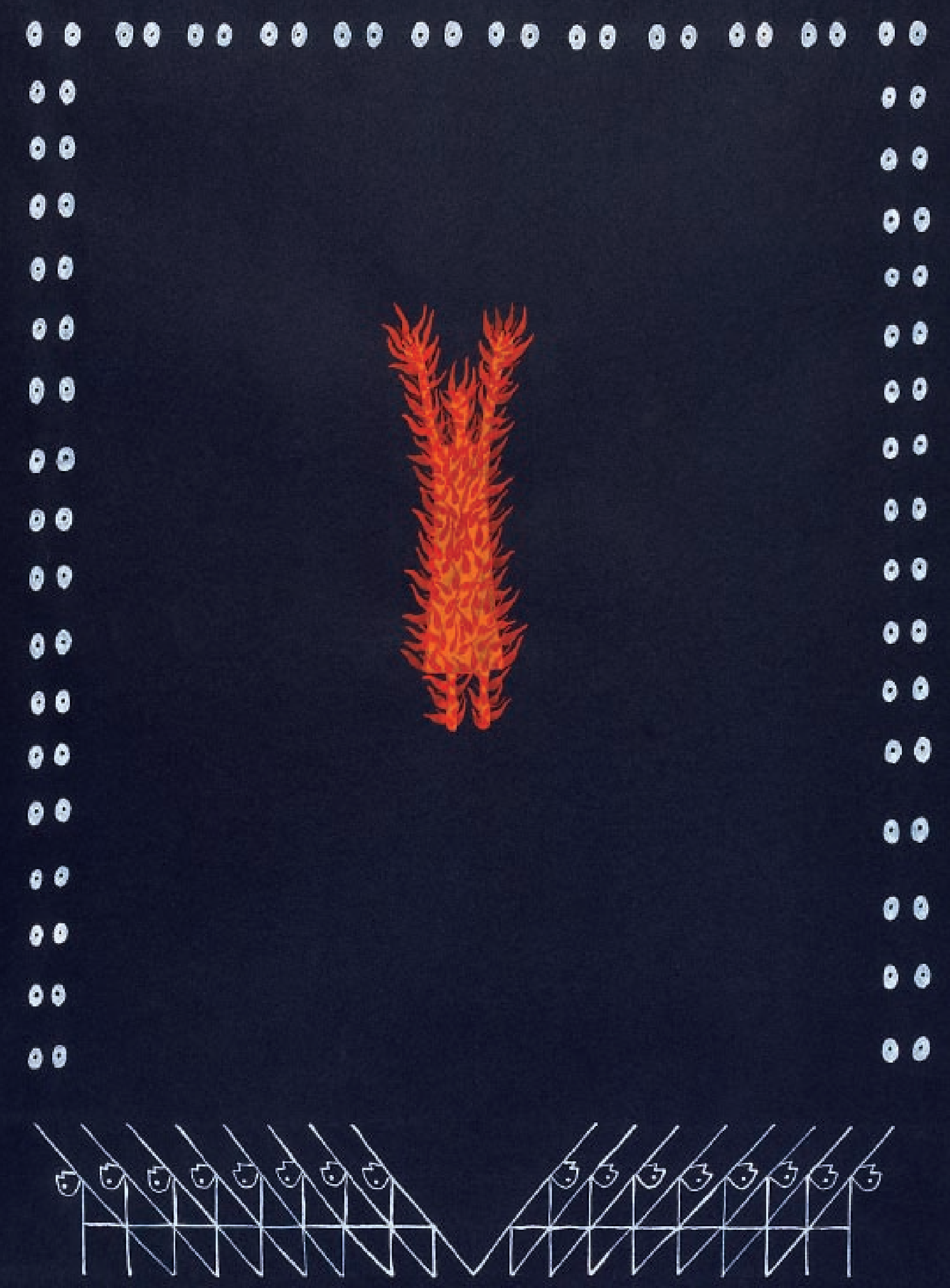




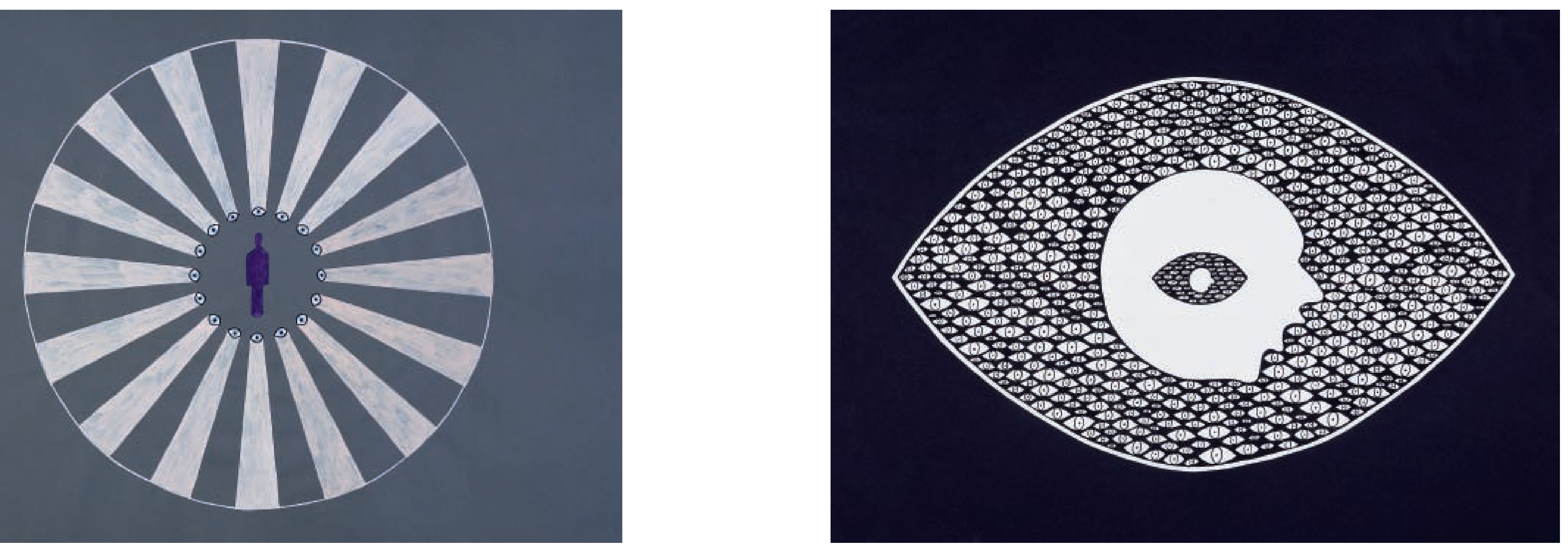

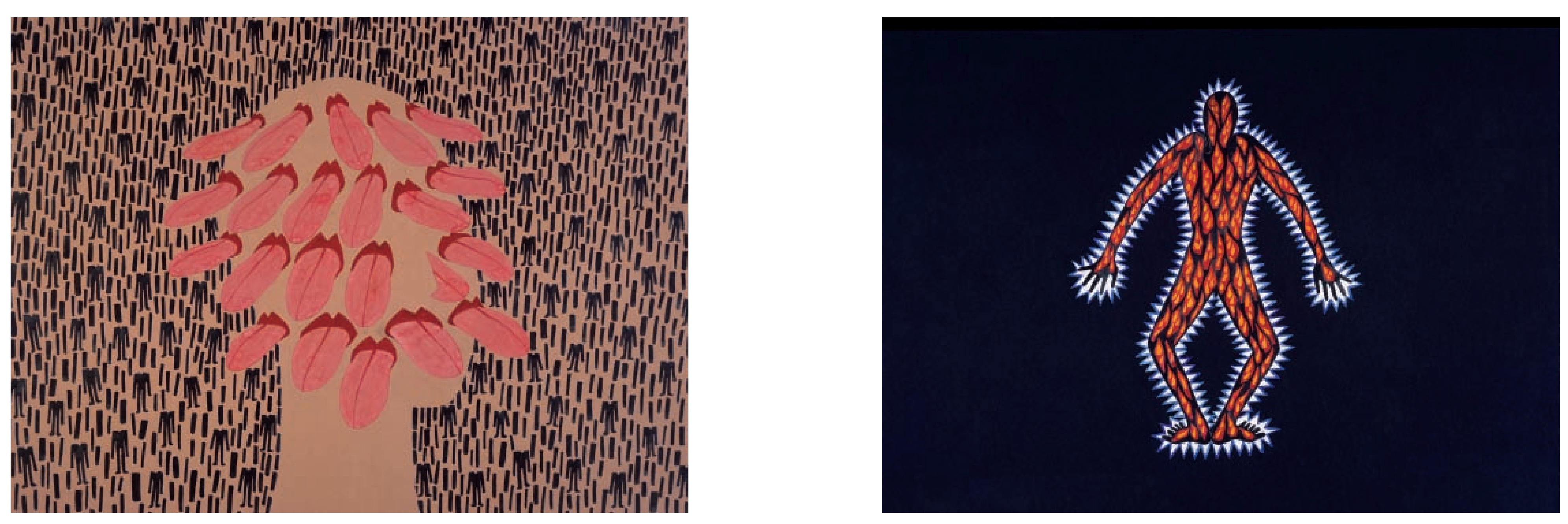

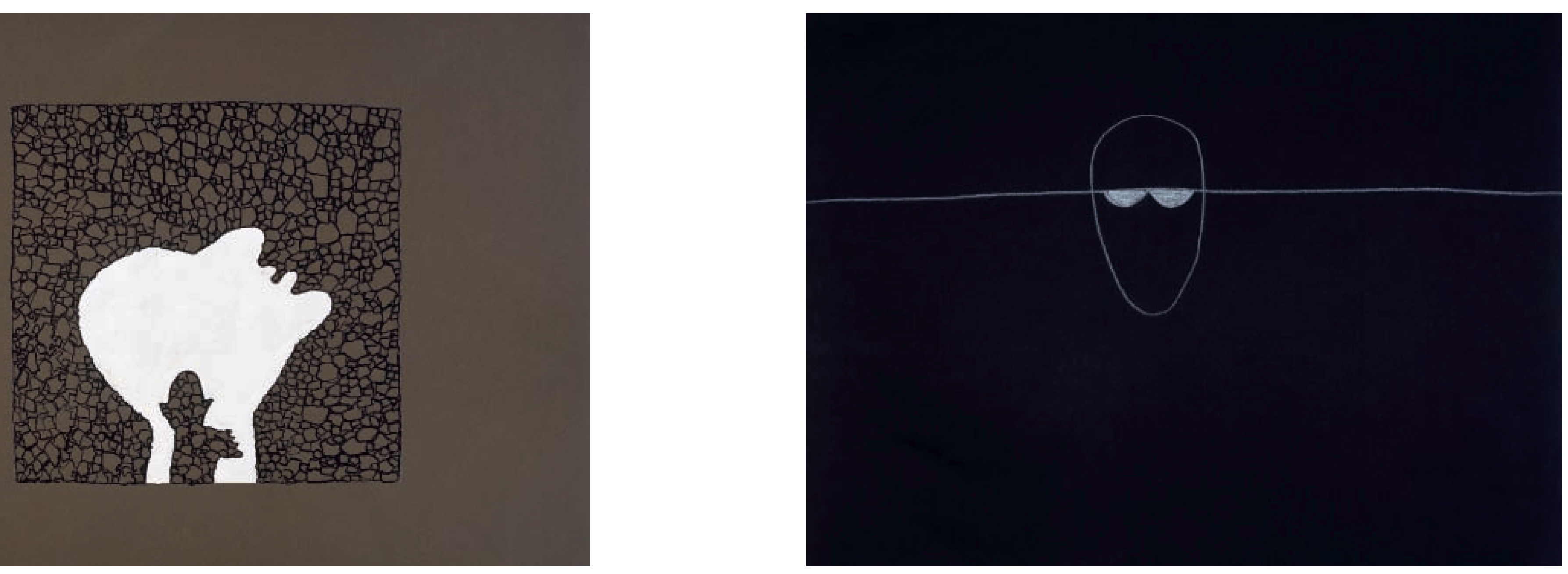


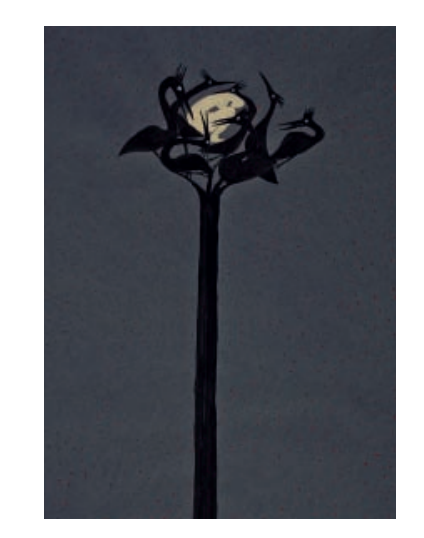

02

Die IBICHE DES DR. Kranikus Traum 196

BILD 1999

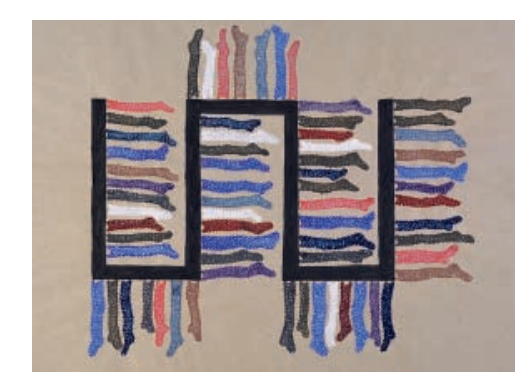
25

STRUMPFGERÜST TRAUM 1978
BLLD 1999

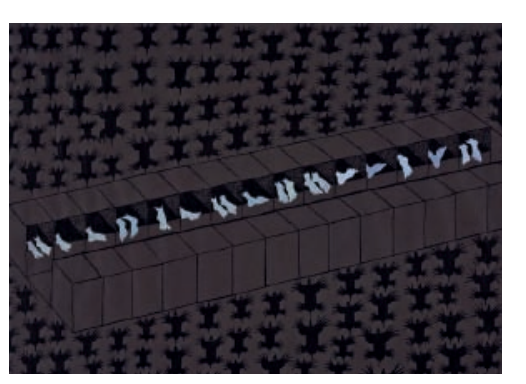

34

GRUFT FÜR FüSSE

Traum 1979

BILD 1998

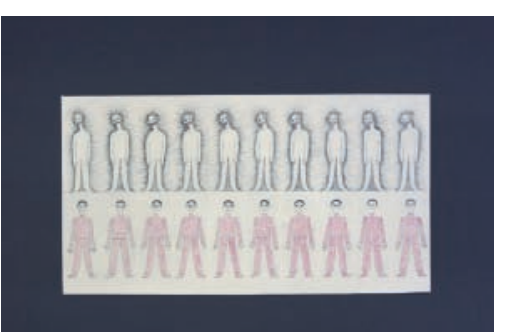

38

AUFHÖREN!

TRAUM 1981

B110 1997

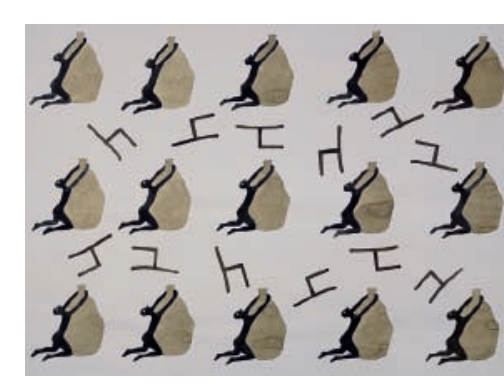

39

Helfen Stützen Helfen

Traum 1989

BILD 2000

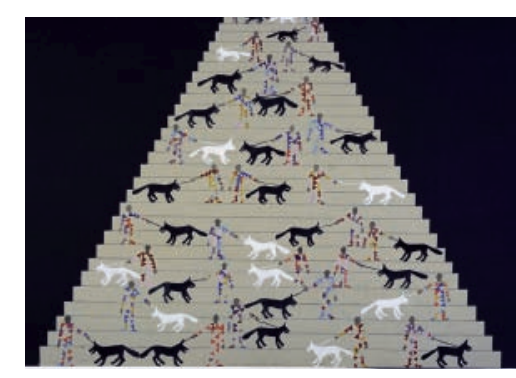

40

FREMDE HUNDE

TRAMUM 1992

BILD 1997

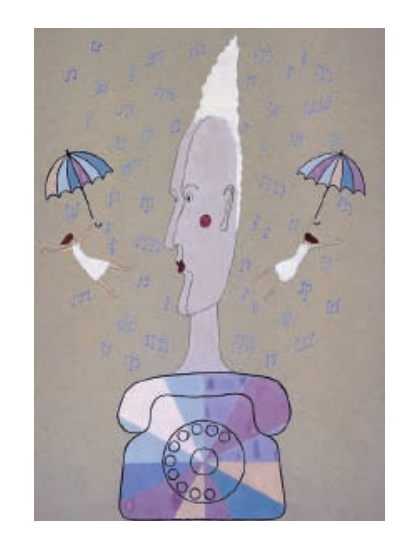

56

GESANG

TRAUM 1993

BILD 1998

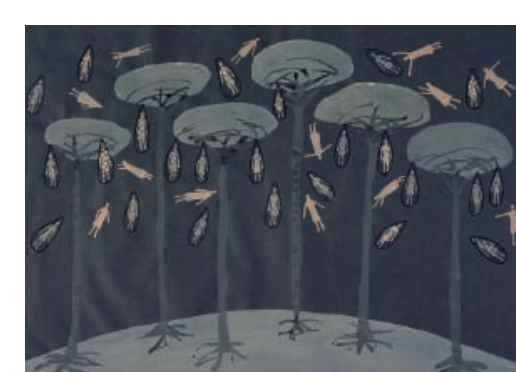

77

ANDOCKEN

Traum 1993

BLD 1998

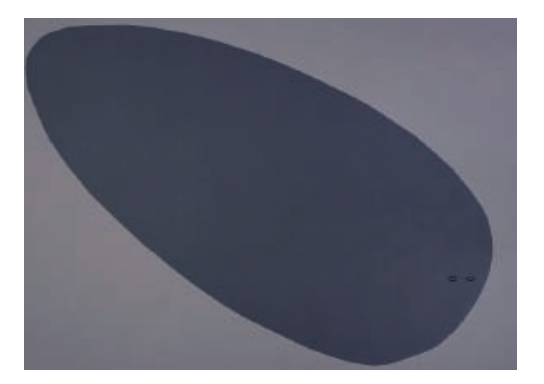

80

SPRECHENDER ZEPPELINWAL Traum 1993 BLD 1998

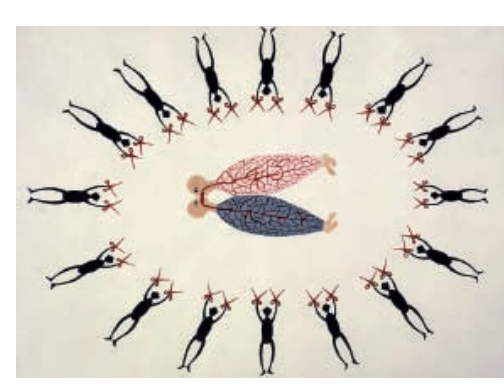

\section{4}

Rote VAMPYRFRAU

Traum 1994

BILD 1999

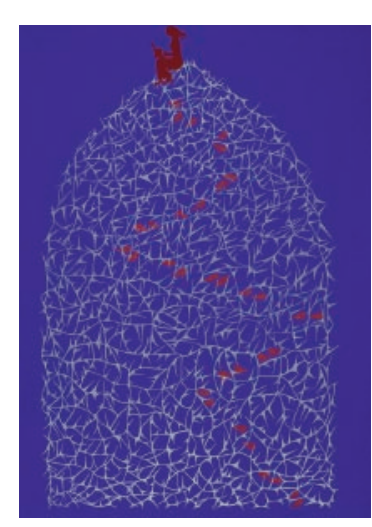

100

GANZ OBEN

TRAUM 1994 BILD 200

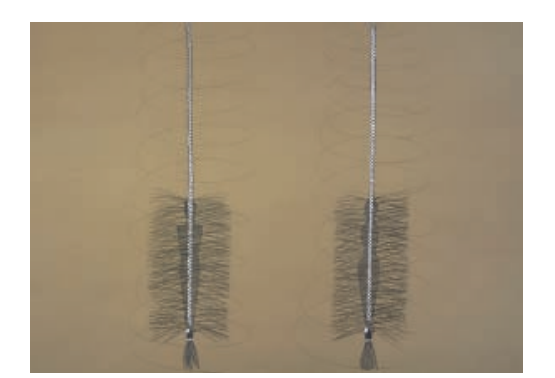

103

ZWEI FLASCHENBÜRSTEN

TRAUM 1994

BLD 1999

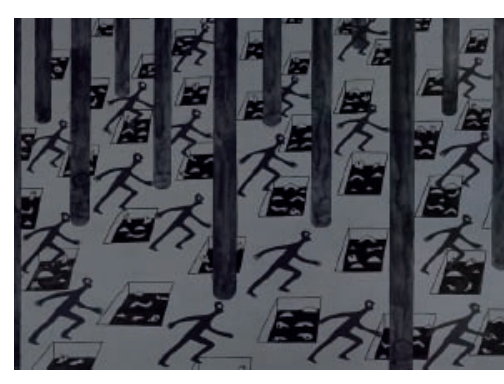

125

DIE LECHENLÖCHER

Traum 1995

BILD 1998

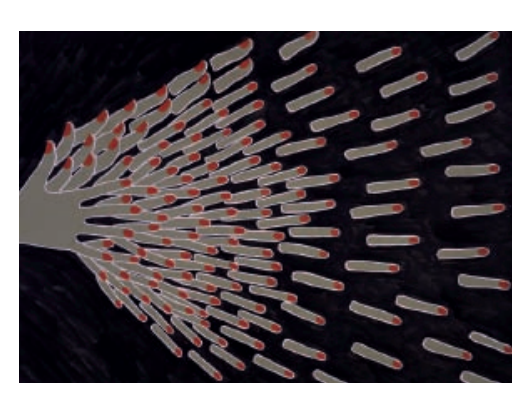

\section{0}

NEUE FINGER

BILD 1998

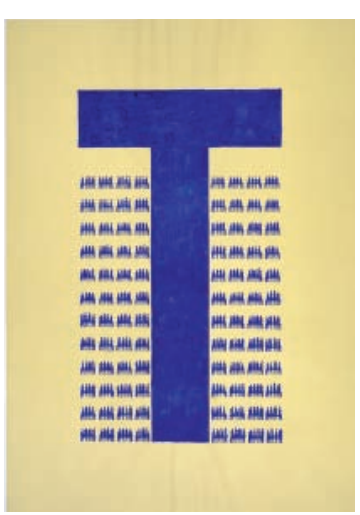

147

Der Altar

Traum 1995 BILD 1998

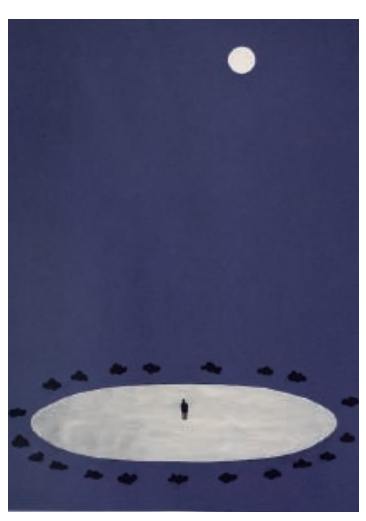

148

Die LEERE ERDE Traum 1995 BILD 1997

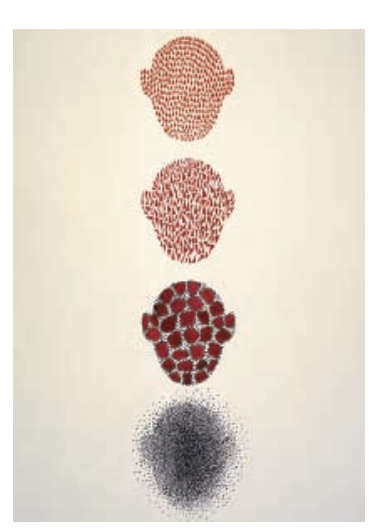

160

AUfLÖSUNG

Traum 1995

BILD 1998

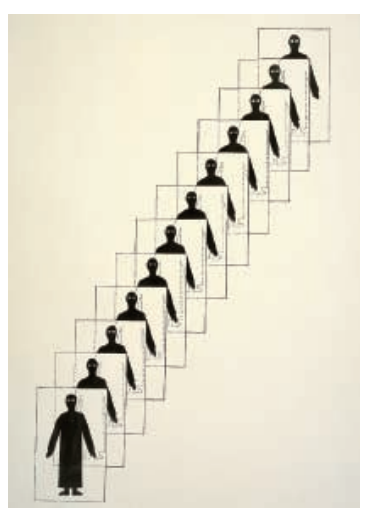

186

SCHICHTUNG

Traum 1996

BILD 1998

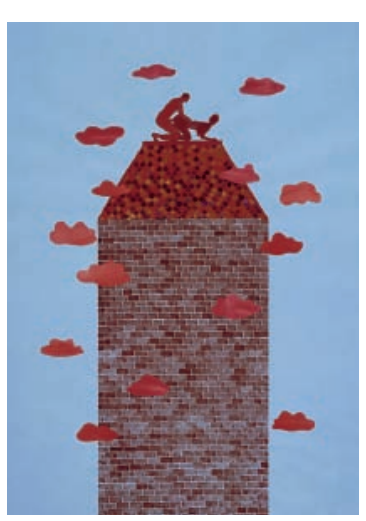

187

TRAUM 1996

BILD 1998

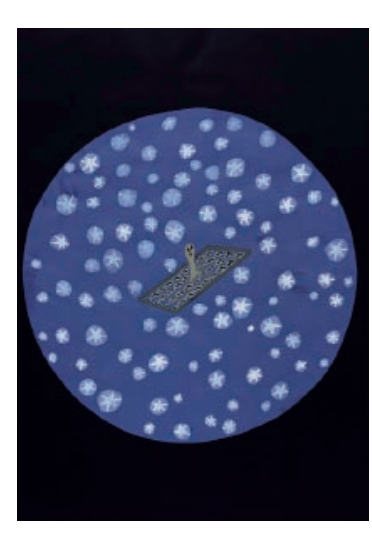

204

DÜNN

Traum 1996

BILD 1998

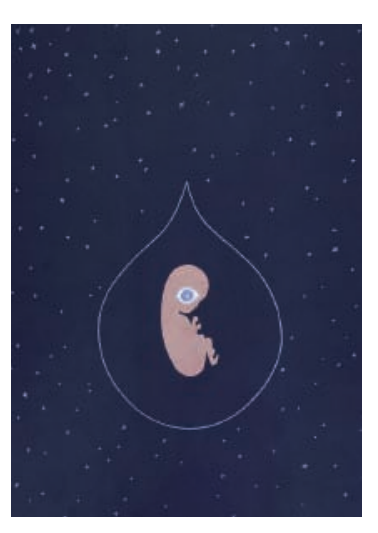

234

EMBRYO

Traum 1996

BILD 1999

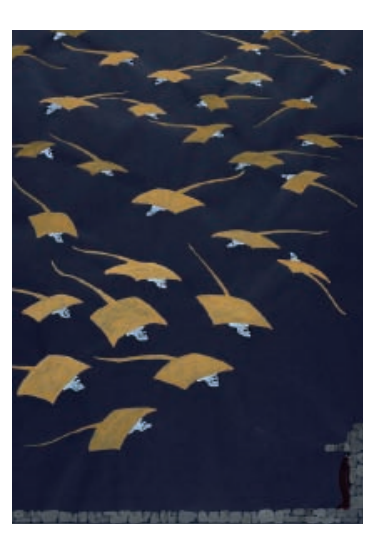

245

NÄCHTLCHE GLetTFLLEGR

TraUM 1996

BLD 1998

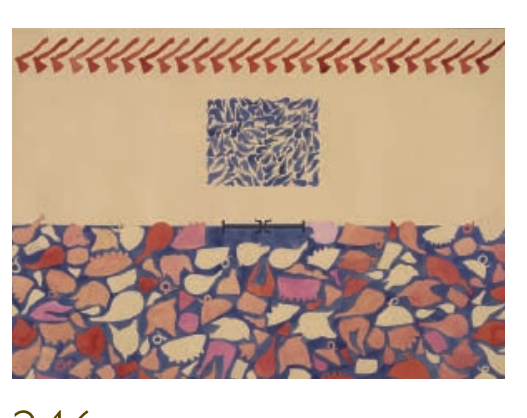

246

RESTEV VON LEBEN

TRAUM 1996
BILD 2000

BLD 2000

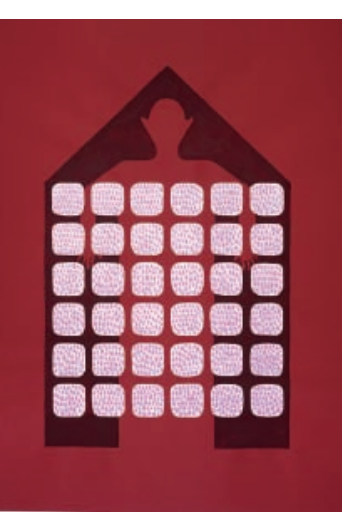

253

ROSAROTE FoLterTRÄNEN TRAUM 1996

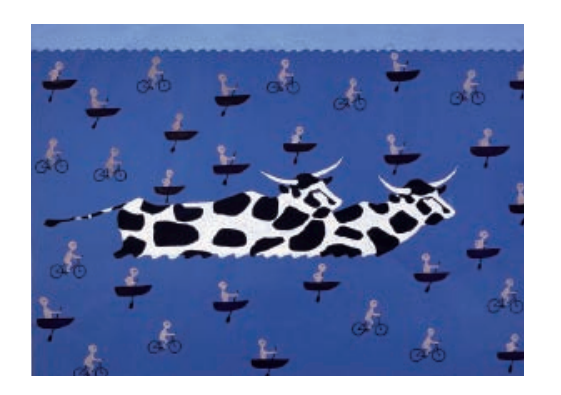

260

HOCHGESCHWINDIGKETS-

DOPPEKKUH

BLD 1999

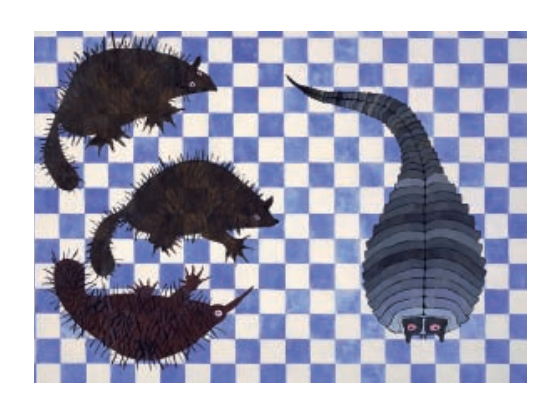

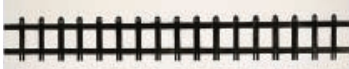

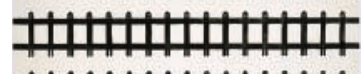

\#曲曲曲

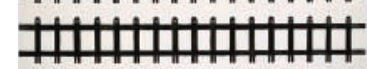

\#\#\#

261

STACHELTIERE IM BAD

TRAUM 1996

287

THE WAKERS

TrAuM 1996

BILD 1999
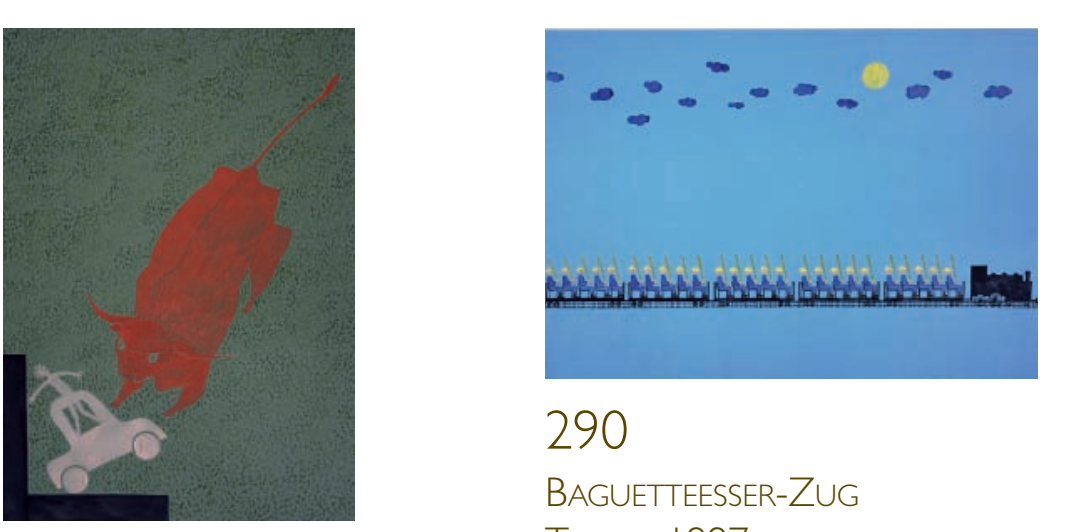

290

Baguetteesser-Zug

Traum 1997

276

DER RIESENSTIER

TrauM 1996
BLD 1999

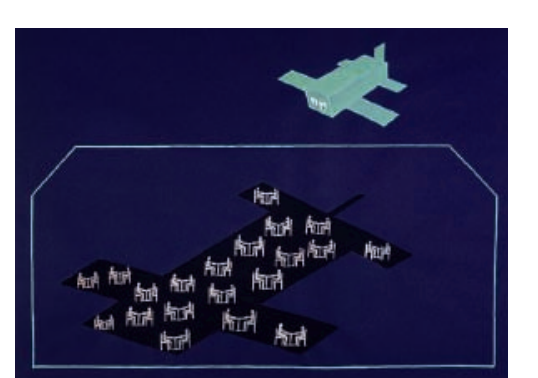

282

TODESFLUGZEUG

BILD 1999
292

SPINNWEBENGANG 


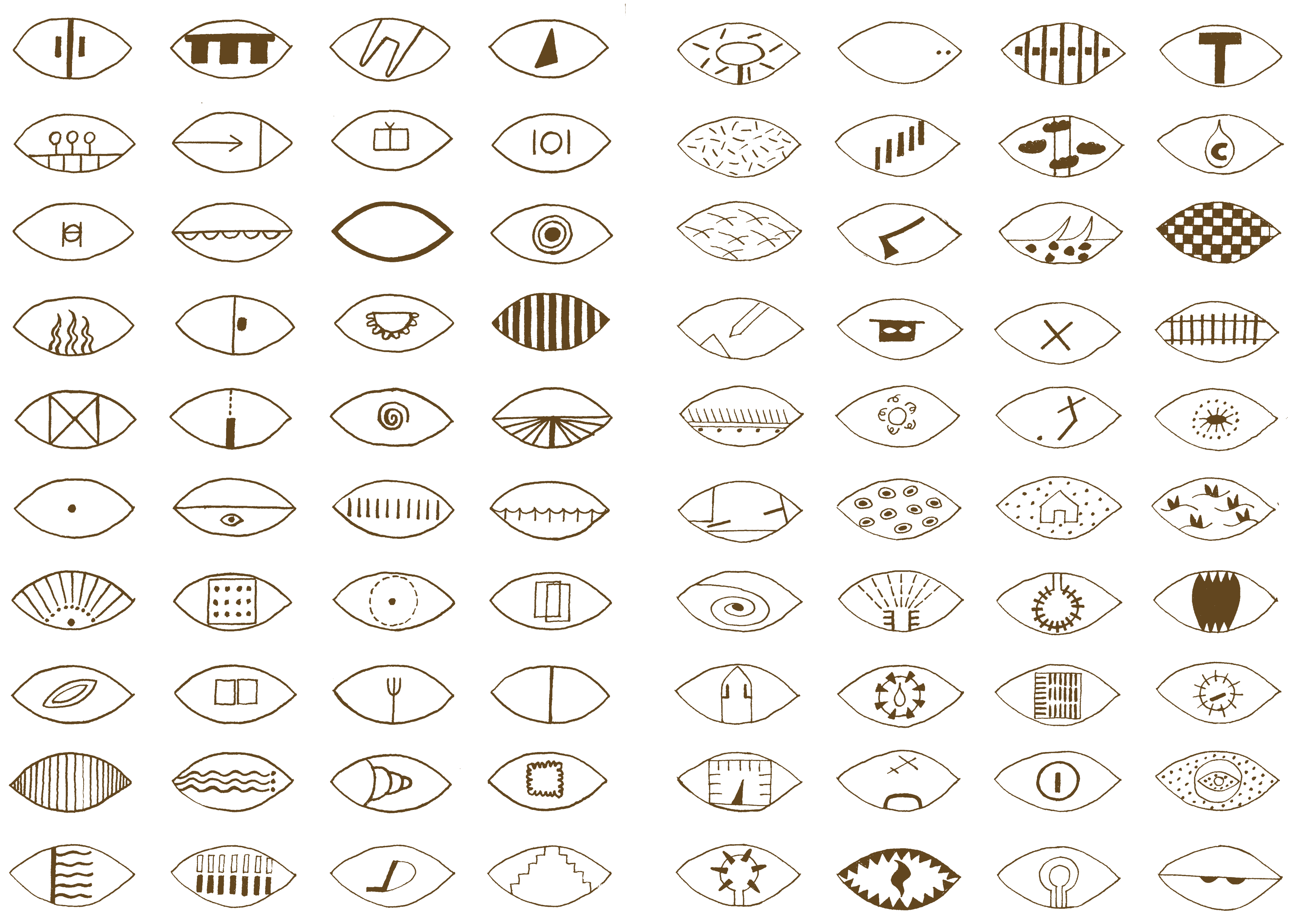




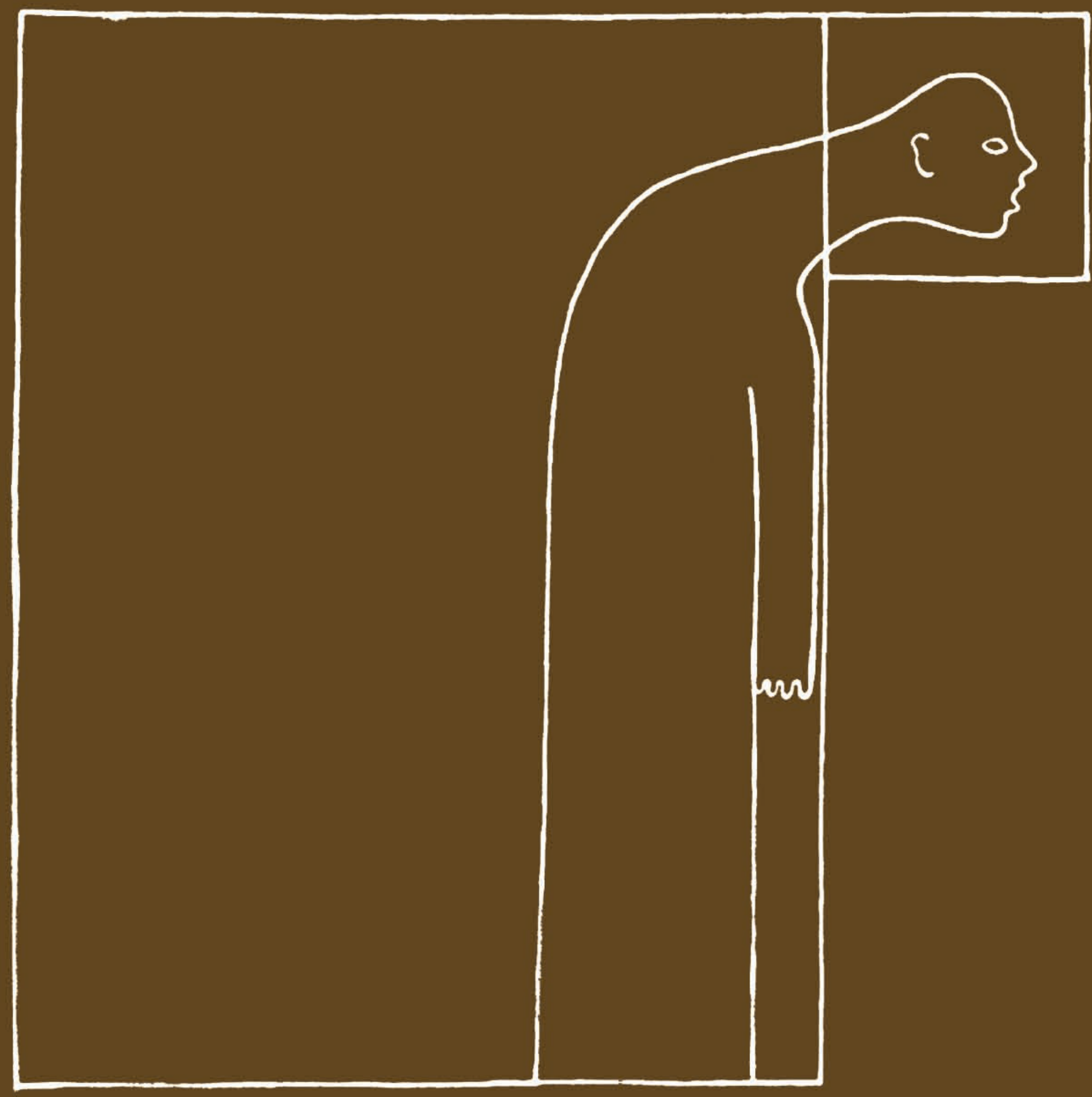

